
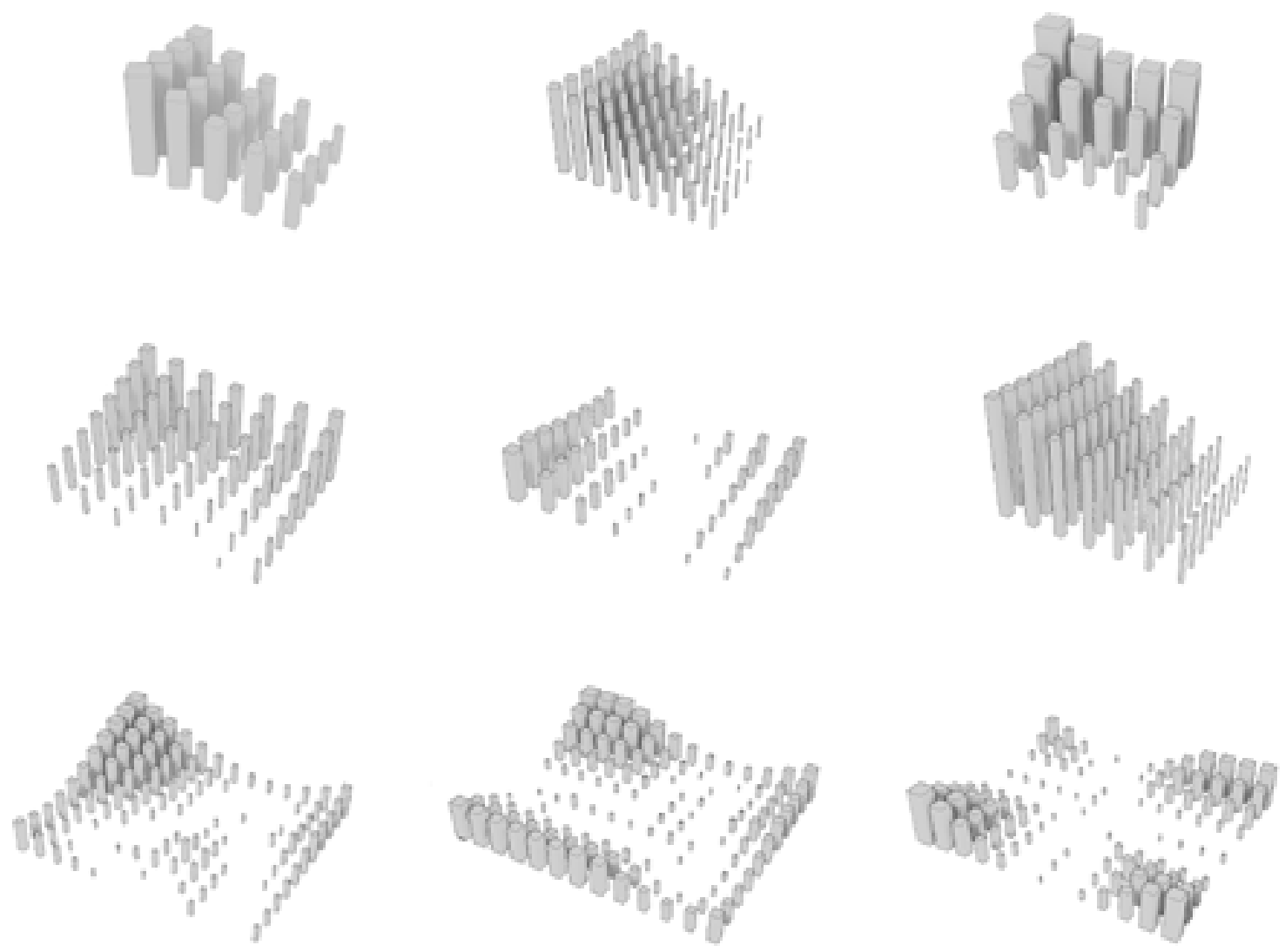

Parametric Urbanism

Sebastian Wooff $\quad 2015 / 2016$ 


\section{Parametric Urbanism}

A Digital Methodology for Manipulating Typological Forms of Density in 21st Century Urbanism

by

\section{Sebastian Wooff}

A thesis submitted to the Faculty of Graduate and Post Doctoral Affairs

in partial fulfillment of the requirements for the degree of

Master of Architecture

Carleton University

Ottawa, Ontario

(C2016

Sebastian Wooff 


\section{par-a-met-ric}

.parə'metrik

adjective

of, relating to, or expressed in terms of a parameter or parameters.

\section{STATISTICS}

assuming the value of a parameter for the purpose of analysis.

\section{ur-ban-ism}

noun

1. the lifestyle of city dwellers.

2. urbanization. 


\section{Acknowledgements}

First and foremost, thank you to my thesis advisor Benjamin Gianni, for your encouragement, guidance and patience, as well as to my co-advisor Johan Voordouw for your continual participation, feedback and support. Without both of you, this thesis would not have sparked such interesting discussions.

Thank you to my colleagues Peter Akiki and Tim Lobsinger for taking the time of day for teaching me the parametric tools necessary to complete this thesis. Thank you to my dearest friends (you know who you are) for this long, yet unforgettable journey through architecture school.

A special thank you to my Dad, Grandparents, and family on two continents for continuous support, love and the occasional critique.

Finally, I must express my very profound gratitude to my Aunt, Ania for always believing in me, encouraging me through this journey, giving me the confidence to be the best that I can be. Your strength and support is unparalleled. 

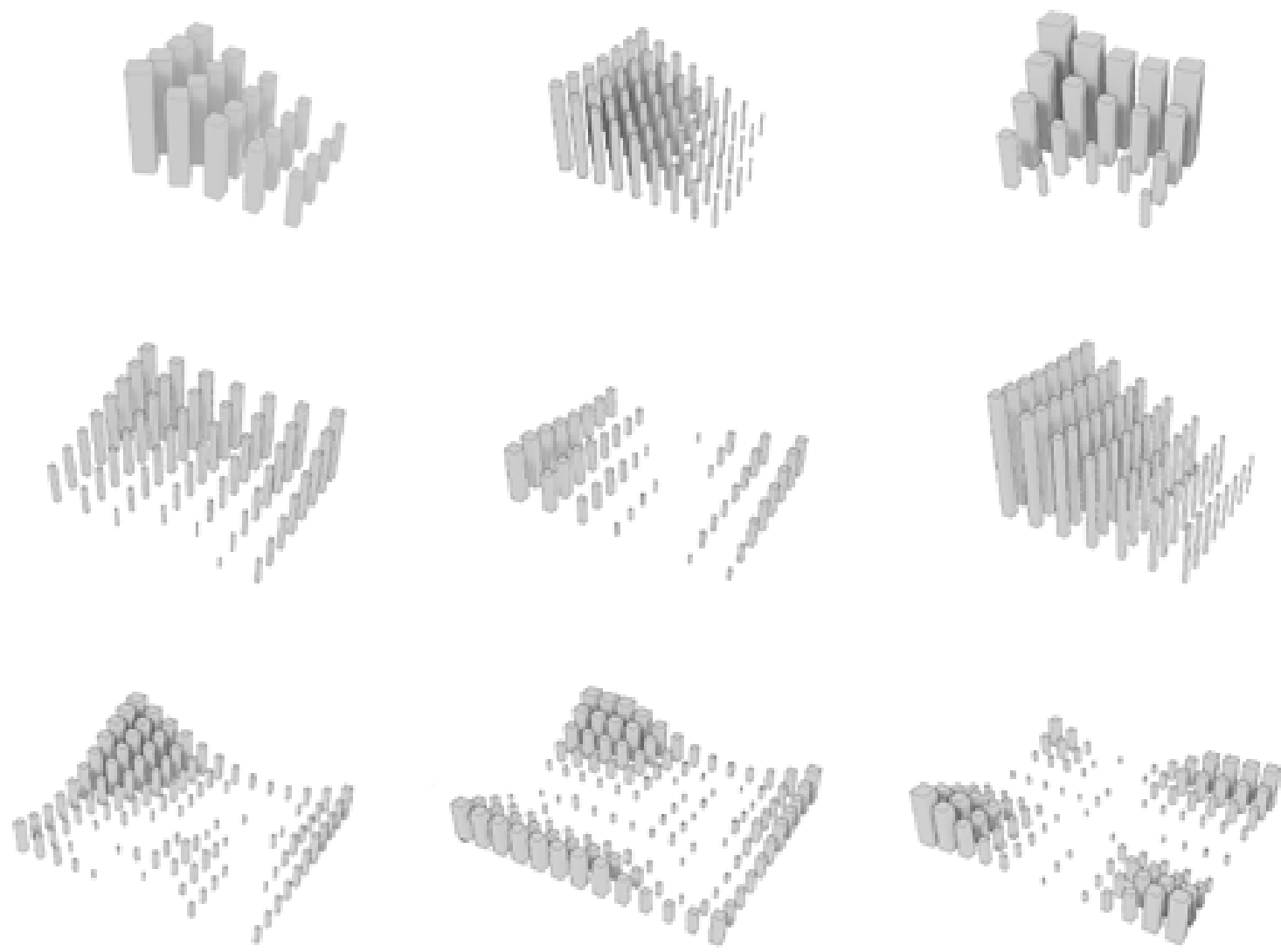

Parametric Urbanism

Sebastian Wooff

2015/2016 


\section{Abstract}

In 2011, the global population reached 7 billion people -- with more than half residing in urban areas. The world's population is expected to increase to 9.3 billion by 2050 . As the level of urbanization is also expected to rise (from 50 to $70 \%$ globally), the bulk of population increase will occur in cities. Urban areas will be expected to accommodate an additional 3 billion people over the next 35 years. As a result, even those of us in land-rich countries like Canada will be expected to live at higher densities.

These numbers alone are enough to emphasize the magnitude of challenges facing city planners and architects. Current methods of urban planning, whether in North America, Asia (China in particular) or Africa do not adequately accommodate the multitude of variables 
that generate urban form. Urban planners would benefit from more robust tools and techniques to manage urban growth.

Responding to this challenge, this thesis explores the potential of parametric design to facilitate the process of urban design specifically in assessing the effects of various forces, targets policies and bylaws on the form and density of the city. Parametric design is defined as a "process based on algorithmic thinking, that enables the expression of parameters and rules that, together, define, encode and clarify the relationship between design intent and design response." ${ }^{\prime \prime}$ It is a paradigm in design where the relationship between elements is used to manipulate and inform the design of complex geometries and structures. For urban design, this presents the ability to quickly visualize the impact of changes to bylaws or density targets that could in theory enable planners to make more informed choices among a variety of alternatives. As such, the goal is to incorporate a multitude of variables into a cohesive system to evaluate the dynamic effects of different parameters on each other and on the form of cities.

Within the limits of time, resources and the current capabilities of the technology, this thesis explores ways in which parametric 
tools might be advantageous to urban design. It is my hope that this thesis will provide insight into the potential of parametric design to more effectively generate and assess alternatives for accommodating urban growth. 


\section{Statement}

Through an iterative, analytical process, this thesis aims to develop a logical and methodical approach to the use of parametric software tools (such as Grasshopper) for urban design. If successful, these tools would enable users to manipulate variables in order to visually assess the impact of changes to targets, bylaws and policies on each other and on the form of the city. At the same time this thesis attempts to remove parametric design from the realm of aesthetics in order to explore its more practical applications. As such, the goal is to bring computational and visualization tools to bear on increasing the efficiency and responsiveness of urban design.

The practical orientation of this thesis departs from the predominantly aesthetic use of parametric tools to concoct novel 
and visually compelling architectural forms. To a great extent parametric design has been championed by high-profile designers such as Zaha Hadid Architects. In recent years, Hadid's firm has applied its aesthetic to urban-scaled projects using parametric tools to effect "organic" transitions between various sizes and scales of buildings and between more or less regular patterns of streets. Examples include the Kartal Pendik Masterplan for Istanbul, the Thames Gateway in London proposal and redevelopment projects in Singapore. As described below, these proposals have tended to privilege the manipulation of forms over transitions between building types and may not adequately account for the changes in type that accompany changes in building scale. One of the key contributions to this thesis, then, is to associate established building typologies with different heights and urban densities.

The process of urban design involves working with quantitative parameters that affect the form of buildings, open spaces etc. and the relationships between these elements. In order to more effectively choose among alternatives in the interest of optimizing urban form and density, it is helpful to generate and evaluate multiple scenarios. By using parametric design methods it is possible to manipulate and adjust parameters such as F.A.R (Floor Area Ratio), height, setbacks, lot coverage, percentage of open 
space, etc. to visualize and assess various outcomes. By assigning different values to the parameters one can generate different configurations. Thus, the objective of parametric design is particularly relevant at the urban scale, in which individual buildings, streets, transport systems, etc. are related to a larger system. Parametrics has tremendous potential and over the past two decades architects have explored the possibilities of parametrics capabilities. Parametrics enables designers to manipulate several variables at the same time and to link basic operations together to assess the aggregate effect of different targets and choices. 
v| preface

abstract

statement

xi| Introduction

01| Chapter 1

The Failures of Urbanized Cities

09| Chapter 2

Computational

Urban Planning

16| Chapter 3

Parametric Urbanism

The Approach

27| Chapter 4

Parametric Urbanism

33| Chapter 5

Methodology

67| Chapter 6

Contextualizing in

site

98| Conclusion

102| Bibliography

images

graphics

citations 


\section{Introduction}

This thesis delineates a possible line of research that applies the techniques and methodologies of parametric design to the field of urbanism. First, between the emerging use of parametricism as a design style and its use as a design tool Patrik Schumacher of Zaha Hadid Architects argues in his self-written manifesto entitled "Parametricism as a Style" that "Parametricism is the great new style after modernism." ${ }^{2}$ He states that the defining heuristics of parametricism contradict the taboos and dogmas of contemporary architecture or the formulas of modernism. It (Parametricism) allows for structures to have a more dynamic form based on the desired concept. Is then parametricism a style for structures resembling organic entities or is it a tool that can be attributed to any style or design problem?

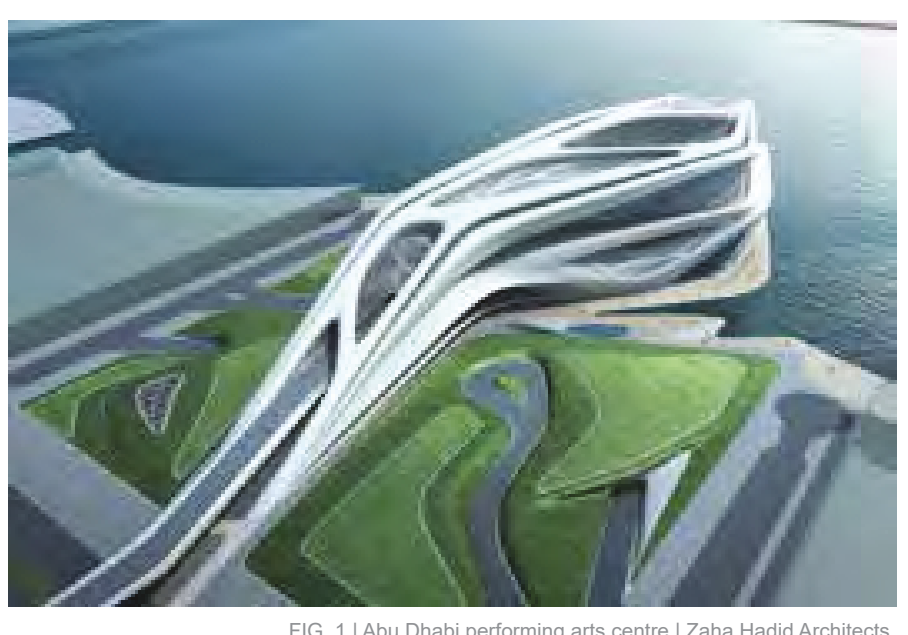

FIG_1 | Abu Dhabi performing arts centre | Zaha Hadid Architects 
Architectural style can often push innovation in design technology and construction, as "styles are design research programmes"3. After all, architecture is built and analyzed through styles associated with different time periods and civilizations. Nonetheless in a post-Fordism era, the cost of producing parametrically designed structures often presents an economic challenge, as only highprofile clients can support such costs, parametricism is therefore branded as a luxurious style of high-end design. While the economic model is still in its infancy, the price of producing organically shaped buldings may decrease as demand for such buildings increases. However, parametrics are fundamentally based on the parameters that have been plugged in to the computational algorithm which manipulate the forms of masses developed in the software. Therefore the inherent question is whether variables related to urbanization can be manipulated parametrically, and if so how can such manipulations might proce useful for the urban planner and architect, moving beyond architectural style?

Given the unprecedented rate and extent of urban growth occurring in countries such as China and Africa, the consequences include haphazard, uncontrolled growth, informal settlements, and lowdensity sprawl. According to Tom Verebes, founder and creative

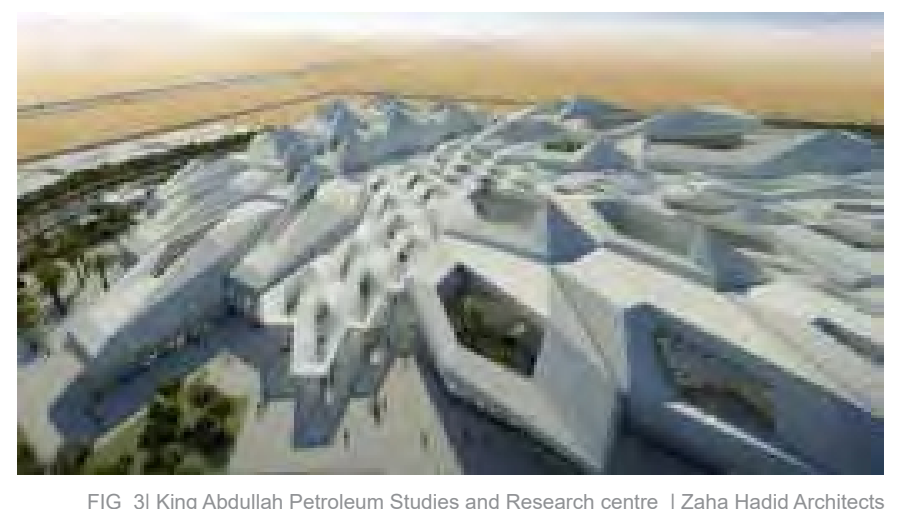


director of OCEAN.CN,${ }^{4}$ there seems to be an urgent need for new paradigms in "the face of imminent global urban practice." Verebes argues that "The paradox of the endurance of architecture and its inevitable dysfunctionality and possible obsolescence creates the conditions for new adaptive models of urbanization." ${ }^{5}$

Where the effects of urbanization are concerned, parametric tools have the potential to enable a multitude of variables to be incorporated into a large-scale design formula in order to generate a variety of scenarios in response to needs. Digital tools can be used to generate urban form in response to the adaptive logical processing of selected information and data. With parametric platforms, design does not offer a univocal response to a group of pre-established conditions, but instead becomes a dynamic model able to rapidly respond to input provided by the designer/planner.

In a scenerio where it might be advantageous to increase density in an established area in order to more effectively manage growth, how might we go about this? Increase height? Increase allowable lot coverage? Increase F.A.R? Should this be done equally everywhere or should density be restricted to arterial streets? To areas well served by public transit? Form does not always 
follow its intended function. Functionality does not have any ideal stable state; it is in constant flux. A balance must be struck between fulfilling a stated purpose and allowing for the capacity of a building to adapt to future criteria. What triggers cities to adapt, evolve and be continuously renovated to fit the contingencies of the present? ${ }^{5}$ In a series of essays by Tom Verebes and other co-authors in the book Masterplanning the Adaptive City, Verebes argues that "....urbanism has always been parametric, in that the city is comprised of complex associations and interactions of diverse and numerous agendas, systems, and forces." ${ }^{\prime 6}$ The relation between organizational components, or parts of a whole, is what makes the city dynamic; adaptive rather than fixed and final.

The challenges in urban planning in the current century are in part the result of the unprecedented scale of urbanization. A series of oppositions characterize the evolutionary mechanisms of urbanism, including history and the future, convention and innovation, endurance and ephemerality. All of these help to explicate the concept of evolution in cities, societies and culture. Parametrics formulas could enable us to quickly predict scenarios, cross reference questions and analyze scenarios in model form. As the only constant is change, parametricism may help to more 
effectively respond to the manifold repercussions of rapid urbanization. 


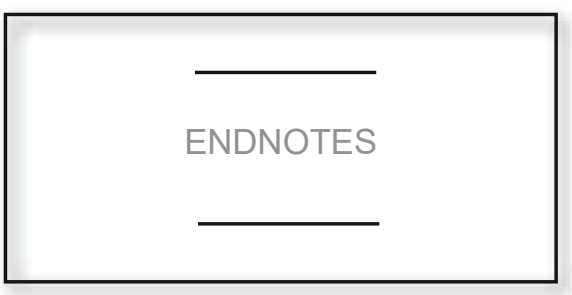

1 Jabi, Wassim (2013). Parametric Design for Architecture. London: Laurence King 2 Schumacher, Patrik. "Parametricism as Style - Parametricist Manifesto." Parametricism as Style - Parametricist Manifesto. 2008. Web. 7 Oct. 2015. <http://www.patrikschumacher.com/Texts/ Parametricism as Style.htm>.

3 Schumacher, Patrik. "Parametricism as Style - Parametricist Manifesto." Parametricism as Style - Parametricist Manifesto. 2008. Web. 7 Oct. 2015. <http://www.patrikschumacher.com/Texts/ Parametricism as Style.htm>.

4 Tom Verebes has written, published, exhibited and lectured extensicely all around the globe. He is as wel the Associate Dean in the Faculty of Architecture and Associate Professor in the Department of Architecture at the University of Hong Kong. It is his book titled "Masterplanning the adaptive city" which is the main resource of this thesis. Verebes explores today's urban complexities and contradictions that lie in the task of planning in an increasingly uncertain world. Investigating a deficiency of the preeminent masterplaning tools and techniques of the twentieth century to keep up with the pace of rapid urbanization I the developing world, this lecture challenges the capacity of conventional design methodologies to manage the indeterminacies of urban development, the environment, the economy, migration and other dynamic forces which shape the dynamic nature of urbanity. Through a kaleidoscopic journey, Tom Verebes addresses issues associated to the evolutionary nature of cities, and the endurance, obsolescence, and the adaptive and transformative capacity of architecture and urbanism.
Verebes, Tom. Masterplanning the Adaptive City: Computational Urbanism in the Twenty-first Century. Print

6 Verebes, Tom. Masterplanning the Adaptive City: Computational Urbanism in the Twenty-first Century. Print

7 Verebes, Tom. Masterplanning the Adaptive City: Computational Urbanism in the Twenty-first Century. Print 


\section{Chapter 1}

The Failures of Urbanized Cities
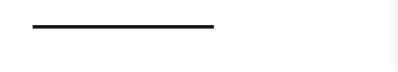

Cities have been growing so rapidly in the last few decades that, as a society, we are having difficulty keeping up with the growth and are in need of treatments for the attendant pains. There are more than thirty megacities in the world, each home to approximately 9 million people. Half a century ago, only two such metropolitan areas existed: New York City and Tokyo. The increase in populations has

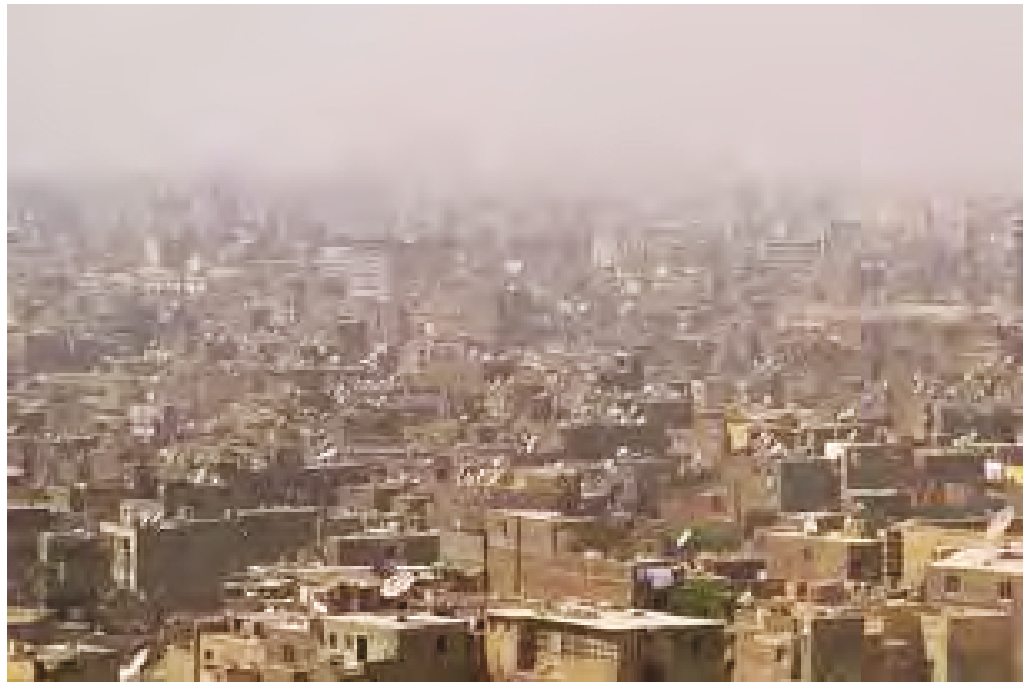
"depleted the amount of opportunities and efficiencies that used to make living in cities desirable." It has led to more pollution, uncontrollably spiralling rent and in some cases crumbling infrastructure.

The population of Egypt's capital, Cairo, is estimated to be more than 18.5 million people. City planners have openly acknowledged 
difficulties in dealing with crowding and congestion for more than a decade. In response to the issue, in February of 2015 Egypt unveiled plans to build a "nameless Cairo" from scratch to the east of the city, according to a recent article in the Guardian newspaper. ${ }^{9}$ It will cost 30 billion GDP and take 5-7 years to complete, measuring a territory of 700 square miles it will accommodate a population of five million citizens. "The problem with this type of planning is that it often does not pay attention to human nature," says urban planner Wendell Cox. "There is a tendency on the part of planners to presume that they can put people in jobs where they want and they'll stay there....But the world is dynamic. So that kind of thinking just does not work." 10

China's economy is growing at a rapid $7 \%$ and its megacities are feeling the effects. In Shanghai, analysts believe steel, cement, and glass plants may have increased pollution, which has prompted the local government to issue residents anti-pollution masks. Pollution has had a detrimental effect on people's health. Former Chinese health minister Chen Zhu recently claimed that nearly 500,000 people die in China each year from severe pollution. ${ }^{11}$ China plans to cut pollution in places like Shanghai by 2017 , partly by closing coal-fired power plants.

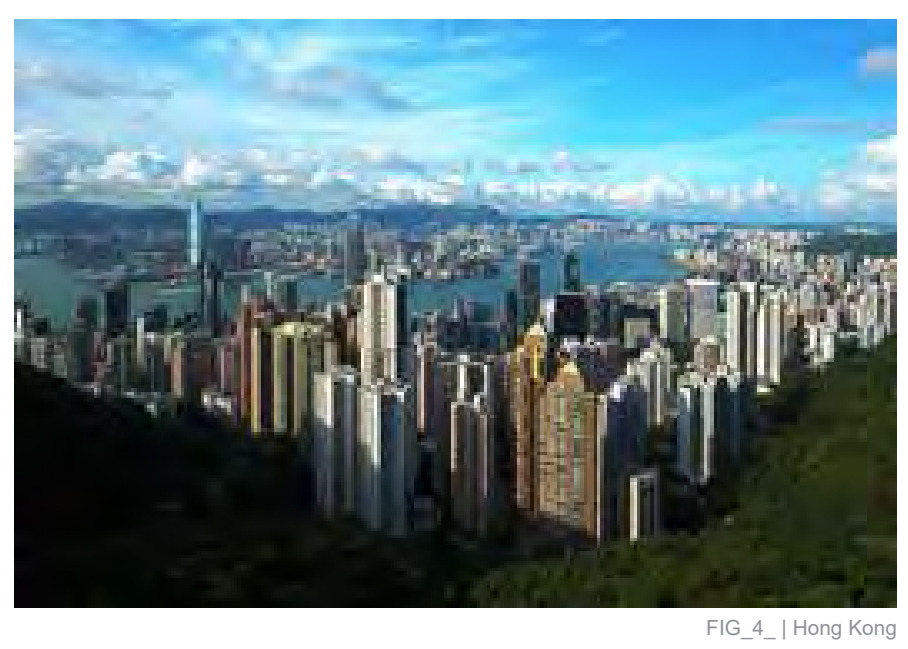



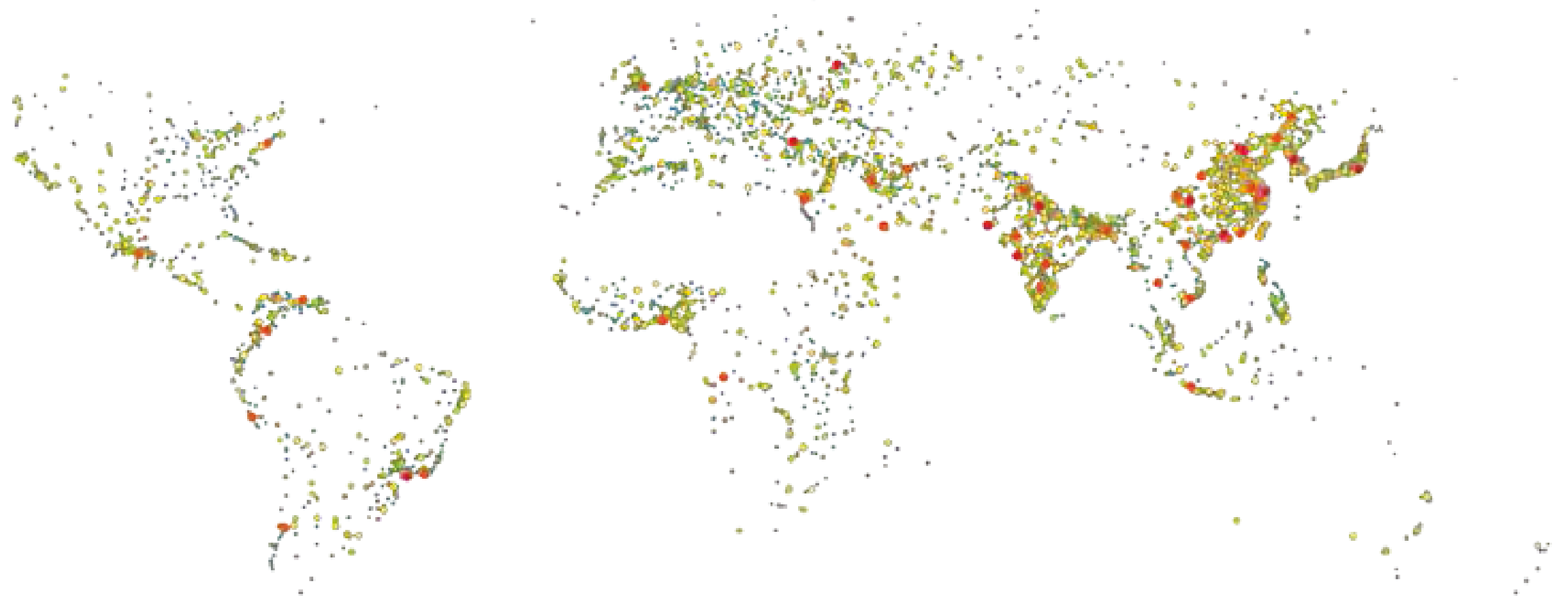


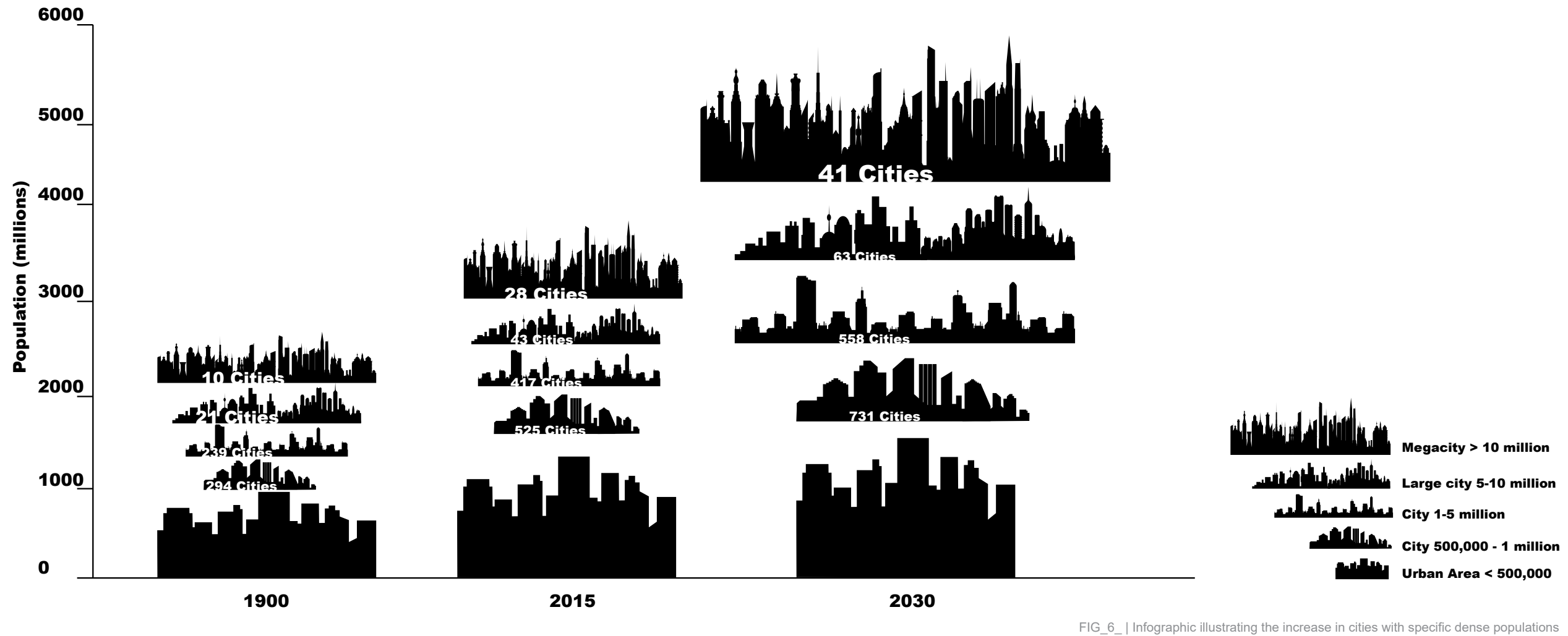


However, this strategy leaves the country scrambling to find cleaner alternative power source. In the meantime, the city's air continues to be a hazard to health.

More and more cities will face similar problems if the United Nations is correct in predicting that there will be 41 megacities total with a population of 10 million people by 2030 . With population growth not predicted to stabilize until 2050 at the earliest, the need for better planning must happen now. As architects and urban planners, we need to prepare for this eventuality and plan accordingly. Building codes and zoning regulations must be changed to adequately predict growth and its relation to the built environment. We need tools that will enable us to explore and assess multiple scenarios, especially for those areas of the planet where growth is expected to increase.

In the North American context, more and more cities are falling into the hands of the developers who acquire land and change the zoning. The result is a chaos of typologies and differences in height that have made many buildings poor neighbors. (Refer to Fig_8). In some cases, a luxury 30-story condominiums and/or office towers are constructed within residential districts comprised
People living in cities

\section{0 | 1990 |

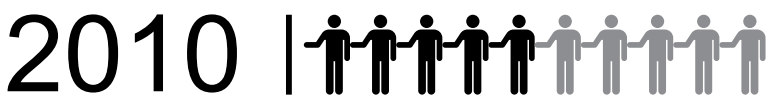 2030 | imithithin 2050 | impiritin}

FIG_7_ I Infographic illustrating the predicted increase of people living in cities 
of single-family detached houses. Such discontinuities challenge every rule associated with appropriate ways of building cities. The mesh of zoning creates awkward traffic congestion and strange consequences especially for neighborhoods in dense downtown cores in typical North American cities. In the absence of other alternatives for increasing density, it seems far too easy for developers to make a case for changing the zoning to maximize his profit without any consideration for the city's urban plan for the area.

In the last several decades, New Urbanism and Smart Growth techniques have been brought to bear on creating more environmentally, economically, and socially sustainable cities. Mixed-use/mixed-demographic communities help to mitigate the negative effects of gentrification with affordable housing to promote social equity, decrease automobile dependance to lower the use of fossil fuels, and promote a localized economy. Walkable communities have a $38 \%$ higher average GDP per capita than less walkable urban metropolitan areas. ${ }^{12}$ Can parametric urbanism aid in the principles of Smart Growth and New Urbanisms principles such as walkability, mixed-use development, comfortable high density design, land conservation, social equity, and economic
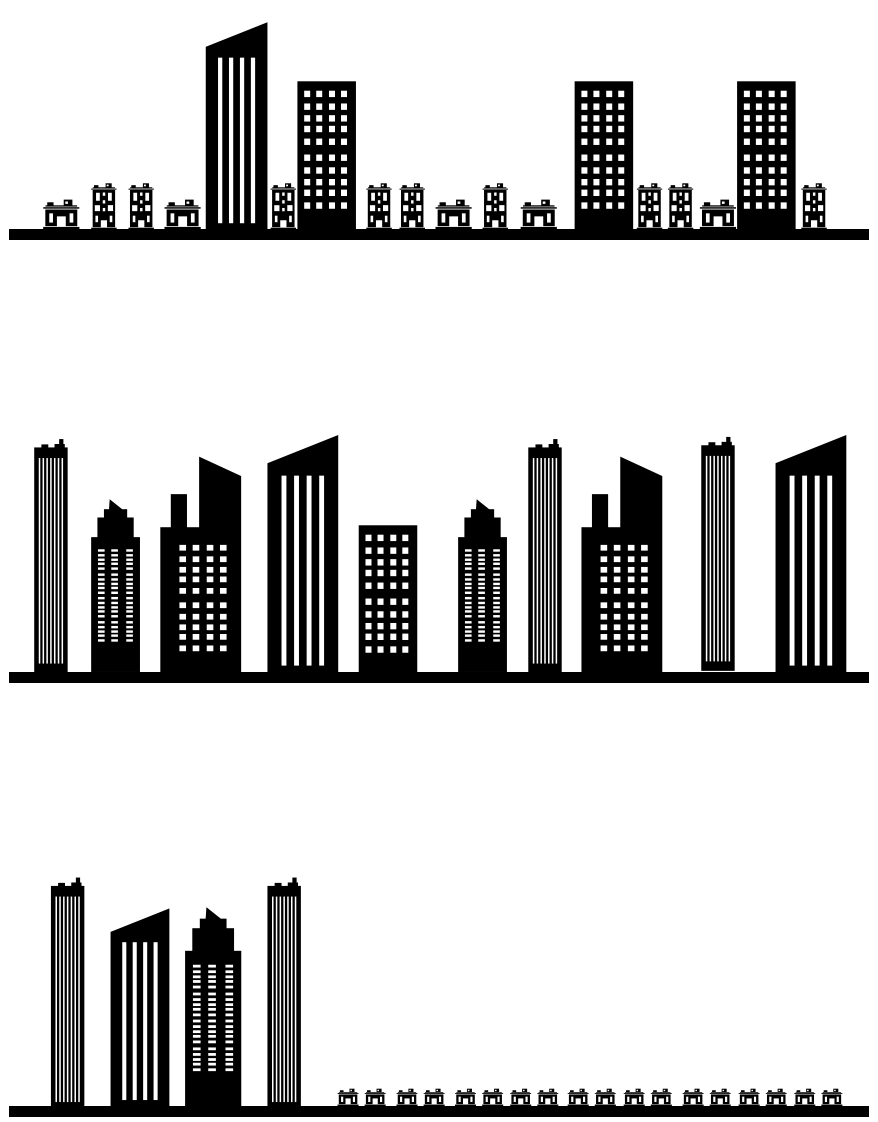

Infographic illustrating the variety of urban different programatic builing typologies across the globe.

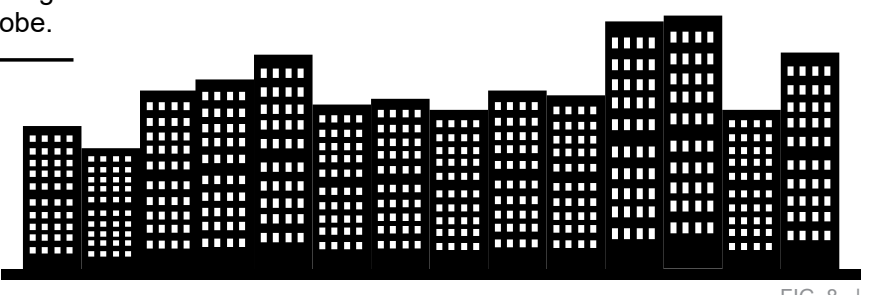


diversity?

Master planning strategies that seek an enduring final state of urban completion tend to lead to dysfunctional cities with limited capability to adapt to change. Given the current instability of global urbanization, it is all the more important to challenge, reassess and propose alternatives to conventional urban master planning and its associated conventions, types and standards.

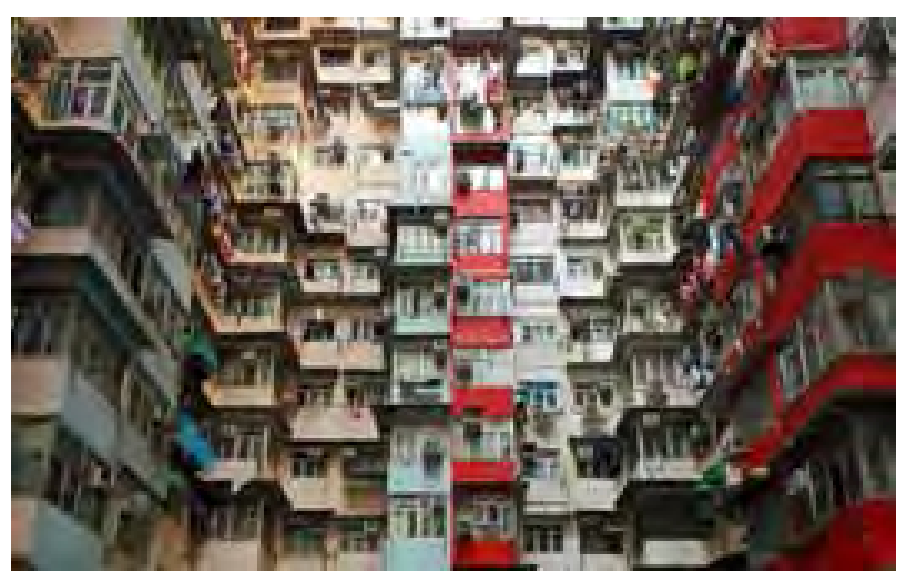

FIG_9_ | Kawloon Wall, Hong Kong | Lueng Chopan 


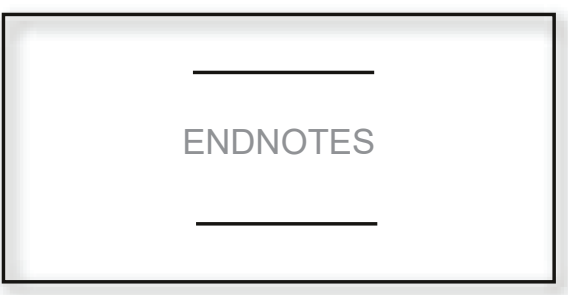

U. N. Department of Economic \& Social Affairs Population Division, "World urbanization prospects: the 2011 revision," April 2012. [Online]. Available: http://esa.un.org/unpd/wup/pdf/ WUP2011_Highlights.pdf

$9 \quad$ Schumacher, Patrik. "Parametricism as Style - Parametricist Manifesto." Parametricism as Style - Parametricist Manifesto. 2008. Web. 7 Oct. 2015. <http://www.patrikschumacher.com/Texts/ Parametricism as Style.htm>.

10 "Monitoring Urbanization in the 21st Century." Earthzine. Oceanic Engineering Society 21 Jan. 2013. Web. 12 Oct. 2015. <http://earthzine.org/2013/01/21/monitoring-urbanization-in-the21st-century/>.

11 Flint, Anthony. "The Potential Perils of Rapid-Fire Urbanization." City Lab. Web. 7 Oct. 2015. <http://www.citylab.com/politics/2013/05/potential-perils-rapid-fire-urbanization/5491/>.

12 Leinberger, Christopher B. "Foot Traffic Ahead - Ranking Walkable Urbanism in America's Largest Metros." Smart Growth America. The George Washington University School of Business, 2014. Web. 8 Dec. 2016. <http://www.smartgrowthamerica.org/documents/foot-traffic-ahead.pdf>.

13 Leinberger, Christopher B. "Foot Traffic Ahead - Ranking Walkable Urbanism in America's Largest Metros." Smart Growth America. The George Washington University School of Business, 2014. Web. 8 Dec. 2016. <http://www.smartgrowthamerica.org/documents/foot-traffic-ahead.pdf>. 


\section{Chapter 2}

Computational Urban Planning

Over the last several decades, digital tools and technologies have become the norm in architectural culture transforming both office and educational settings. ${ }^{14}$ Digital technologies have enabled architects to question established notions of space, form, manufacturing, delivery, assembly and construction. Similarly, computational urbanism may alter the way we think about the built environment by enabling us to manipulate and assess interactions between parameters that affect urban form. Tools that empower us to model and visualize growth may be key to managing urbanization in the 21st century. The city is perhaps the most complex entity produced by humanity and thus can be difficult to model. There is no one standard for cities and standards, like cities, are constantly changing. This chapter explores the promise of parametric design 
for urban planning by examining selected case studies which will give us a better understanding of the theory and practice behind computational urbanism.

Generative codes produce unexpected and not wholly predictable outcomes. As such, they enable us to observe phenomena and interactions that we might not otherwise be able to see. In this light, an emergent approach to coding in urbanism is not one that applies rules as limits of an acceptable, familiar design outcome, but one that enables the correlation of multiple constraints to produce innovative solutions. In turn, these surpass expectations and normative cultural and professional practices. "Coding can inform the pattern of streets, massing morphology, social order, activities and so on. Code-based design can lead to multiple hierarchies and emergent, unexpected patterns." ${ }^{15}$

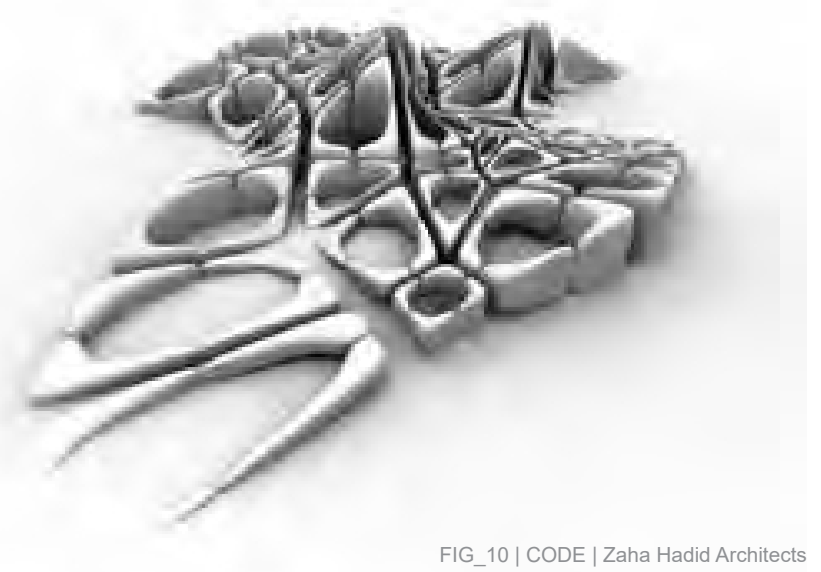

To date, however, the best-known attempts to apply parametric modeling to urban design appear to be primarily form-driven. They are characterized by masses that replicate and transform over a landscape, creating non-typical urban growth patterns. These forms are frequently based on random lines that distort conventional rectilinear buildings and blocks into organic shapes and patterns. 
The in-house computation and design group "CODE" at Zaha Hadid Architects, for example, links designers with programmers to develop specialized tools for generating what they describe as "spatial and experiential complexity in geometry."16 The aim of these experiments is to analyze topological complexity, cellular logics, and field structures on urban scales. The urban projects undertaken by the firm deploy digital design technologies to produce urban spaces with an "architect's sensibility."17 Projects from ZHA include proposals for the Thames Gateway in London and redevelopment projects in Istanbul, Singapore and Appur, India.

According to the designers at ZHA, the aim of these projects is to generate patterns that respond to varying environmental parameters. The first step in the design process is to construct a typological catalogue of architectural and urbanistic fields and elements (i.e., points, fields of residences, line fields of towers, plane fields of slabs, and volume fields of urban blocks). The next step is to analyze a series of digitally generated parametric variations. The designers then play a "matrix game" of recombination and interpenetration to arrive at a scheme whose richness and complexity are appropriate to an urban territorial strategy. ${ }^{18}$
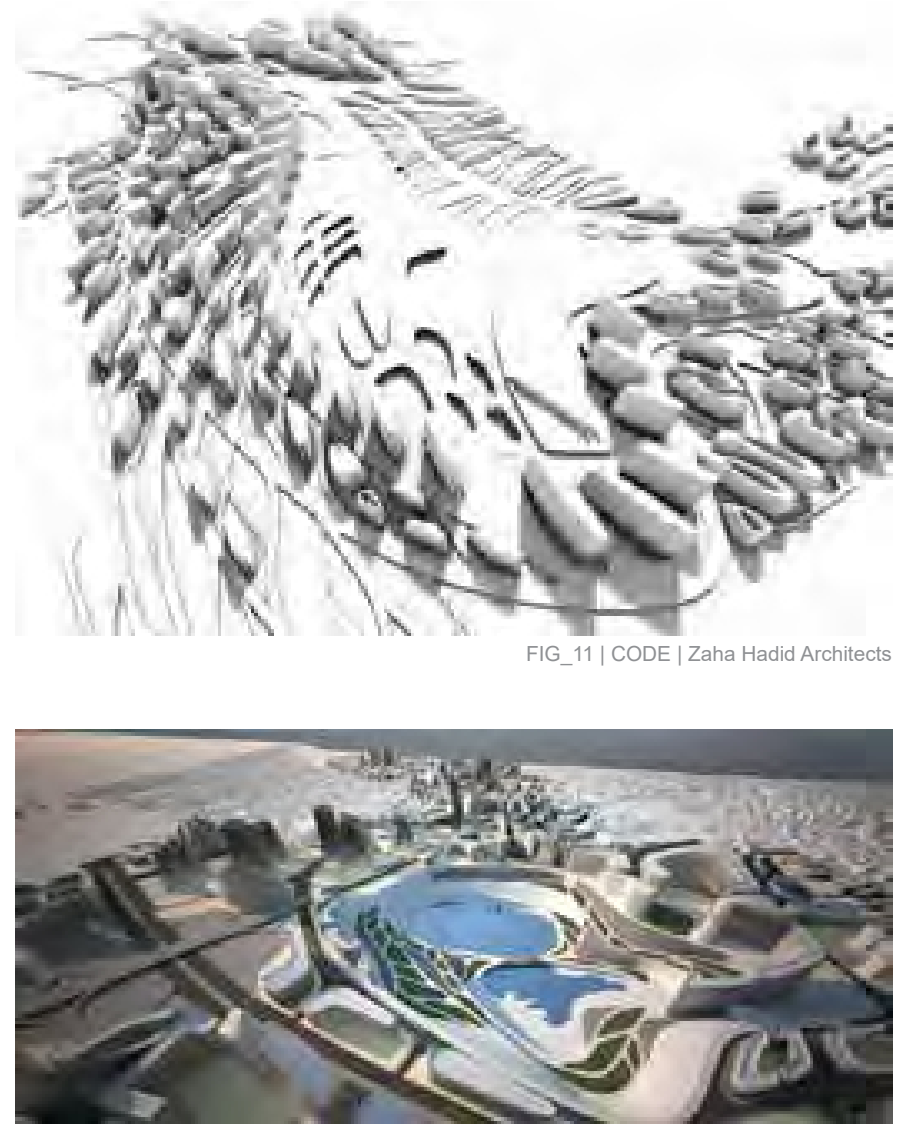

FIG_12 | Kartal Pendik Masterplan | Zaha Hadid Architects 
same "soft selection tool," which enables designers to distort grids at their discretion. This suggests that the projects are driven by an aesthetic agenda more than by firm data or targets. While the disposition and shape of masses in these proposals appear to embody Schumacher's definition of parametricism, the logic and parameters used to generate these proposals are both unclear and questionable. Without the quantitative logic grounded in things like target densities (e.g., units per acre or FAR) or reciprocal relationships between total built square footage and open space, we are left to conclude that the primary objective is to make compelling objects that challenge the status quo.

In the forward to Parametric Architecture author Fulvio Wirz (from ZHA) explains, "an architectural concept is supported by the metaphor, the mental algorithm and the logical process that we set as the foundation of design intent." If this basis is strong, the formal result will be not only coherent, but will also be robust enough to adapt to the countless variations possible within the defined parameters. Otherwise, even a simple cube can look like banal formalism inasmuch as the choice of form does not seem a logical response to program or site but an outcome led by the aesthetical judgement. "In parametric or algorithmic design, we recognize that

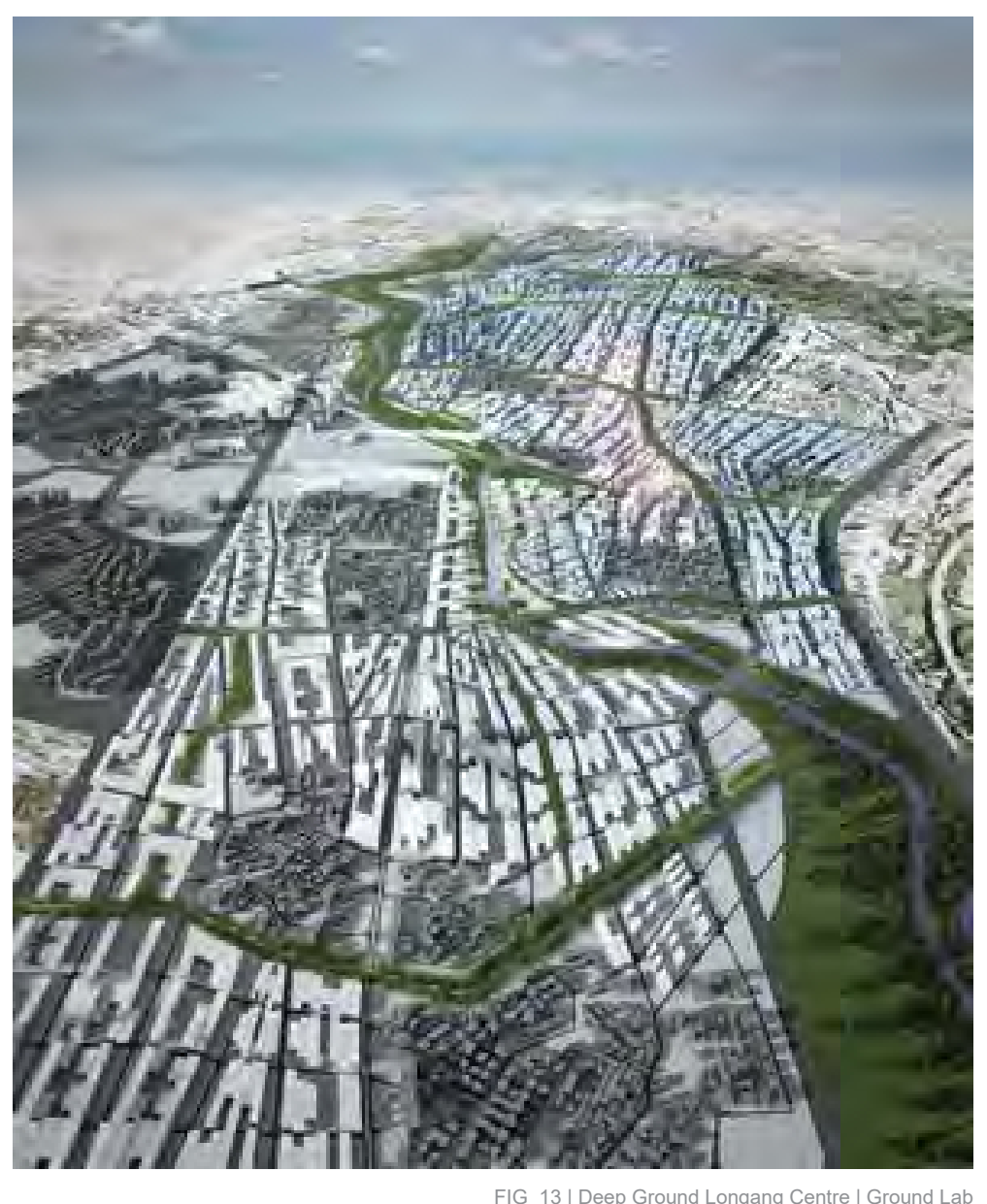

FIG_13 | Deep Ground Longang Centre | Ground Lab

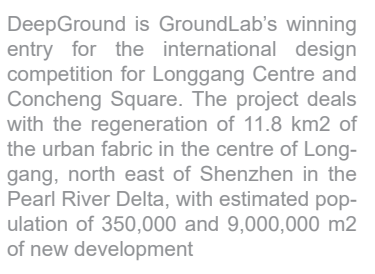


traditional values of architecture are not only unchanged but at the same time evolved and reinforced."19

What distinguishes a parametric architecture from traditional projects is a kind of complexity that is generated by a definition of rules that control its generation and differentiation of form and space. The result is a complex order where every element is continuously connected and in which the project achieves a selfreferentiality that enables changes to be made without threatening the legibility of the larger concept. "The software itself does not ensure this coherence if it's not associated with a strong logical process that will always be domain of the human mind, therefore, a designer attitude." 20 To clarify, the real formalism lies in limiting the architectural design within software's boundaries, while the design coherence consists of mastering and leading the software to express the aim of architecture and its intended design.

In summary, the application of parametric design to urban planning and the logic behind the choice of parameters are blurred in the examples cited above. As embodied in the projects by ZHA, the rationale for the use of parametricism appears to be "form-driven urbanism" i.e, the desire to create buildings with a signature look, 
form and style that deviate from conventional form.

Again, it is difficult to assess these proposals against target data like FAR, UPA, or breakdowns in the percentages of built to open space, commercial to residential space, etc. However visually compelling these proposals might be, the use of parametricism appears to be divorced from many if not most of the parameters we associated with urban planning. This is less an indictment of parametricism, than the way it is used and/or understood by its best-known proponents. 


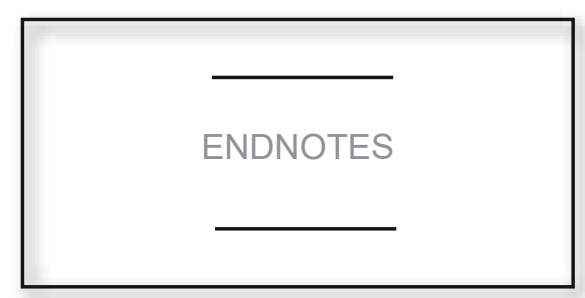

Verebes, Tom. Masterplanning the Adaptive City: Computational Urbanism in the Twenty-first Century. Print pg 181 Verebes, Tom. Masterplanning the Adaptive City: Computational Urbanism in the Twenty-first Century. Print pg 182 "Forward." Parametric Architecture with Grasshopper 1.1 (2010): 7-9. Print. Forward." Parametric Architecture with Grasshopper 1.1 (2010): 7-9. Print.

"3lements - an Urban Strategy - Lab-eds." 3lements - an Urban Strategy - Lab-eds. Web. 7 Oct. 2015.

Forward." Parametric Architecture with Grasshopper 1.1 (2010): 7-9. Print.

Forward." Parametric Architecture with Grasshopper 1.1 (2010): 7-9. Print. 


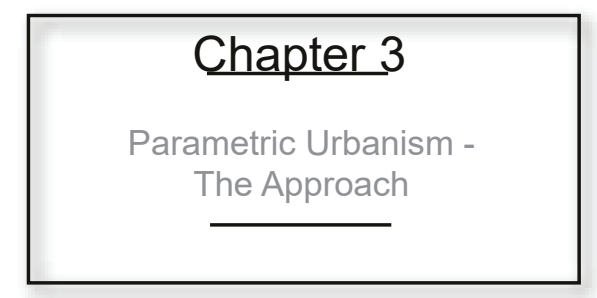

"Modernism was founded on the concept of universal space. Parametricism differentiates fields." 21 Contemporary avant-garde architecture and urbanism attempt to address the post-modern demand for spatial differentiation by deploying a rich panoply of parametric design techniques. However, what confronts us is a new style rather than merely a new set of techniques. The techniques in question - the use of animation, simulation and form finding tools, as well as parametric modeling and scripting - have inspired a new movement with radically new ambitions and values. In turn, this development has led to many new, systematically connected design problems that are being worked on competitively by a global network of design researchers. 
The repercussions of parametric design may transcend both the search for of a new style and today's fascination with complex, curvilinear forms. The potential to update, revise and alter a master plan in real time in order to observe and assess changes over time has the potential to revolutionize the discipline of urban planning. This requires, however, the appropriate parameters and systems of logic.

Parametric tools promise to provide 21st-century architects with unprecedented freedom of form making, both with respect to the design and the execution of buildings. For many architects, iconoclastic form making has become an end in and of itself -- their primary goal being to design 'signature' buildings that stand out. As practiced by its champions (e.g., ZHA), parametric urbanism takes this iconoclasm to the scale of the district, producing novel urban morphologies characterized by the repetition and manipulation (in both height and scale) of the same geometric form. As stand-alone pieces of imagery, parametrically generated urban proposals are impressive inasmuch as they present new and different ways of approaching the design of cities. Arguably, however, there is a blurring or confusion between architectural and urban design, i.e., design at the scale of an individual building and design at the scale 
of the neighbourhood or district.

On an urban scale, things are a lot more complex. Different scales and functions of buildings are often associated with different building types. However related, museums, hospitals, mid-rise residential buildings, high-rise residential towers, office towers and single-family detached houses are all relatively distinct building types. They are not necessarily simple variations of the same basic form or sets of proportions. Changes in scale and density often correspond to changes in building types, which, arguably, parametric design has yet to adequately consider. Differences in urban density also frequently correspond to differences in building types, not just to simple variations on the height or scale of individual buildings. Different rules apply to different building types. An office tower, for example, is not just a scaled up version of a single-family house nor is a Wal-Mart a scaled down version of a mid-rise apartment building.

Beyond building form and typology, other factors come into play when considering urban morphology. These include the organization of street grids, the width and hierarchy of roads, setbacks, shadows, the flow of traffic, the location of transit stops, the need for surface 
parking, the amount and distribution of open space, compatibility of uses and the distances between buildings. The height of buildings, for example, may affect the width of streets, and vice versa.

Instead of manipulating a single geometric form (e.g, a perimeter block - as per Fig. 9), parametric urbanism should attemp to construct a field of logics that operate within correlated and mutually accentuating urban systems: fabric modulation, street systems, and logics for open spaces. Distinctions should be made between use types and building forms.

The early stages of this thesis, undertook a series of basic parametric manipulations generated to both mimic the current practices of parametric urbanism and to better understand the software and techniques. The models in Figures 14-16 explored the assumption that density was a simple function of height height and that a building's height should be controlled in relation to its proximity to arterial streets, view corridors or particular urban nodes (e.g., transit stops). Although interesting from a compositional point of view, the results reinforced the notion that buildings cannot be limited to a single form (or floorplate), nor can density be limited to height. 

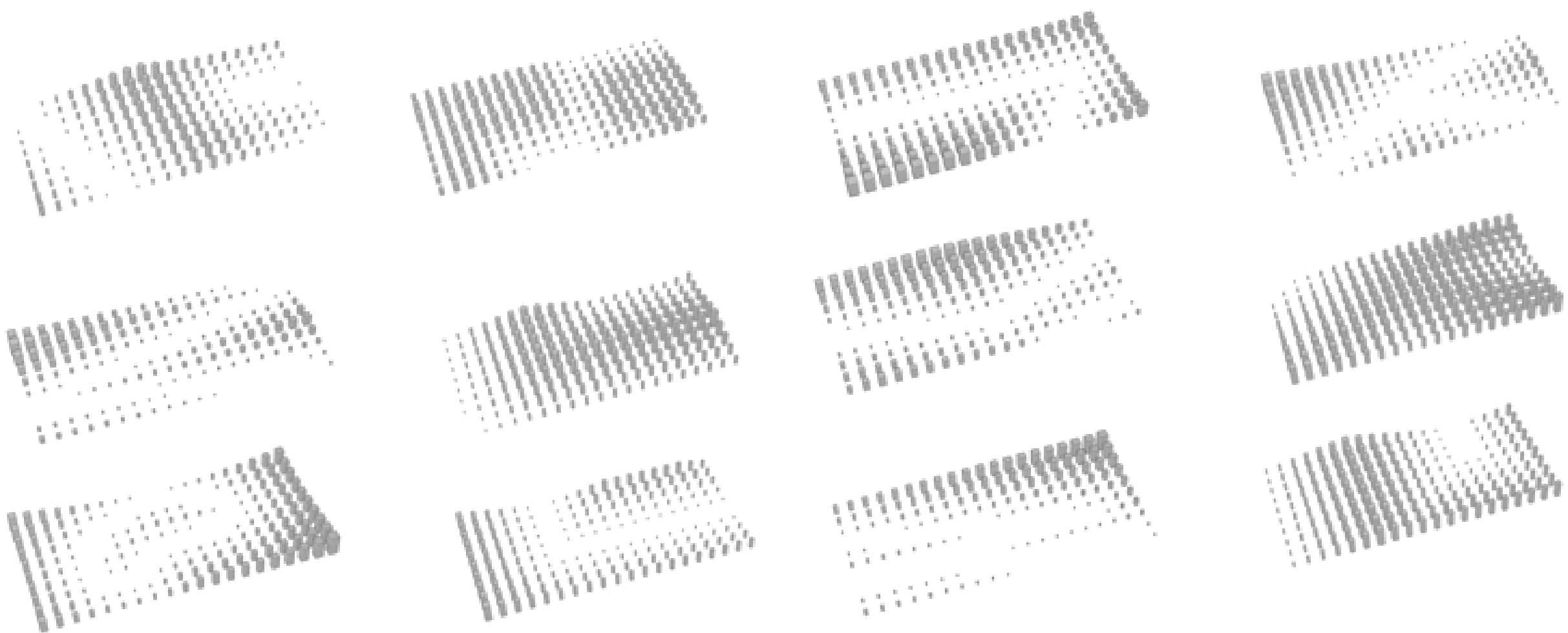

FIG_14

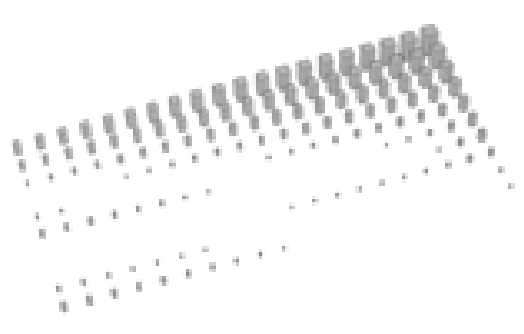

ilibivito 

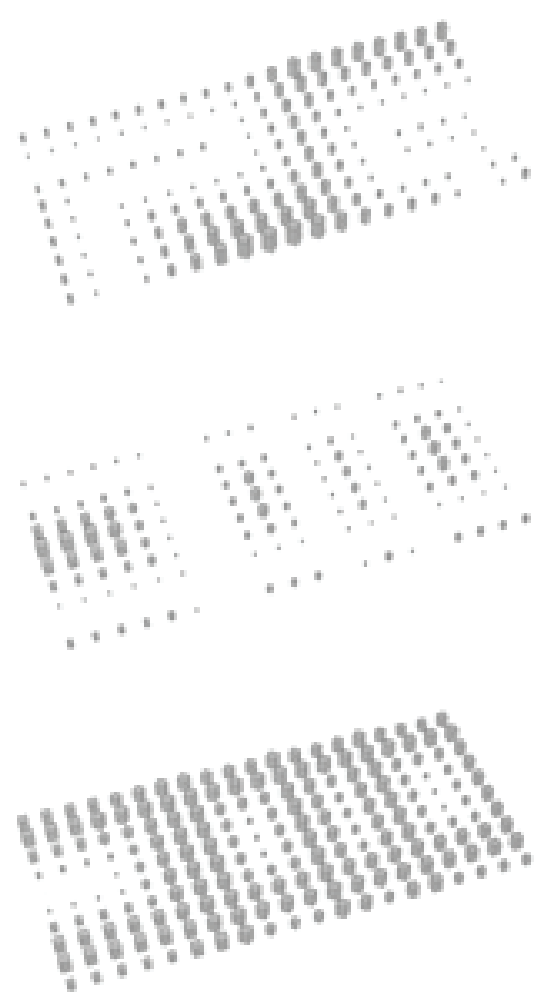

FIG 15 Code-Based Design allows for the development of a series of urban organizational models, generated as computational arrays of massing typologies and densities. This method proliferates new hybrid urban massing prototypes, and varied species of architectural configurations associated with contemporary global cities.
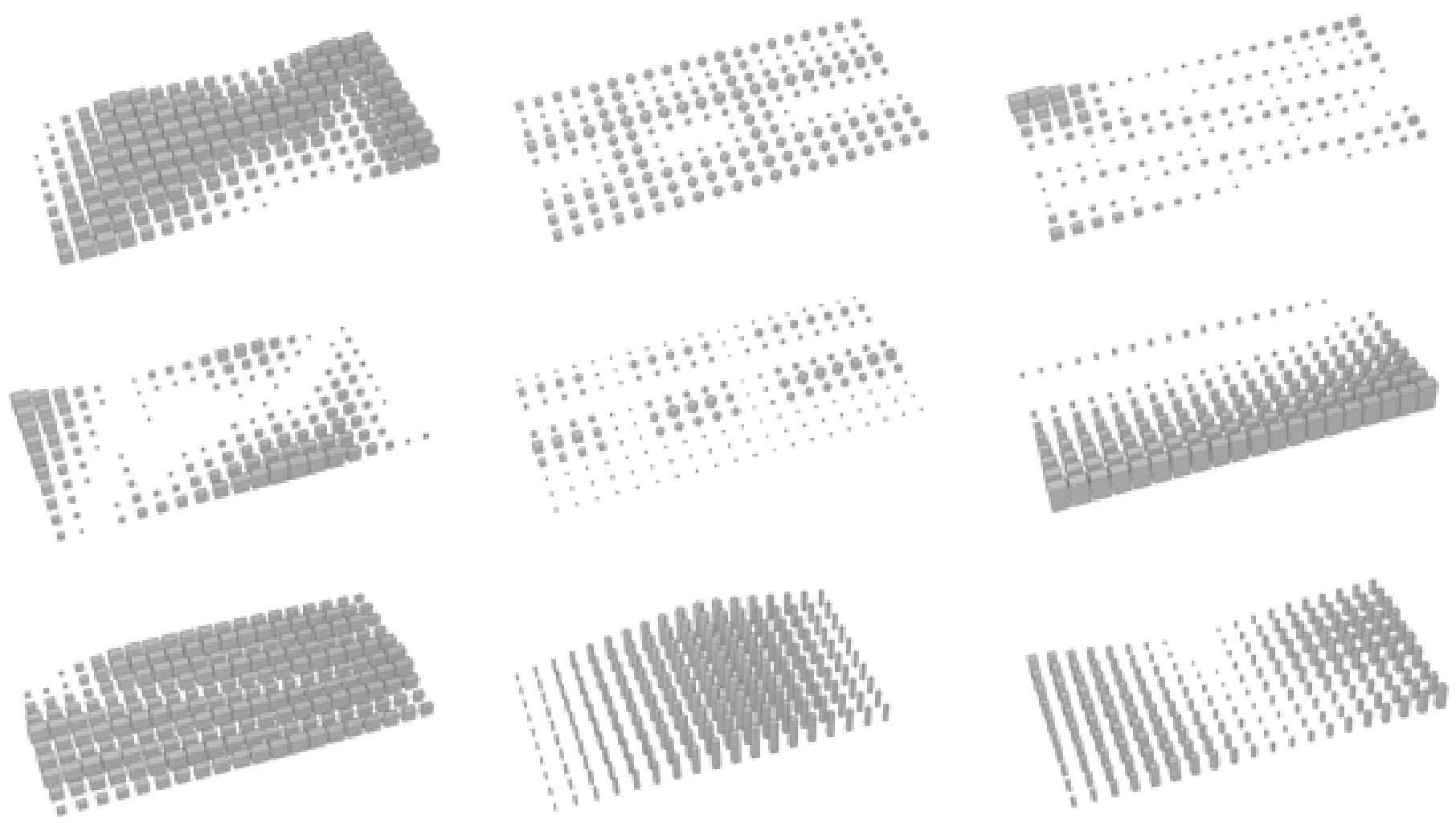

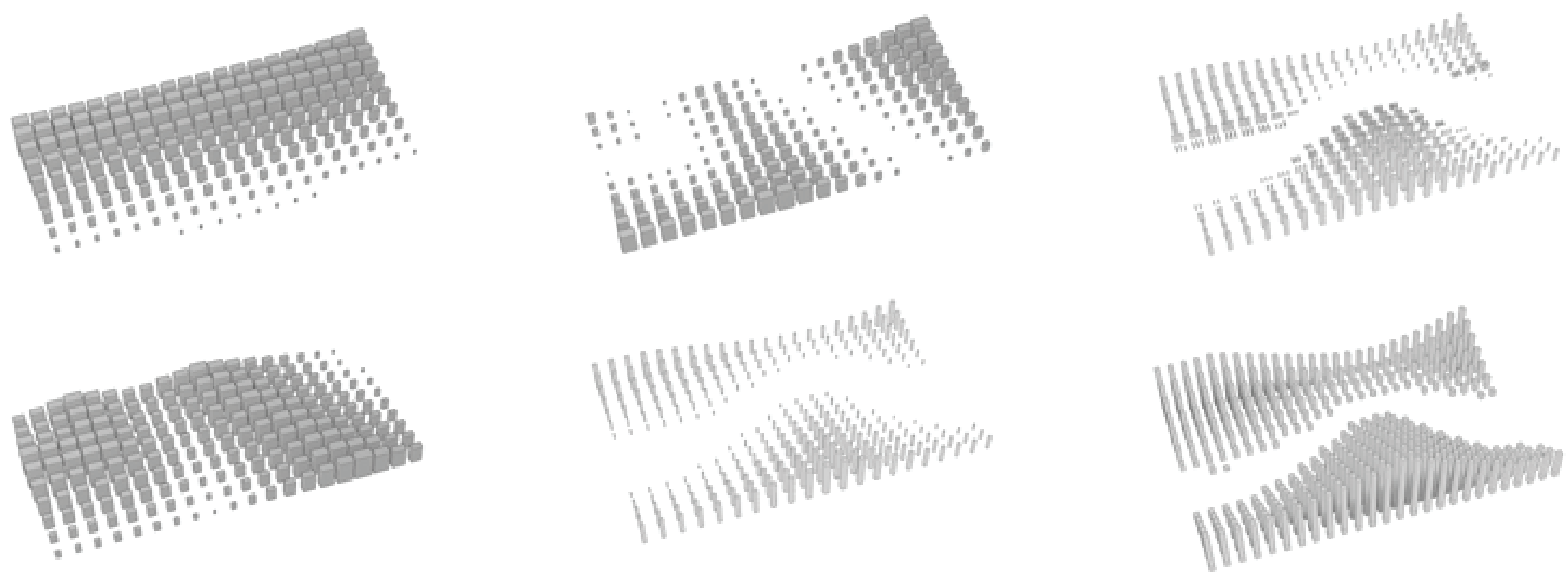

FIG_16 The objective is to propose

alternatives to stable, repetitive

typologies, and to invent a range of

specific, diverse forms of architectural

organization 
In this respect, it is hard to interpret the examples of parametric urbanism offered by designers like Patrick Schumacher (i.e., those produced by Zaha Hadid Architects). Depending on its scale and height, the same rectilinear form might represent a house or an office building. Nevertheless, this infinite elasticity in height and floorplate contradicts to what we know of building typologies. This is especially true with residential buildings, where the depth of floorplates is constrained by the need for access to natural light.

The movement from lower to higher residential densities, then, might be characterized as a series of "phase shifts" from one building/urban typology to another. As noted, it is neither possible nor desirable to increase the density of a residential neighbourhood by increasing the size of individual houses. Floorplates of houses are constrained by size of lots and their height is constrained by the number of stairs residents are willing to climb. Changing densities or scales of development frequently involves a reconfiguration of lots, a reconsideration of setbacks, and the shift from one building type (e.g., a single-family detached) to another (e.g., townhouses or mid-rise buildings). Moreover, while public open space may not be a significant consideration in large-lot neighbourhoods of detached houses, it is crucial to consider in neighbourhoods with 
significant numbers of high-rise apartment towers.

The ultimate criticism of the current practice of parametric urbanism, then, would be that the computational algorithms tend to privilege/operate on a singular geometry or urban typology (e.g., slab building or perimeter block) and transformations are primarily limited to scaling operations.

\section{Morphological Phase Shift}

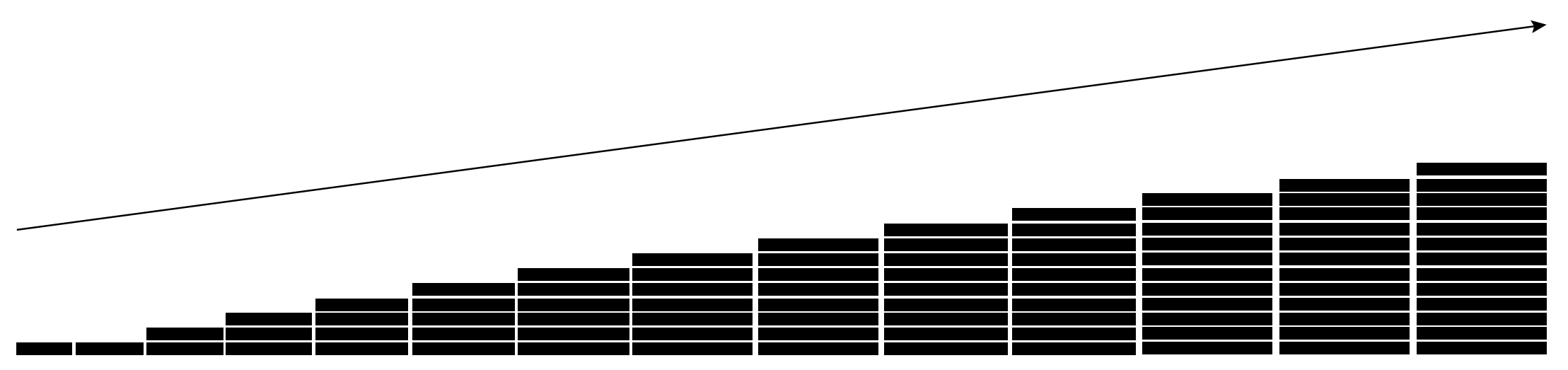


A more effective approach to parametrical urbanism, then, might be to associate different uses and densities to different building types. As such, transformations from lower to higher densities would not be accompished through smple scaling operations but rather through typological "phase shifts." However easy it might be to manipulate scale on a computer, as an approach to urban design this could cause a multitude of problems. 


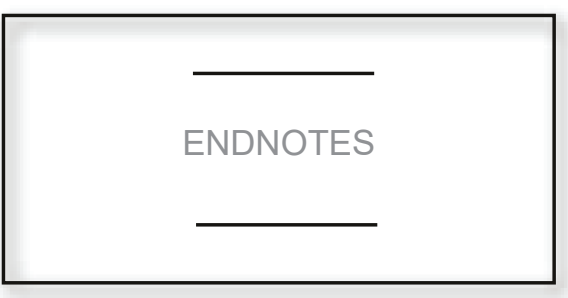

21 Schumacher, Patrik. "Parametricism as Style - Parametricist Manifesto." Parametricism as Style - Parametricist Manifesto. 2008. Web. 7 Oct. 2015. <http://www.patrikschumacher.com/Texts/Parametricism as Style.htm> 


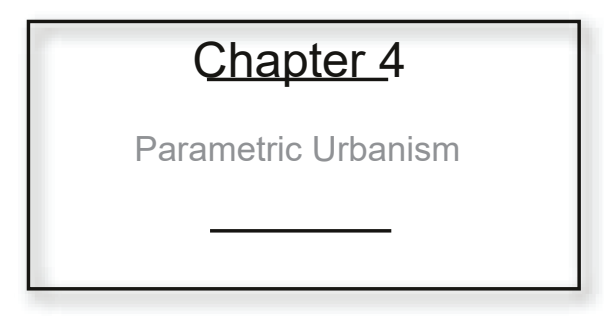

Parametricism is currently not being used to solve issues facing society or the planet. In the case of urbanization, parametric tools enable a multitude of variables to be correlated and manipulated in order to assess a range of scenarios in response to the changing needs of a community or city.

Let's assume that a city needs to add density to developed areas in order to more effectively manage growth - a process known as "intensification." How might we go about this? Increase allowable heights? Increase allowable lot coverage? Establish a minimum FAR? Do we do this equally everywhere or do we restrict increased density to arterial streets or to areas well served by public transit? 
In this scenario, we must consider both the density targets and the area over which they are intended to be achieved. What height limits would need to be set along arterial streets to achieve density targets for a particular neighbourhood or district? What if density could not be distributed equally along an arterial street (e.g. heights should be lower along certain stretch of a road to protect a view)? What if we restricted the amount of shadow any building might cast on another? What impact might lot size have on our ability to achieve target FARs? Are there areas in the city where the sizes of lots should be restricted and others where consolidation of lots should be encouraged? What is the relationship between FAR, height, setbacks and lot size?

Is there a rule of thumb that defines the ratio of open space to the overall density of a neighbourhood? What percentage of land should be set aside for schools and institutional purposes? Should we distinguish residential density from overall density? What land (or percentage of land) should be protected from development and for what reasons? In her book, The Death and Life of Great American Cities, Jane Jacobs criticized post-war planning policies for destroying communities, impeding economic activity, and promoting isolated, unnatural urban spaces. Could parametric 
planning be brought to bear on the creation of livelier, more selfsustaining urban environments?

Beyond its potential to produce aesthetically compelling propositions, might parametric software offer designers new tools for experimenting with novel methods of designing? If so, how might we distinguish projects employing parametric logics from those developed according to traditional methods? The first important difference is conceptual inasmuch as scenarios are less the expression of a design vision than the result of the process of applying various rules and constraints. The second difference can be characterized by the vivacity or liveliness of the system that structures it, namely the change from a static to a dynamic system. The formal result is no longer the definitive crystallization of a particular line of reasoning or design vision, but rather a snapshot of a process in continuous evolution. Proposals are generated to assess the impact of targets and constraints, to observe what happens when the system "automatically" reacts to the stimuli and inputs to which it is programmed to respond. Projects thus evolve autonomously according to the rules established by the designer. It is through the manipulation of input data-not the direct manipulation of form -- that designers are able to modify alternatives, based 
on their evaluation of the "snapshots" that the process provides. The selection of variables, data and constraints is a crucial, component of the design process.

According to Paulo Fusero, the parametric approach to urban design requires the selection and use of open data (this term refers to data sets that are freely accessible to anyone) in relation to pre-established objectives that represent the factors conditioning the design process. They may be strictly urban parameters, such as building form, spacing or overall density. They may also be bioclimactic factors such as solar angle or wind speed. They may include data related to the energy efficiency of buildings, real estate values, levels of urban safety, etc. Having collected the data it is then possible to apply parametric techniques for the definition of the urban morphology. These techniques may respond to restrictions imposed, such as land use zoning, height-to-width rations for buildings, landscaping requirements, building typologies, etc.

Employing these methods when working within the urban system requires an in-depth understanding the intrinsic behaviours of urban environments. Adaptation and self-organisation can only occur if the appropriate rules and constraints are imposed by the

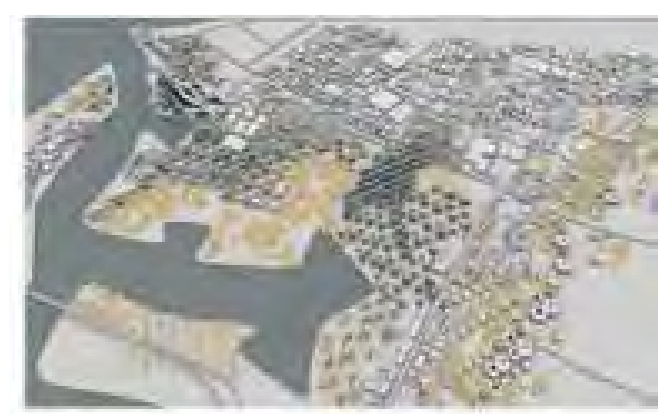

FIG_19: DRL Sahra team (Tutor: Tom Verebes.) 2007-2009 Four different scenarios of urban growth and development of Ras AlKhaimah in UAE.
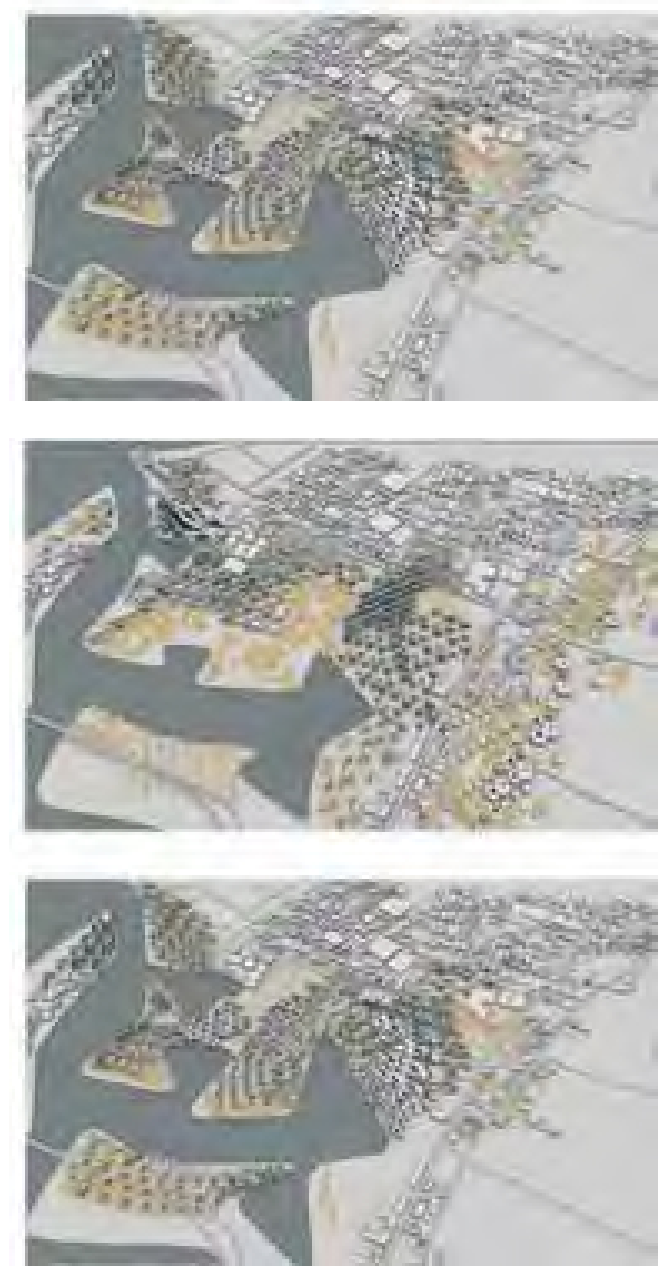
designer. These rules and constraints are continuously tweaked to

optimize the outcome.

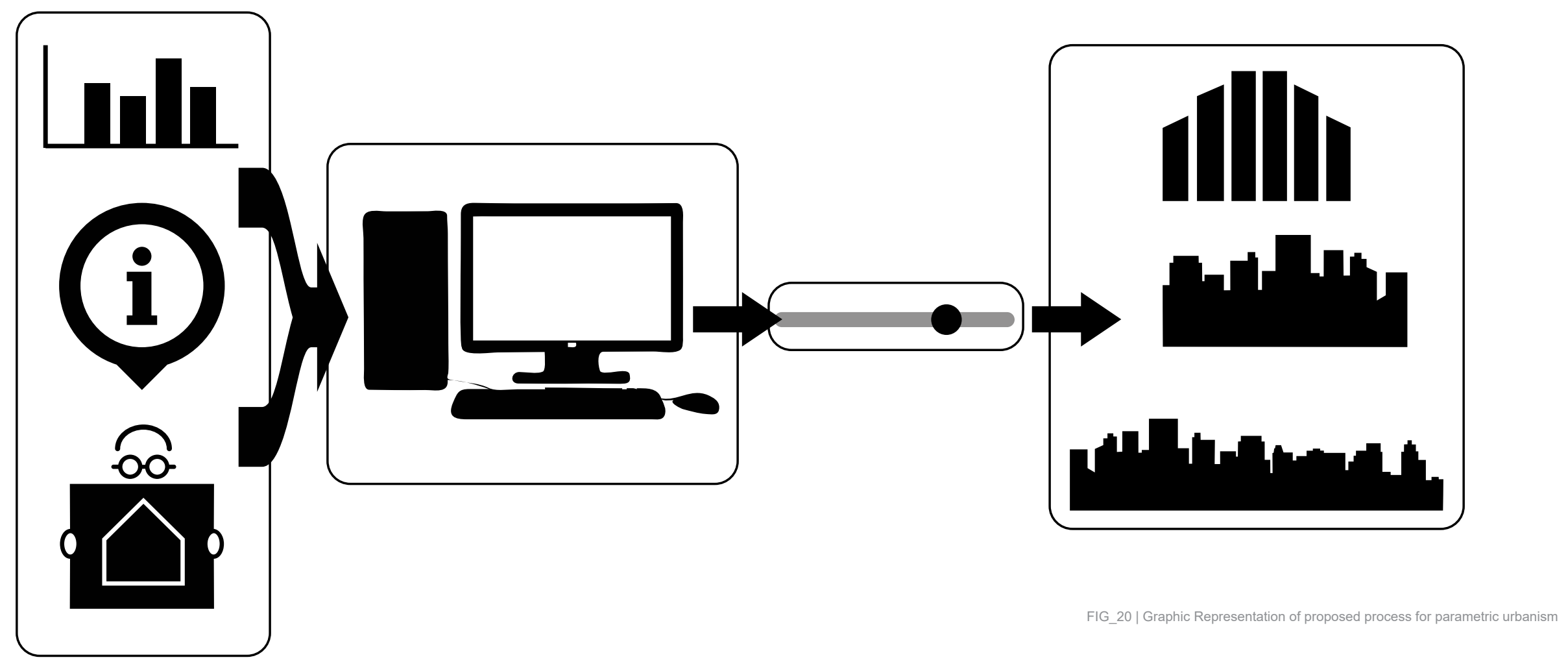

The digital process thus begins with the collection of data, information and professional expertise all of which are incorporated into the parametric tool. Once in the program, the information can be manipulated by adjusting parameters in response to the various iterations and outcomes. 


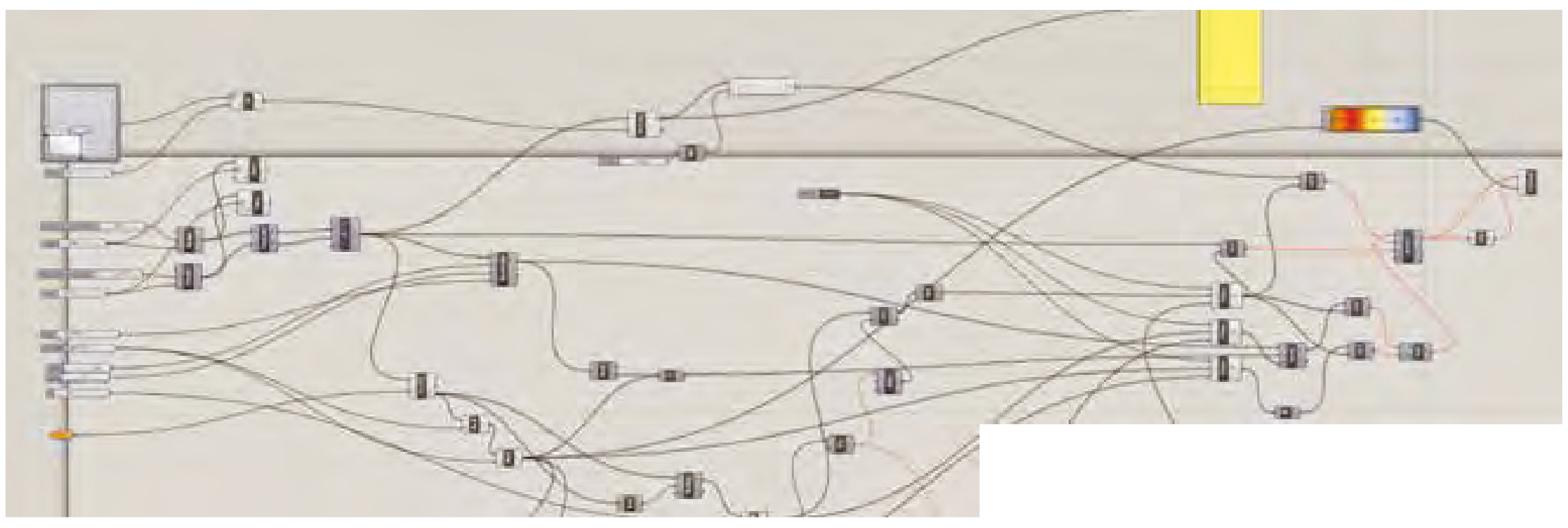

FIG 21_Grasshopper Algorithm/Scripts

Screenshots of the combination of

the purpose of developing the logic

approach to parametric urbanism in this

thesis.
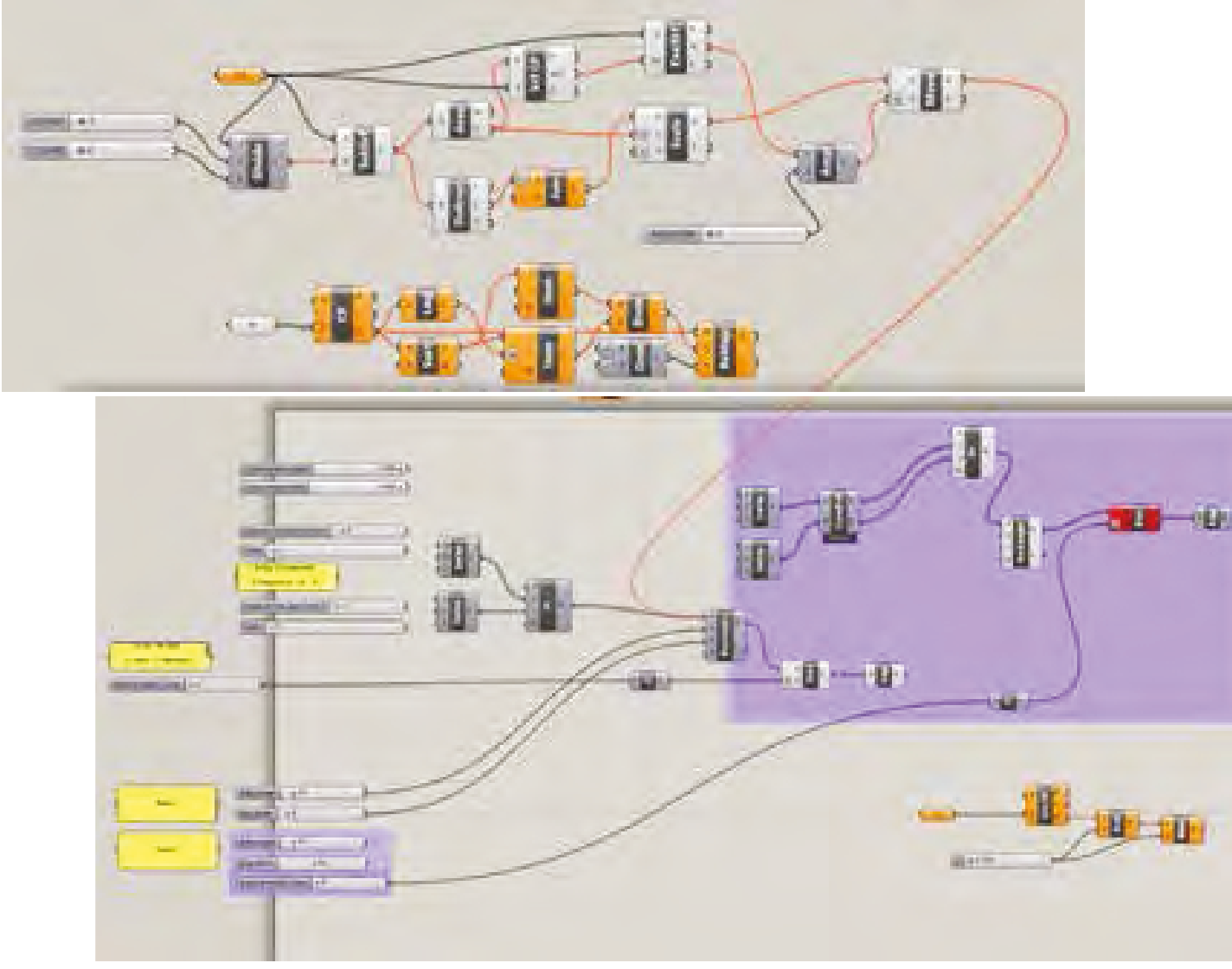


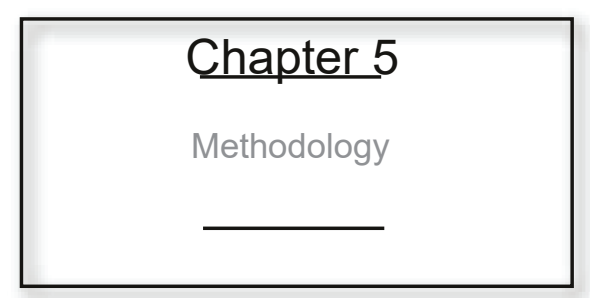

This thesis is not intended as a blue print for the management of growth; rather it is an operating manual for new, potentially pertinent approaches to urban design in the next 30-50 years. The desire here is to explore the emerging toolbox of parametric and algorithmic design to assess its applicability at the scale of the city.

Parametrics, as the name implies, involves the manipulation of parameters, which, in turn, generate form. If parametric software tools are to be applied at the scale of the city, we must begin by defining the parameters and determining how they will be applied. In an overview, the goal of the first process of experimenting with the software tool to give the notion of parametric urbanism validity is to establish a multitude of scenarios and develop them based on 
the quantities provided by basic assumptions of urban planning. This process provides an easily understandable framework from where the result basic coding can begin to be understood. The process will affect multiple scales: the building lot, the city block, and the city.

In this thesis, the very first testing of the tool began by taking the very basic fundamental parameters that generate a built form on the building scale. For the purpose of this thesis, I began with the following parameters:

- $\quad$ Floor Area Ratio (F.A.R)

- $\quad$ Lot size

- $\quad$ Lot offsets

- $\quad$ Block size

- $\quad$ Sidewalk offsets

- $\quad$ The number of lots per block

- $\quad$ The building type and its dimensions

In the case of urbanism, the parametrical tool must recognize the objects it will be manipulating. Therefore we must assume that certain building typologies have designated configurations, which become parametrical objects within the algorithm. For the purpose 
of the thesis, I identified five different residential typologies (refer to typologies diagram_FIG_22):

- Lowest Density:

- Single family detached houses (assume, 2 stories, $12 \mathrm{~m}$ x $30 \mathrm{~m}$ lot, 50 sq. m./unit plus garage).

- Medium Density (three options):

- Row house (assume 3 stories, $6 \mathrm{~m}$ x $27 \mathrm{~m}$ lot, area of 125 sq. m./unit). 6-meter mid-block laneway. No garages (surface parking off of laneway)

- 7-storey mid-rise, $30 \mathrm{~m} \times 15 \mathrm{~m}$ floor plate. Subtract $20 \%$ for circulation and divide the balance by 100 sq. m. to get number of units. This is approx. 25 units per building.

- 11-storey mid-rise, $30 \mathrm{~m} \times 15 \mathrm{~m}$ floor plate. This includes a 5 -meter commercial story at grade. Subtract $20 \%$ for circulation and divide the balance by 100 sq. m. to get number of units. This is approx. 36 units per building, excluding ground-floor commercial.

- High Density:

- 30-storey point tower on 11-story plinth, $24 \mathrm{~m} \times 24 \mathrm{~m}$ floor plate for tower portion. This includes a 5 meter commercial story at grade. Assume 2-meter set-back at 11 stories.

Subtract $20 \%$ for circulation and divide the balance by 100 
sq. m. to get number of units. This is approx. 135 units in tower portion of building and 15 units in plinth portion ofbuilding per building for a total of 150 units, excluding ground-floor commercial.

Subtract $20 \%$ for circulation and divide the balance by 100 sq. $\mathrm{m}$. to get number of units. This is approx. 135 units in tower portion of building and 15 units in plinth portion of building per building for a total of 150 units, excluding ground-floor commercial.

These five types correspond to well-established residential building types in North America. As cities are largely produced by the marketplace, it is important to acknowledge and work within the terms of reference what the marketplace is likely to produce. Restricting our explorations to these five types allows us to visualize density in relation to various building and block typologies. The assumption here is that changes in density are associated with changes in types rather than to changes in the scale (floorplate and/or height) of a single geometric form or type.

Early on I also chose a block type similar in scale and proportion to blocks in many North American cities. The size was set at 144 

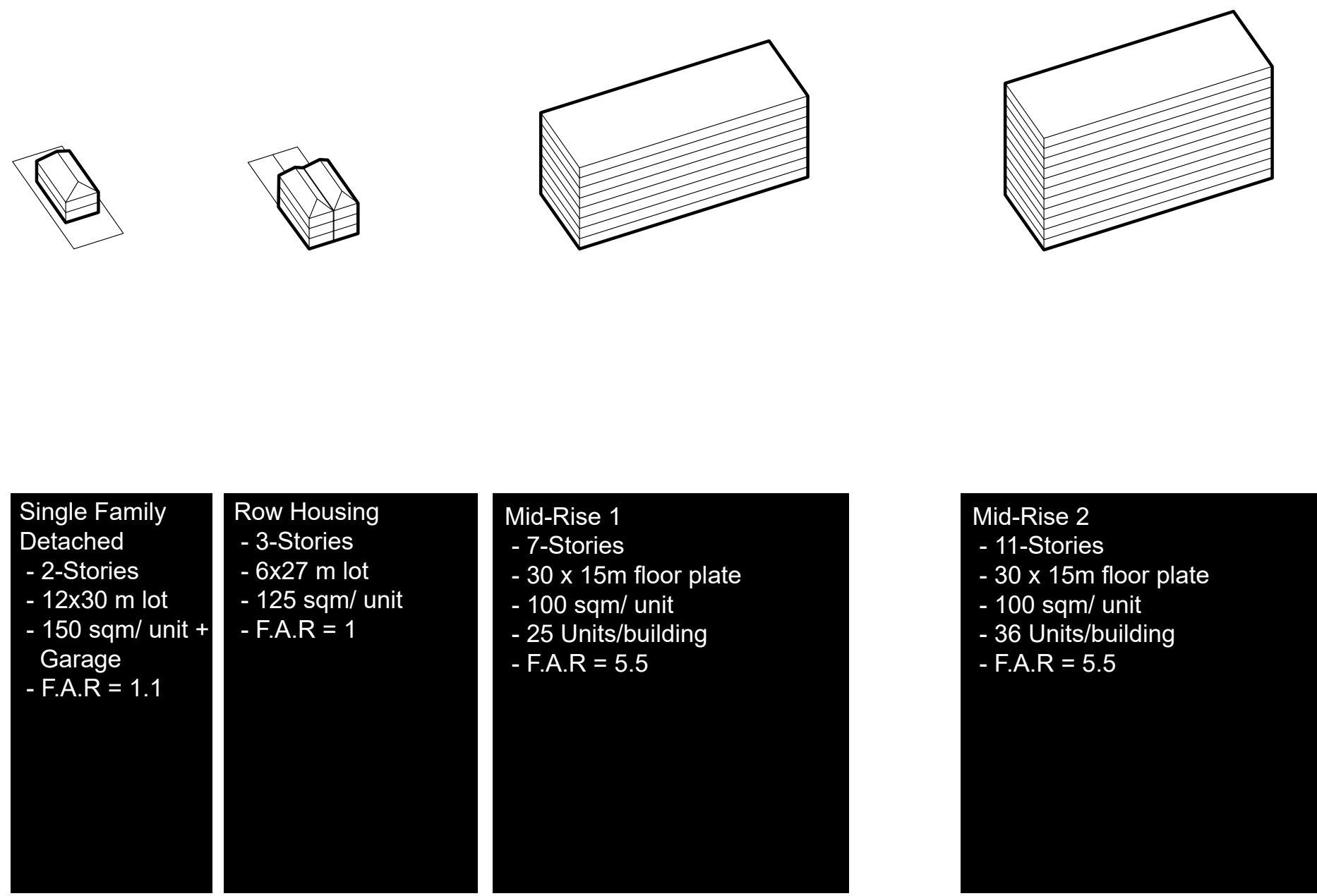
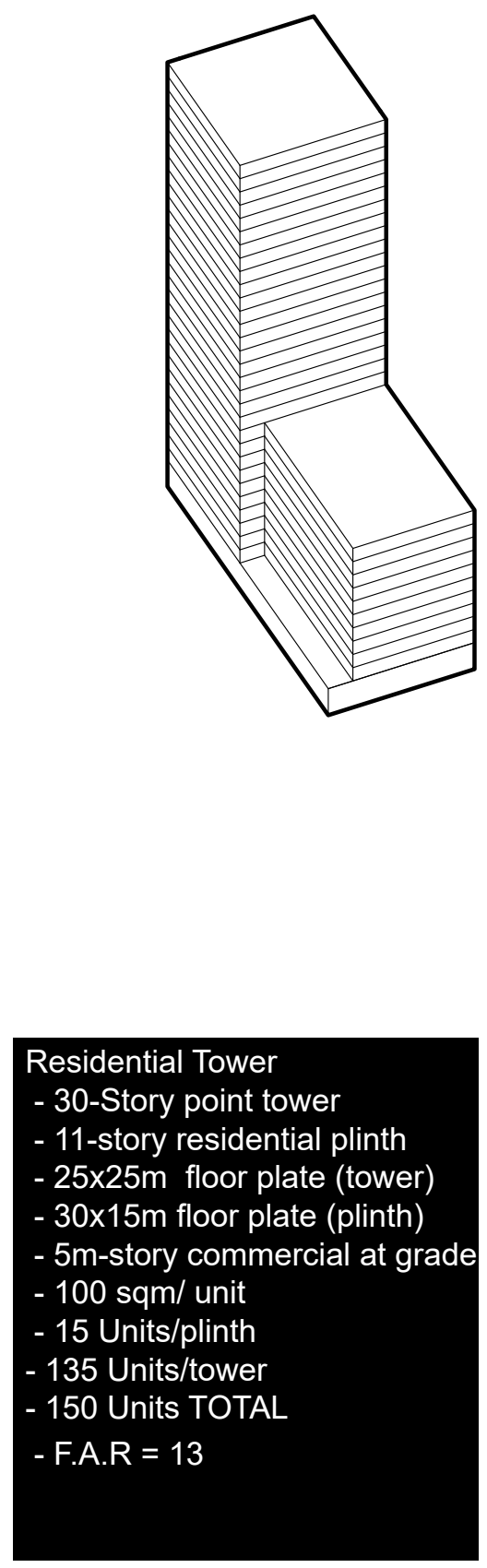
meters $\times 60$ meters, with blocks oriented east/west to optimize solar orientation. ${ }^{1}$ typologies, these are then arrayed over a designated city block (144 meters x 60 meters). I also established several rules to guide how various building types might be organized and/or combined on a given block. Largely these rules apply to residential fabric, which is the focus of this investigation.

- No more than two towers per block.

- Towers may not face each other directly across a street.

- To mitigate the impact of shadows, no building higher

than 7 stories would be located on an east/west street.

In other words, towers and 11-story mid-rises would be

limited to north/south streets, which, in response, would be slightly wider than east/west streets.

Having established building and block typologies, I began exploring the relationship between density and type over a generic 100-block area (10 blocks in each direction). This comprises an area of about 150 acres or 100 hectares. With the gradual increase in the desired density, the formula within the algorithm dictates that the typologies begin to shift on every edge of the block. To increase the density of a block of single-family detached houses, for example, houses on one of the four sides of the block would be replaced
1. Note, the dimension and orientation of blocks is consistent with the Traditional Neighborhood Development Checklist as formulated by the congress of the New Urbanism as well as adhering to LEED - ND Standards. 

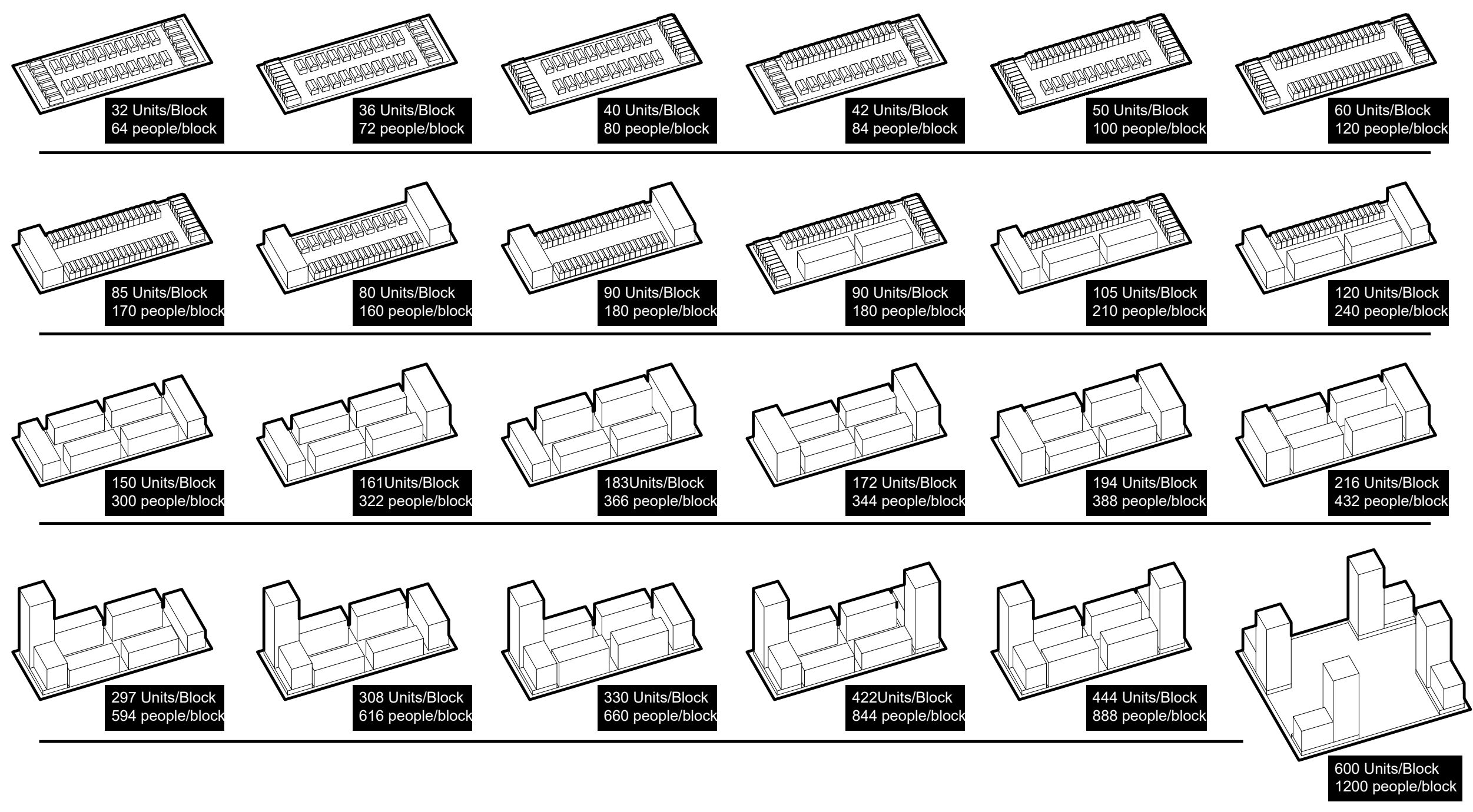
by townhouses. Once a block has fully changed its typology, the typological phase shift would begin anew (e.g., townhouses to midrises - and so on). This process is illustrated in Figure 23. To protect the integrity of the street, I also established a rule that similar types must face each other across a given street. As such, changes in types must occur across a block and not across a street.

As expected, the lowest overall densities correspond to the lowest density building types, namely detached houses. On the other end of the spectrum, the highest densities are achieved when each block is assigned two 30-story point towers (on the east and west ends of the block, with four 11-story mid-rises on opposite corners. (Refer to Fig_23). Figures 24 through 27 illustrate transitions from lower to higher densities, where the highest densities occur at 1) an edge (FIG_25), 2) an arterial street through the center of the district (FIG_26), and 3) at the corner or node (FIG_27). 


$$
=0
$$




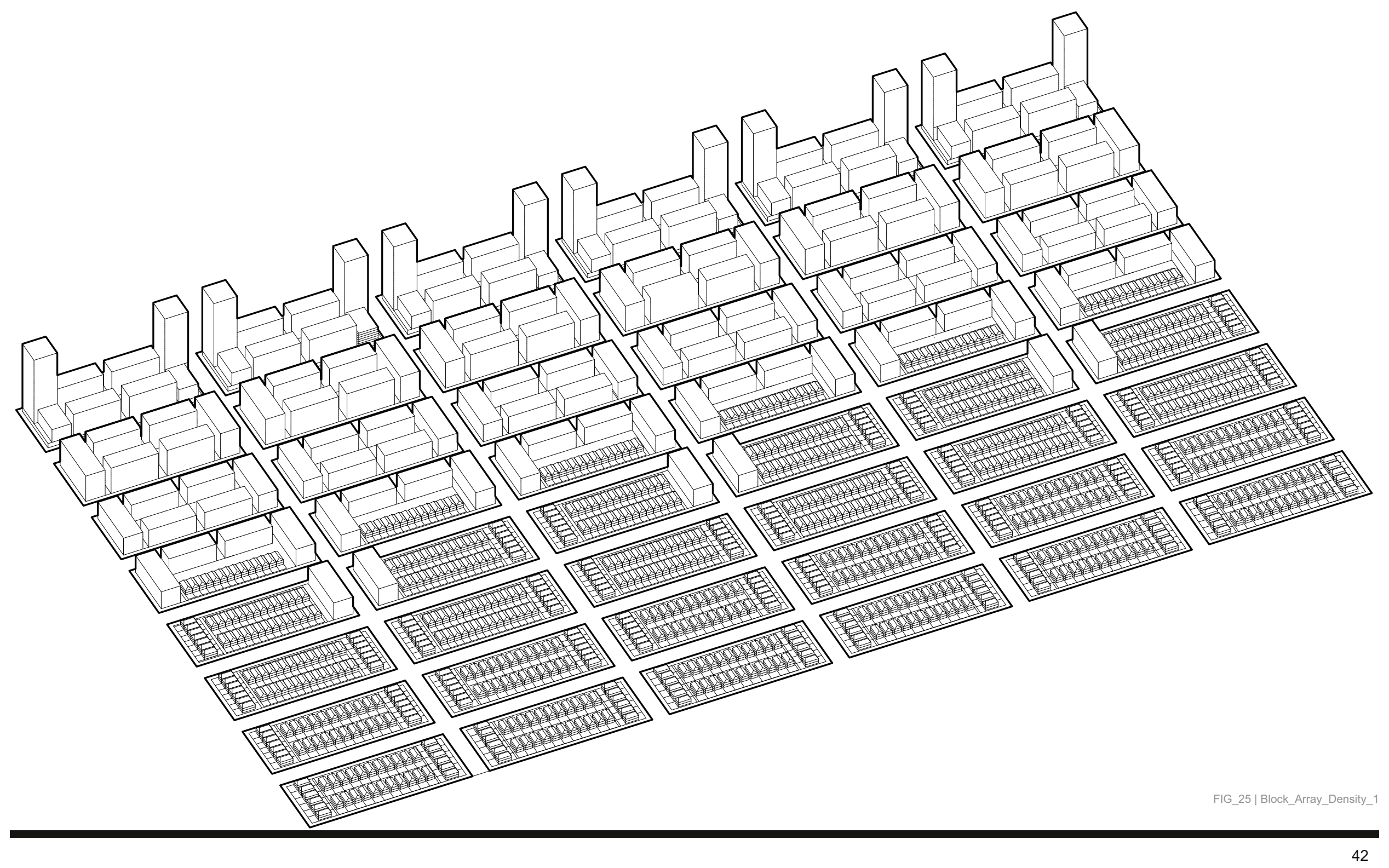




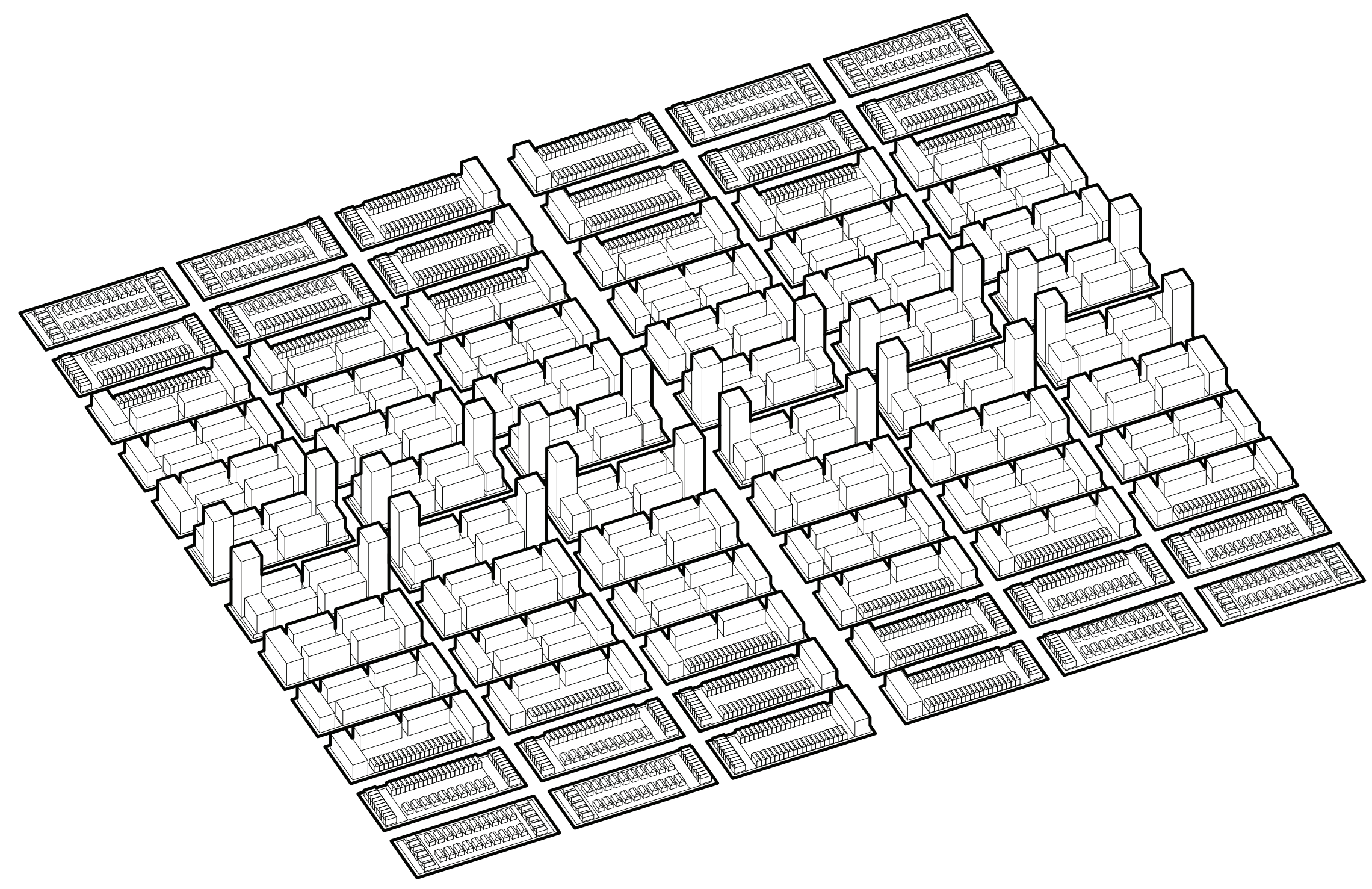




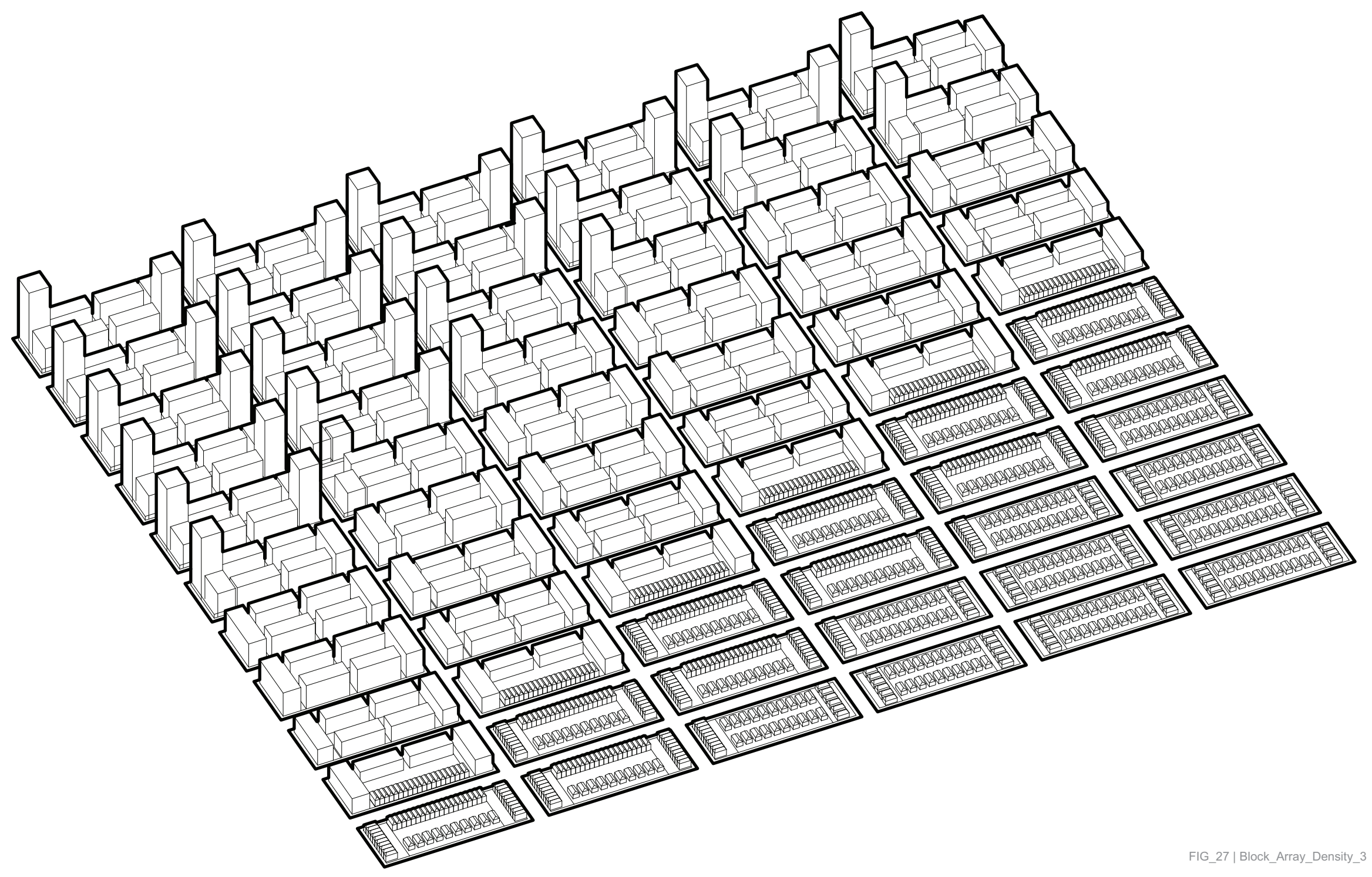


Comparing Figure 27 with ZHA's Kartal Pendik masterplan, we can begin to understand how the logic in the two approaches differs. Although aesthetically appealing in terms of pattern making, the ZHAapproach does not account for the differences in building types that normally accompany differences in use, density and height, nor is there an obvious appreciation for the integrity of blocks or streets. By contrast, this thesis privileges the relationship between density and building type - with a focus on residential fabric - along with the importance of the street in urban environments.

\section{Iteration 1: type in relation to density}

Figure 28 approaches the question of density a bit differently, starting with an assessment of the number of units that can be accomodated with several of the block typologies developed earlier (see FIG_23). Along the horizontal axis we see that the same 100-block area can accomodate: 1) 3,200 units using only single-family houses, 2) 15,000 units using only 7-story mid-rises, 3) 44,000 units using blocks that include 11-story mid-rises with point towers on opposite corners.
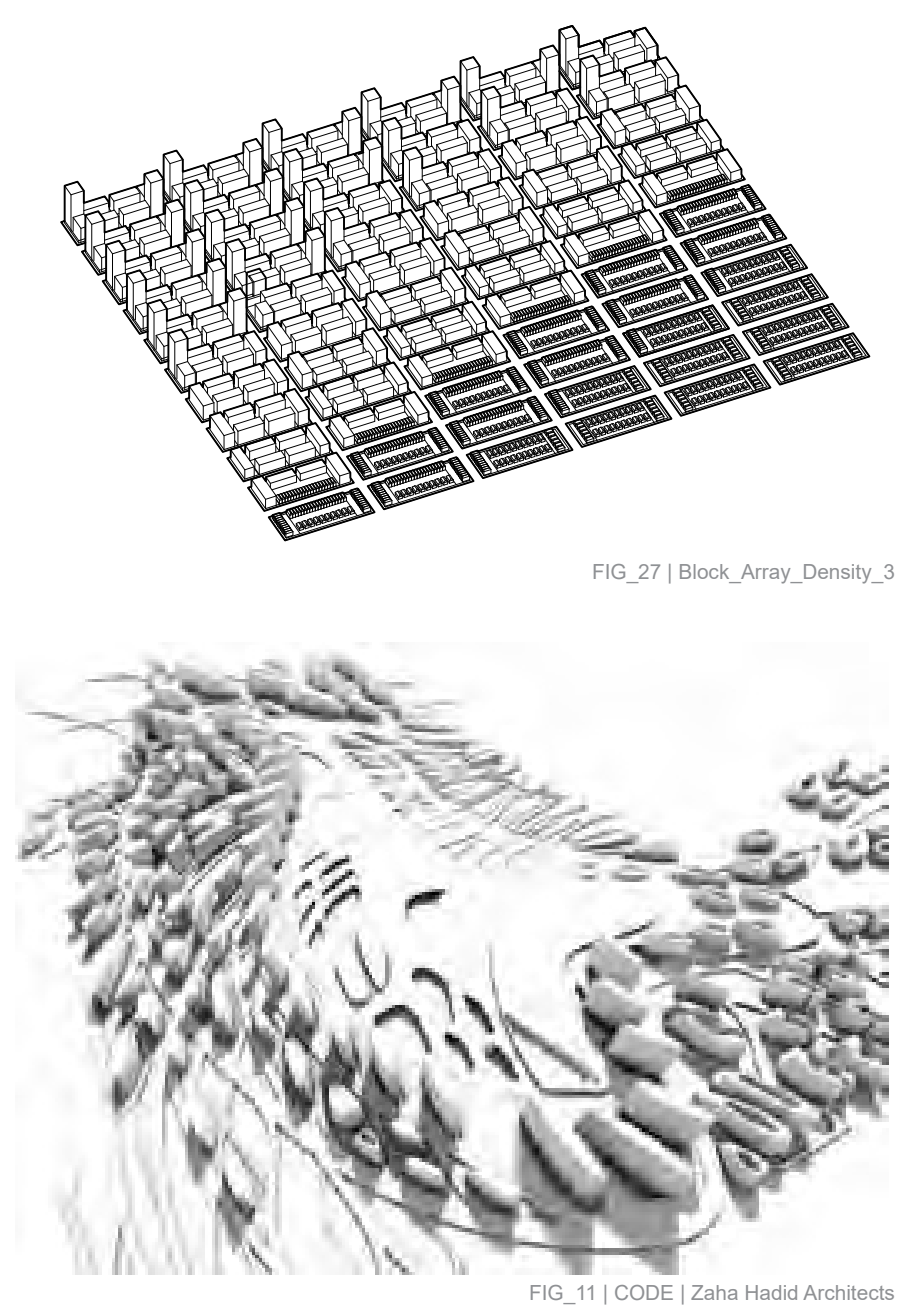


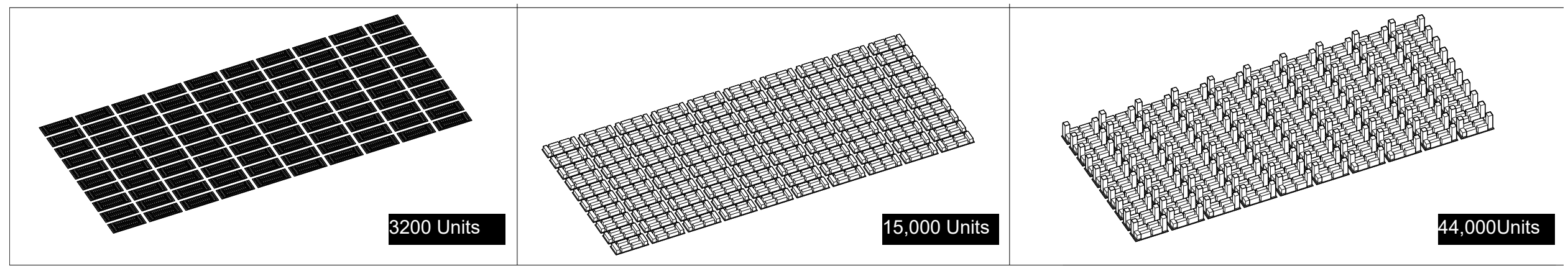




\section{Itteration 2: density in relation to type}

For the purposes of this excercise, 15,000 units - which is the number of units possible if all 100 blocks were built out with 7-story mid-rises - was used as a benchmark. It represents a medium density.

From the horizontal line, then, we can move in two directions: up and down. While the iterations above the "all 7-story mid-rise" iteration privilege open space, those below privilege freehold housing (single-family detached and row housing). Moving upward, then, the diagram demonstrates a direct relationship between the number of towers used and the amount of space that it is possible to leave open and still achieve our target of 15,000 units. Typologically we might identify this as the "central park" approach, where open space is aggregated into the center of the community and density is concentrated, in the form of towers, around the edges.

Similarly, moving downward, if more of the density is absorbed by towers, a greater proportion of our 100-block area can be given over to freehold housing while still meeting our unit target. In contrast to the "central park" approach, however, density is concentrated in the middle of the ensemble of blocks. As such, Figure 39 closely

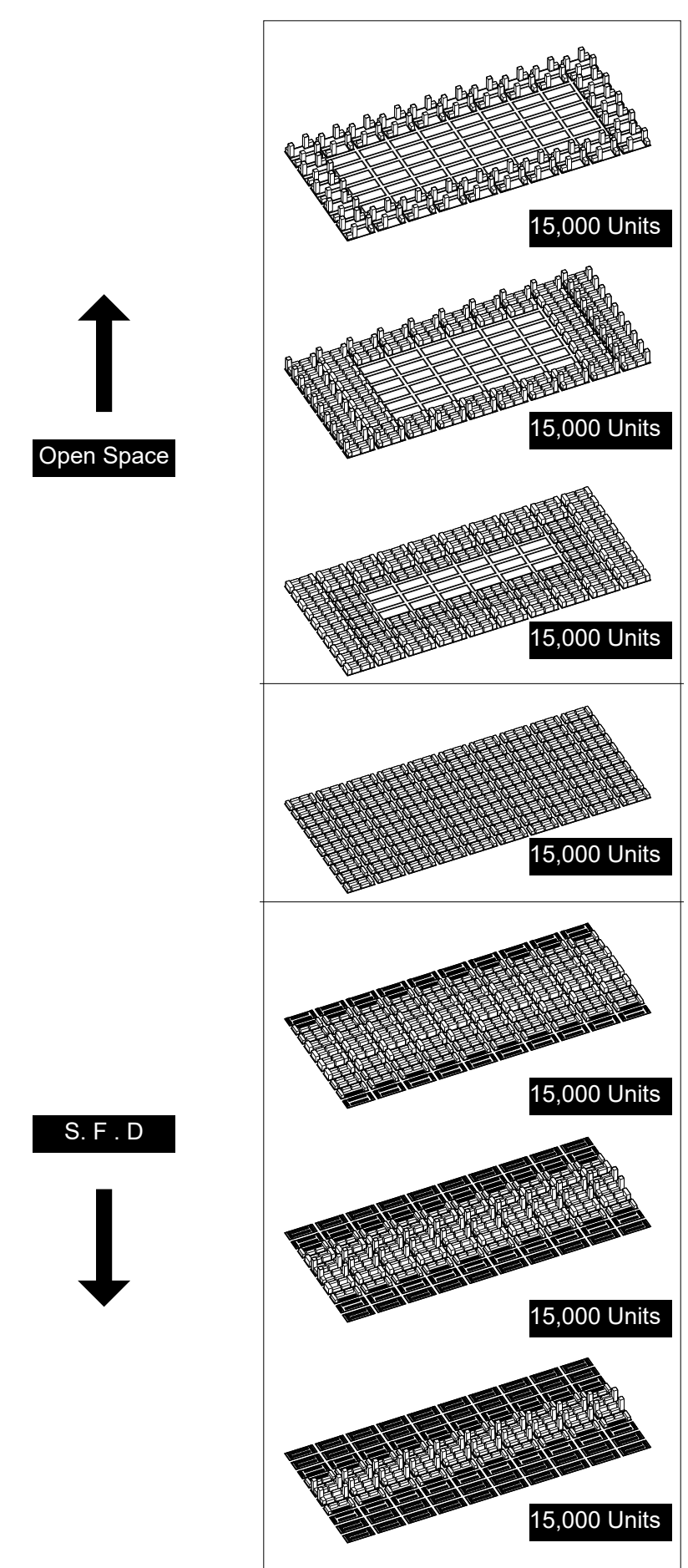


resembles the way that intensification might along an "arterial main street" through a neighborhood comprised largely of single-family houses.

Assuming a scenario where a planner and/or neighborhood association might be considering how best to achieve a medium density over a given 100-block area, these various permutations demonstrate both a range of options and the tradeoffs between height, open space, and freehold housing. In the "central park" iterations, towers are a means of freeing up open space while in the "arterial main street" iterations, towers enable lower-density housing at the edges of the neighborhood. In both cases, transitions are made between lower and higher density/higher rise buildings.

Iterations $3 \& 4$ : Assessing and addressing open space in relation to type:

Having assessed a number of permutations that meet our target density of 15,000 units, we must now confront the fact that open space and low-density housing are not entirely interchangeable. While, in absolute terms, the overall built area ratio ${ }^{2}$ may be similar in the upper ("central park") schemes and the lower ("arterial main street") variations, open space is distributed quite differently. Having

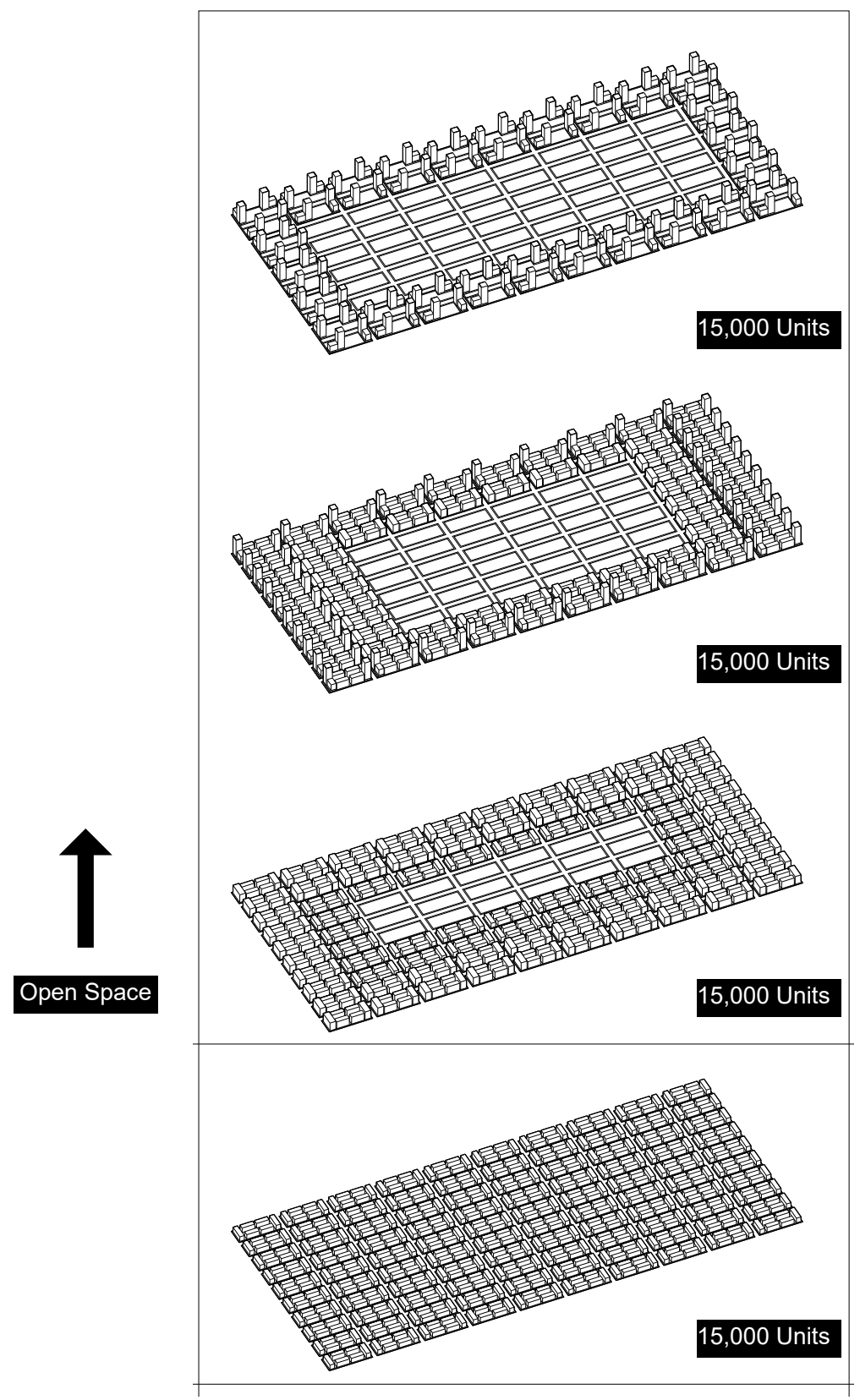

2 Defined as the amount of land covered by buildings in relation to the overall amount of land.

FIG 30 | Diagram Type 
been aggregated into large, park-like spaces at the center of the community, we can presume that open space is equally accessible to all neighborhood residents in the upper variations. This is not the case, however, with the lower variations where much of the open space is divided among private yards.

For the purposes of this exercise we have set a standard of 24 sq. m. of open space per unit ${ }^{3}$ - the assumption being that 15,000 units translates to a population of 22,000 in the "central park" schemes (where all units are flats) and to 25,000 in the "arterial main street" variations (that include a number of larger, freehold units).

Taking into account both space in the middle of blocks and the large aggregations of space at the center of the ensemble, my calculations indicated that the "central park" variations meet our open space targets. This is not the case, however, for the "arterial main street" variations (Figs. 33, 36 and 39). While residents occupying single-family and town houses in these variations are well served by open space, calculations indicate that residents in mid-rises and flats are underserved.

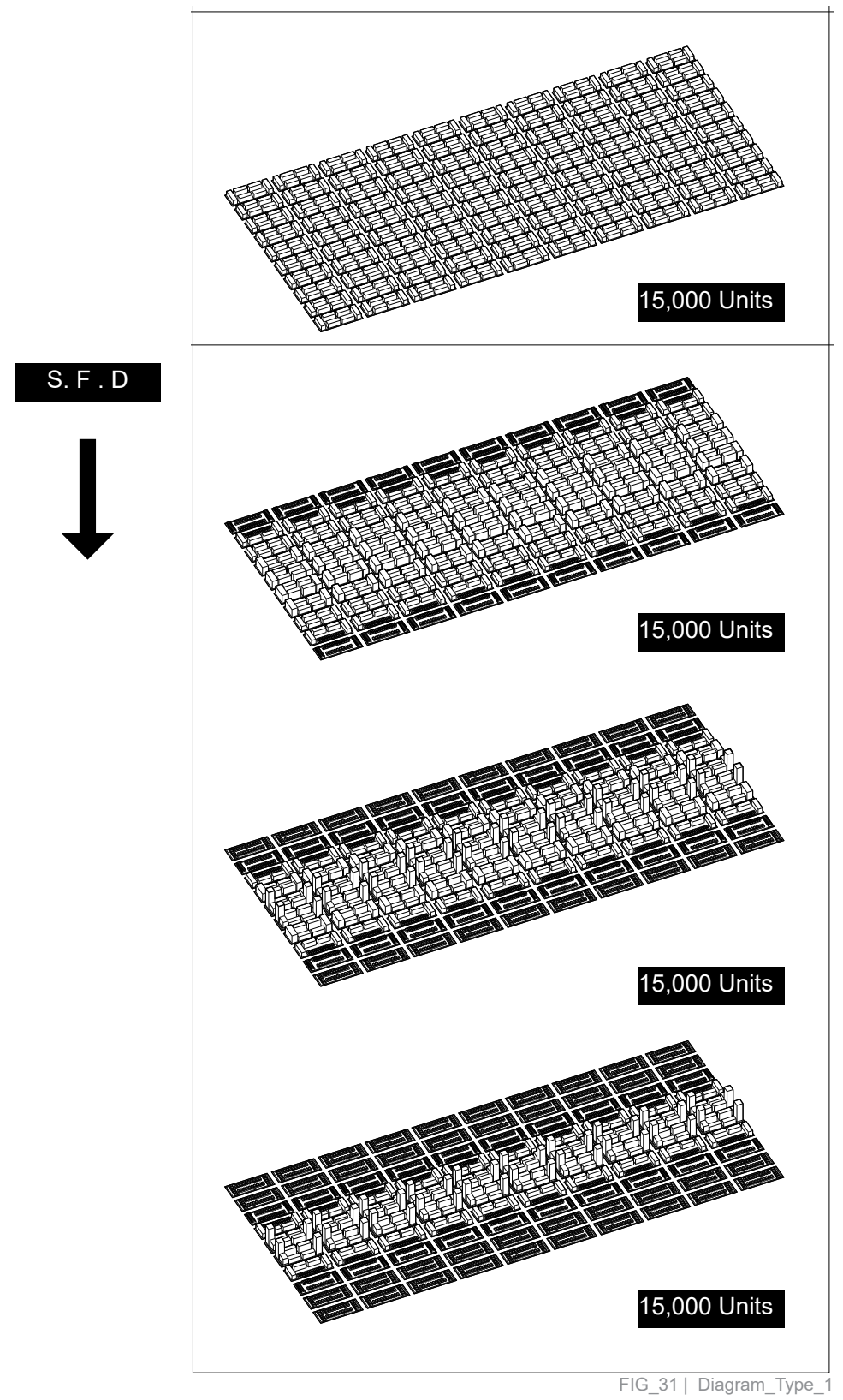

3. 24 sq. m. of open space per unit. This number was selected for the best results withing the parametric software, by no means is it a defined value, can be flexible. 
Our next series of iterations, then, involve adjusting the fabric to incorporate more open space. The process can be described as follows:

1) Iteration 3: removing fabric to open up space.

2) Iteration 4: Replacing the units lost in Iteration 3 - in order to maintain our target density of 15,000 units.

Increasing the amount of open space presents challenges inasmuch as units must be removed to do so. When considering where to remove fabric to meet our open-space targets, then, it makes sense to sacrifice lower-density housing to minimize the negative effects of unit loss. Such a strategy, however, locates open space where it is least needed, namely adjacent to low-density housing with access to private yards. To best serve the units that are lacking in open space, space should be opened up in close proximity to the high and mid-rise housing that it is meant primarily to serve. Removing high or mid-rise blocks, however, presents challenges inasmuch as more units are sacrificed in the process. 


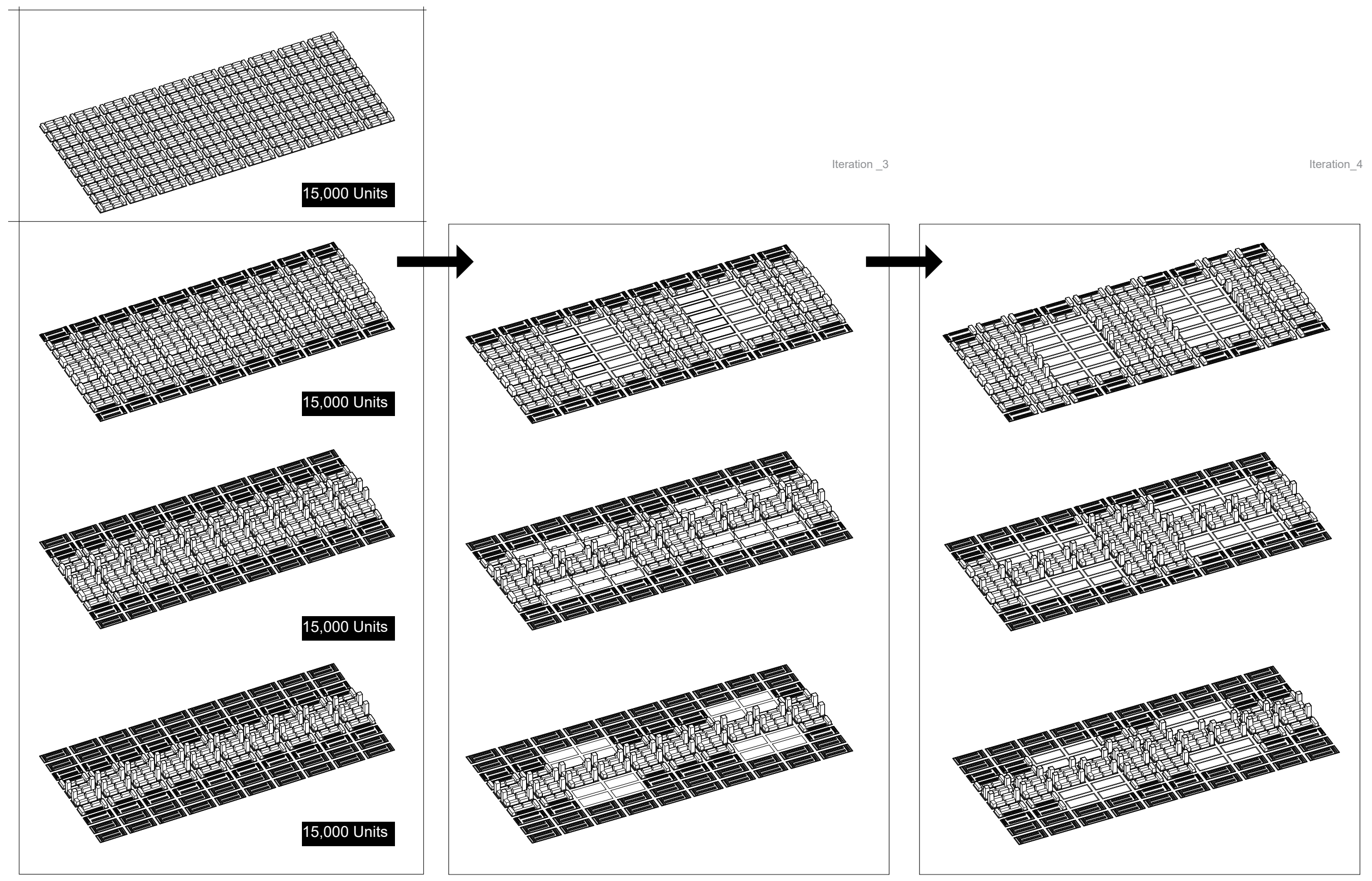

FIG 31 | Diagram_Type_1 


\section{$+\infty$
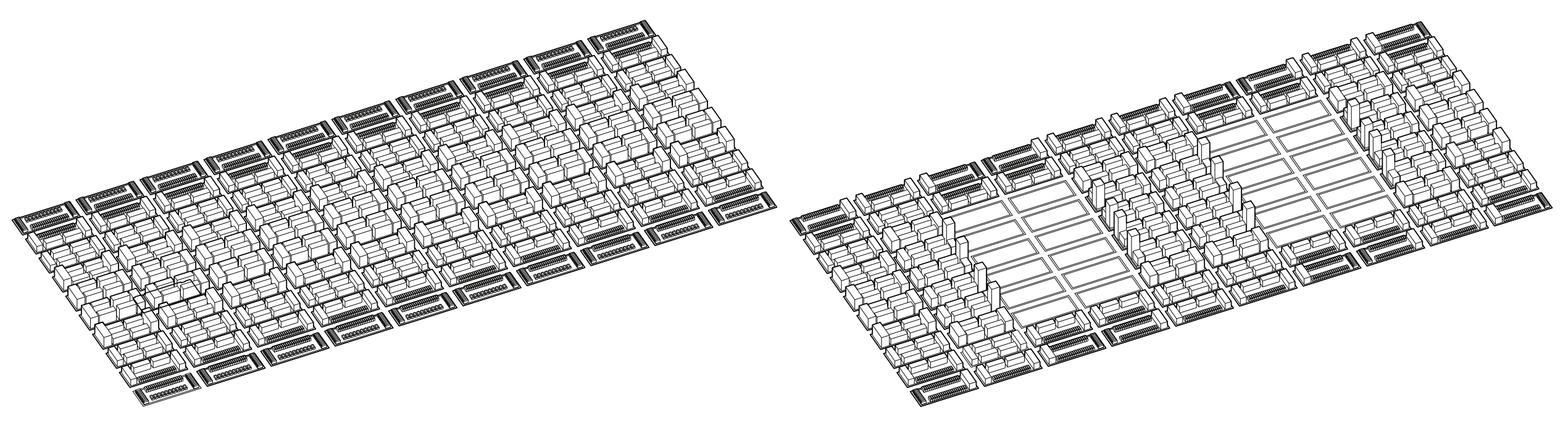

15,000 Units

FIG_35| Diagram_Type_7 

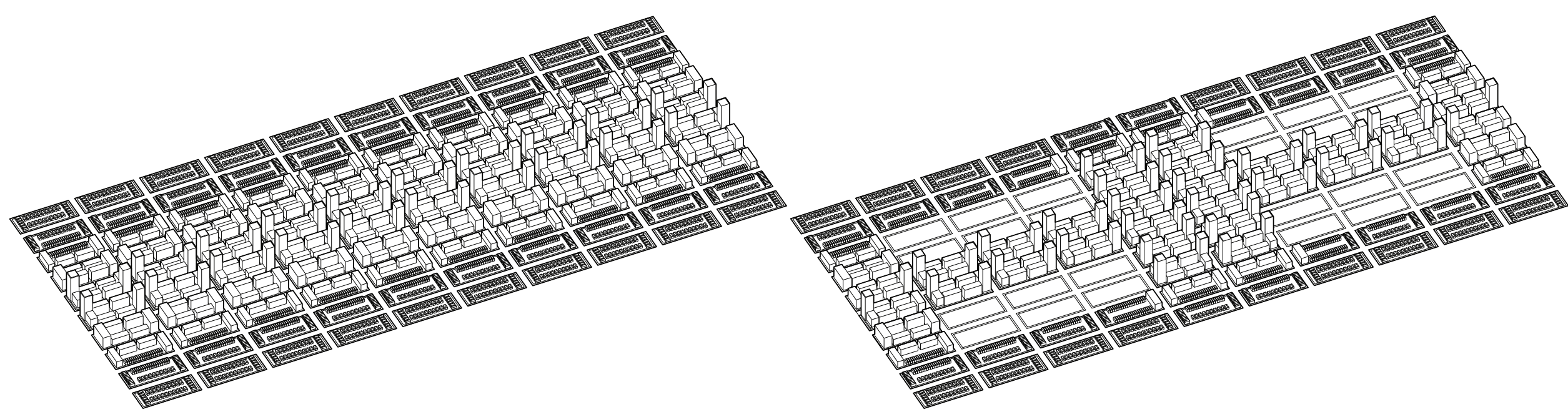

15,000 Units

FIG 38 | Diagram 


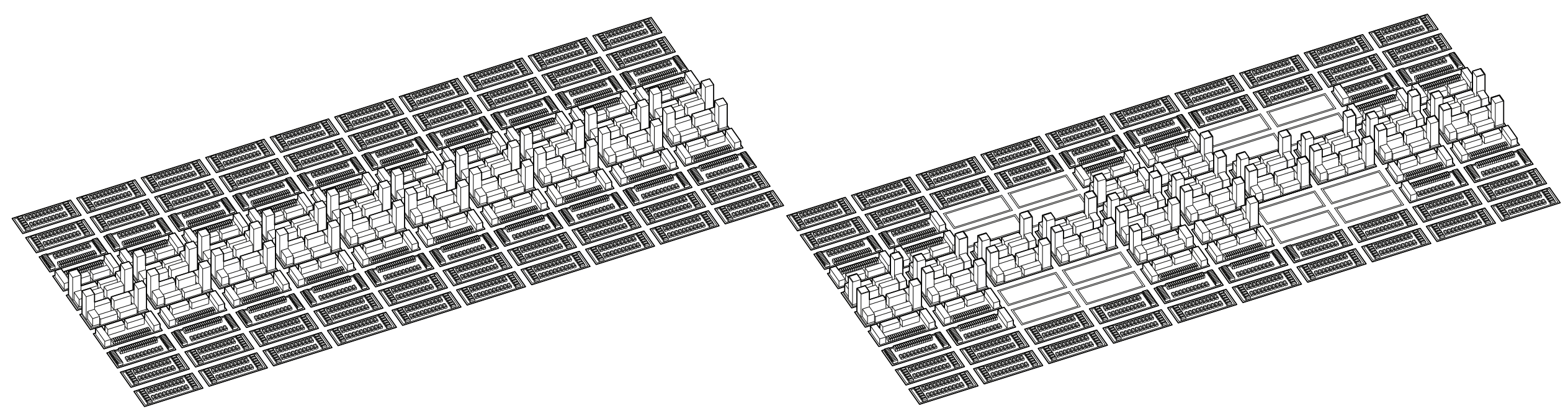

15,000 Units

FIG 41| Diagram_Type 13 
The goal of the investigation was to demonstrate how a planner or architect might deploy parametric tools in the design of a residential neighborhood.

The strategies we identified include:

1) developing block and building types,

2) establishing rules to govern transitions between types,

3) setting targets and preferences for open space and unit types (e.g., in relation to market demand, zoning bylaws, etc),

4) generating and assessing multiple permutations,

5) selecting a permutation to develop further, and

6) calculating and correcting for open space in relation to unit type.

A second goal of this investigation was to identify which parameters to use and at what point to use them (in the design and decisionmaking process). The relatively limited aspirations of this exercise are reflected in the comparatively conventional nature of the forms that were generated. Among the next steps, then, are 1) the incorporation of additional parameters (e.g., shadow casting, solar orientation, view corridors, etc.) and 2) applying these strategies to a real site. We will be attempting both of these in the following chapter. 


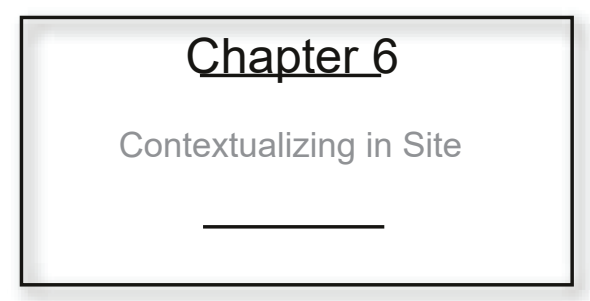

This thesis is not about appropriating a specific design to a particular site, nor presenting a different and better community design plan for a certain area. Rather, this thesis aims to develop a systematic strategy for digitally (parametrically) planned urbanism. It is about a parametrical process, and the stemming scenarios are based on logics to aim for maximizing density i.e. showcasing the logics that the parametrical tools should be doing. Whether a digital process or not, any project is in need of context and such investigations cannot be left without a site to digitally use as reference. Unlike the previous examples, the algorithm should find an appropriation for densifying the existing city and not aim to create new and arbitrary lands. Therefore for the purpose of a site appropriation exercise in order to test the parametrical logic in a real world scenario, the 
algorithm will be tested on the Rockcliffe site in Ottawa, Ontario.

The 134-hectare site is a former Canadian Forces Base in Rockcliffe located in the eastern part of Ottawa that has been underused for decades. The City of Ottawa has joined ventures with Canada Lands Company in 2011 to develop the lands. All existing buildings and houses have since been town down and all that remains are empty roads.
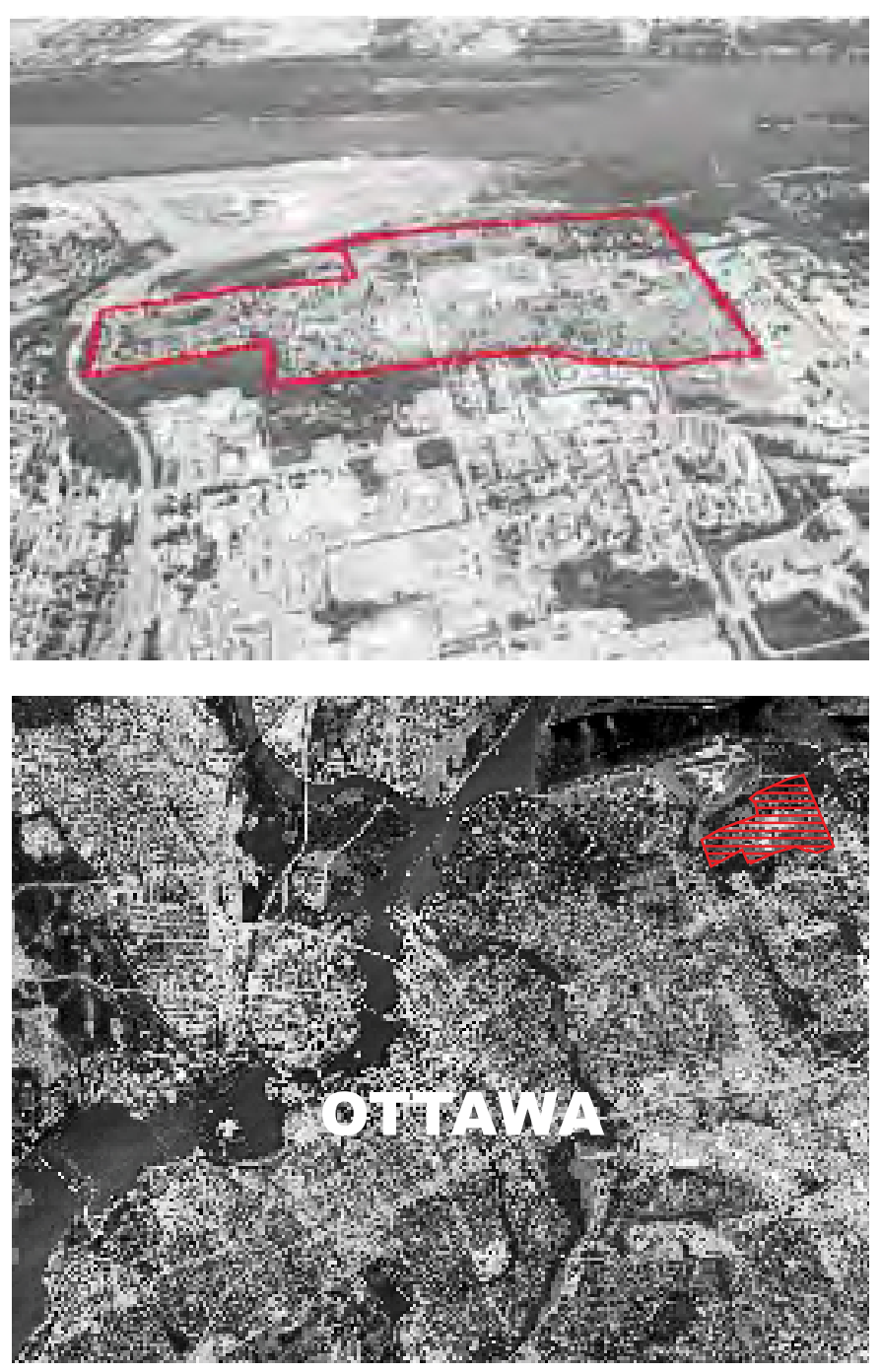


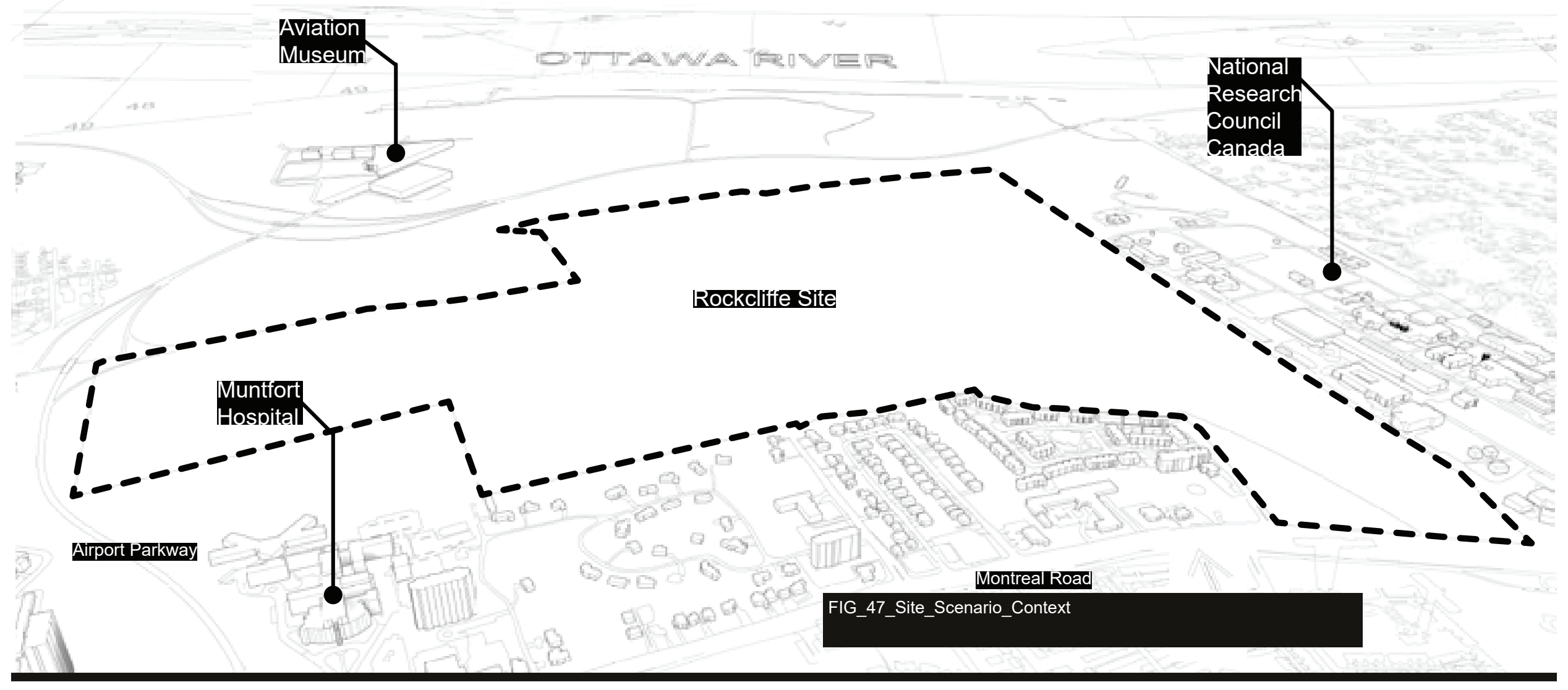




\section{Parametric Urbanism with a Site - The Strategy}

1) Road placement - logic of street layout.

The obvious first step in a digital sense is to simply begin arraying the typology blocks across the site to fit within its boundaries. On the contrary, the process needs multiple layers of process before the algorithm can even begin to be appropriated. The initial step in this strategy is establishing the main arterial streets that would connect Airport Parkway in the west end of the site, and Montreal

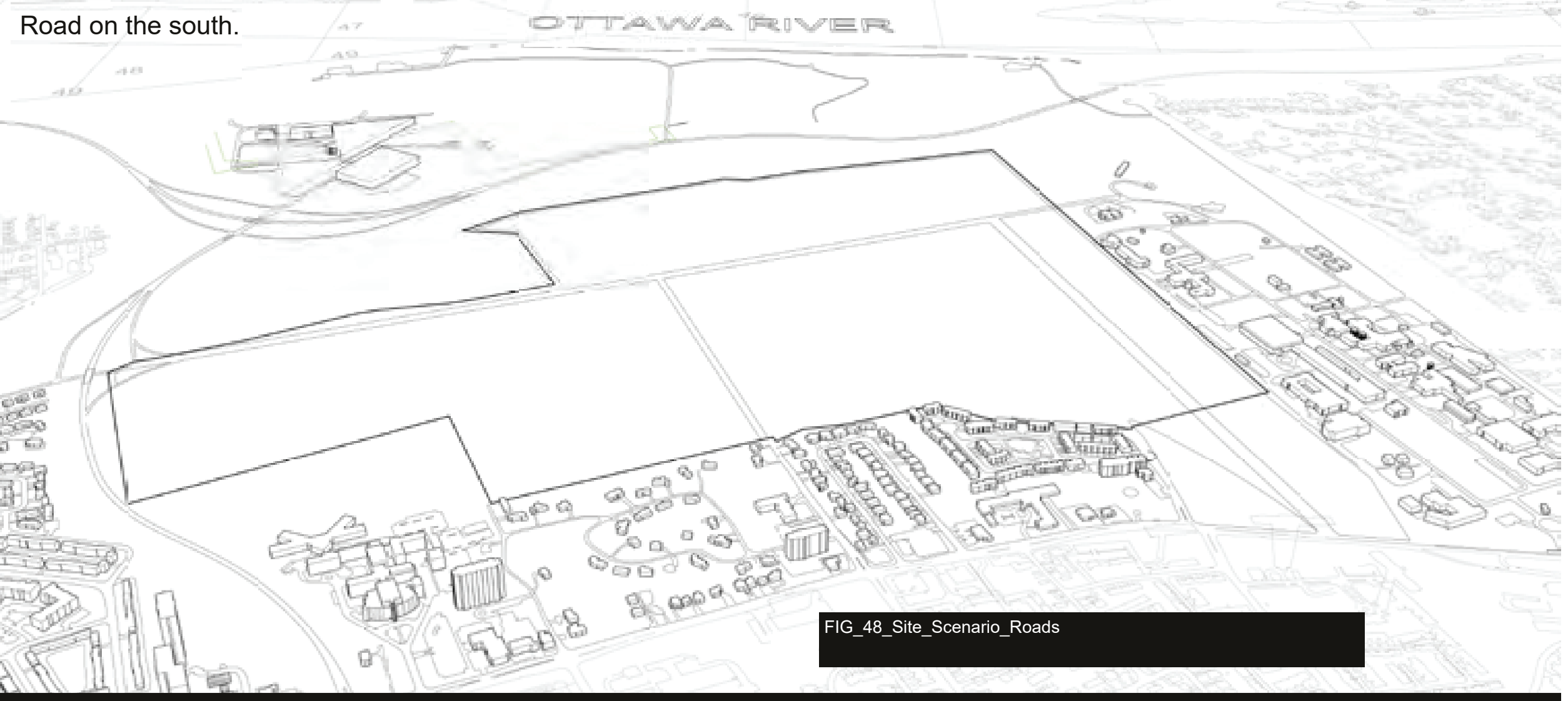




\section{2) Commercial District placement}

The site borders on the National Research council lands, therefore the inclination is to put a commercial and business district along the east perimeter of the site, acting as a buffer between the industrial area on the east and the residential area to the west. Because commercial buildings do not necessarily associate with a certain building typology due to the varying programs (i.e. a two storey Walmart has a different gross squarearea than a typical r office building) the commercial district is represented in different scales to showcase a certain example of how the commercial infrastructure could work, however, this is not the focus of this thesis therefore the commercial infrastructure is left merely as a method of representing infrastructure. This could be altered if the commercial programs where known, and a separate parametrical

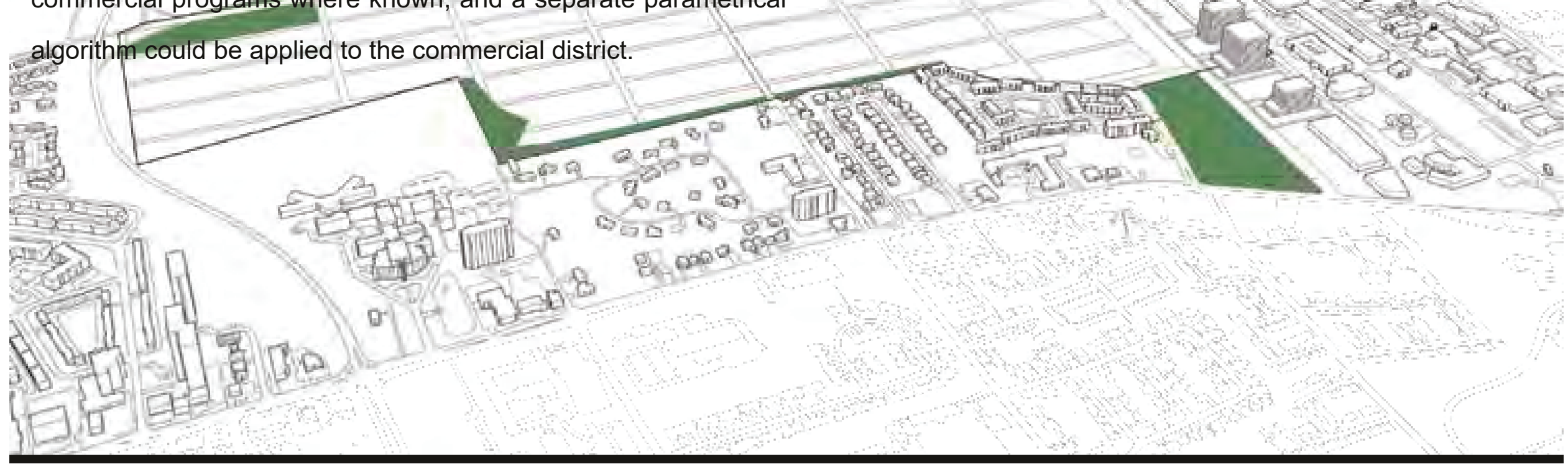




\section{3) Establishing boundaries within the site that should not}

\section{be developed}

The Rockcliffe site has a series of old and rare trees that have value to the local community, therefore these areas are left out of

the algorithm and set up as boundaries to not be interfered with.

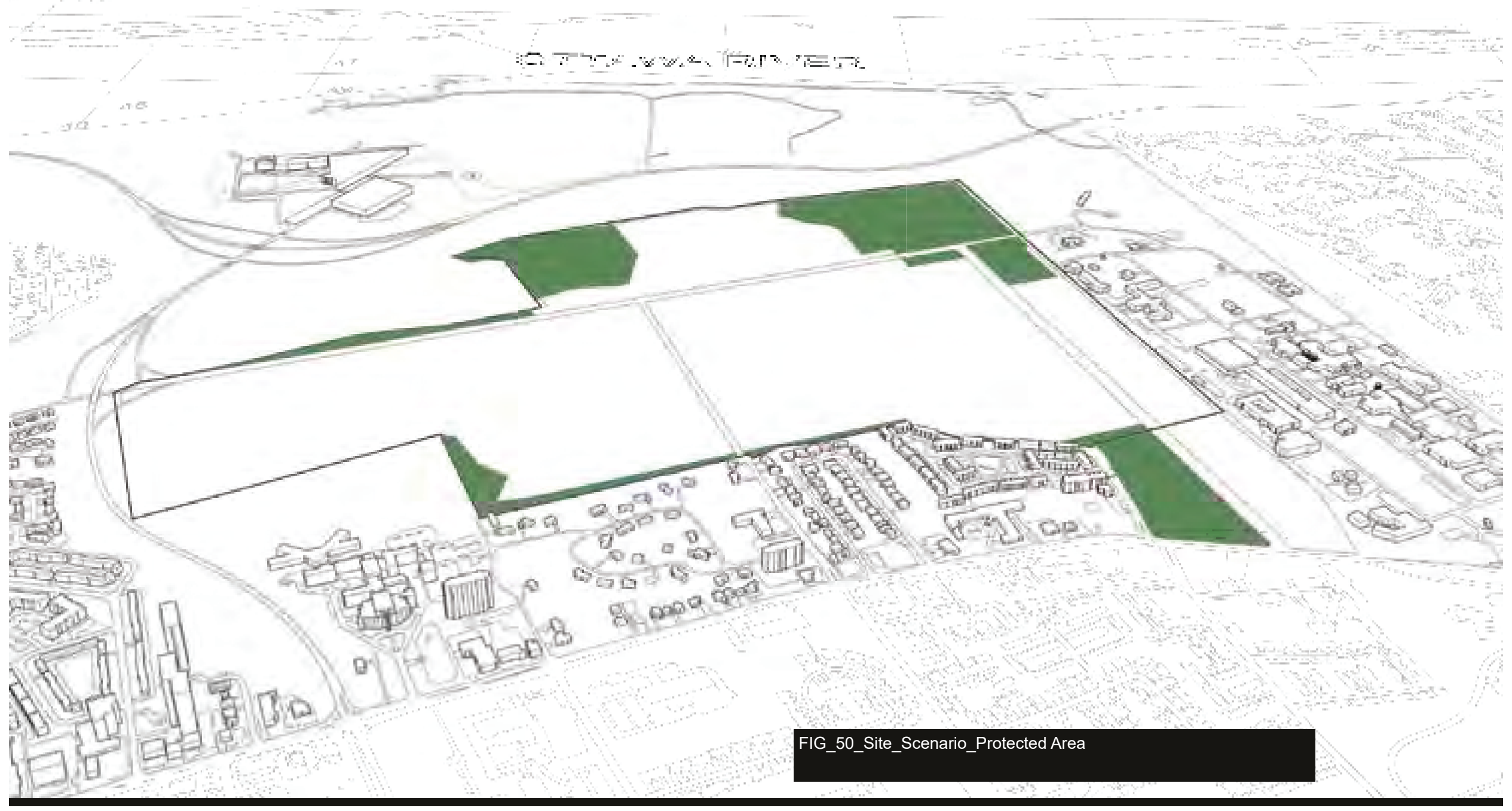




\section{4) Parametrical Block arrangement}

Once the main arterial roads and boundaries within the site have been established, the algorithm can then array the typical city block within the boundaries. Where the blocks intersect with the main streets, that's where the blocks become cut and divided, therefore the blocks become transitional.

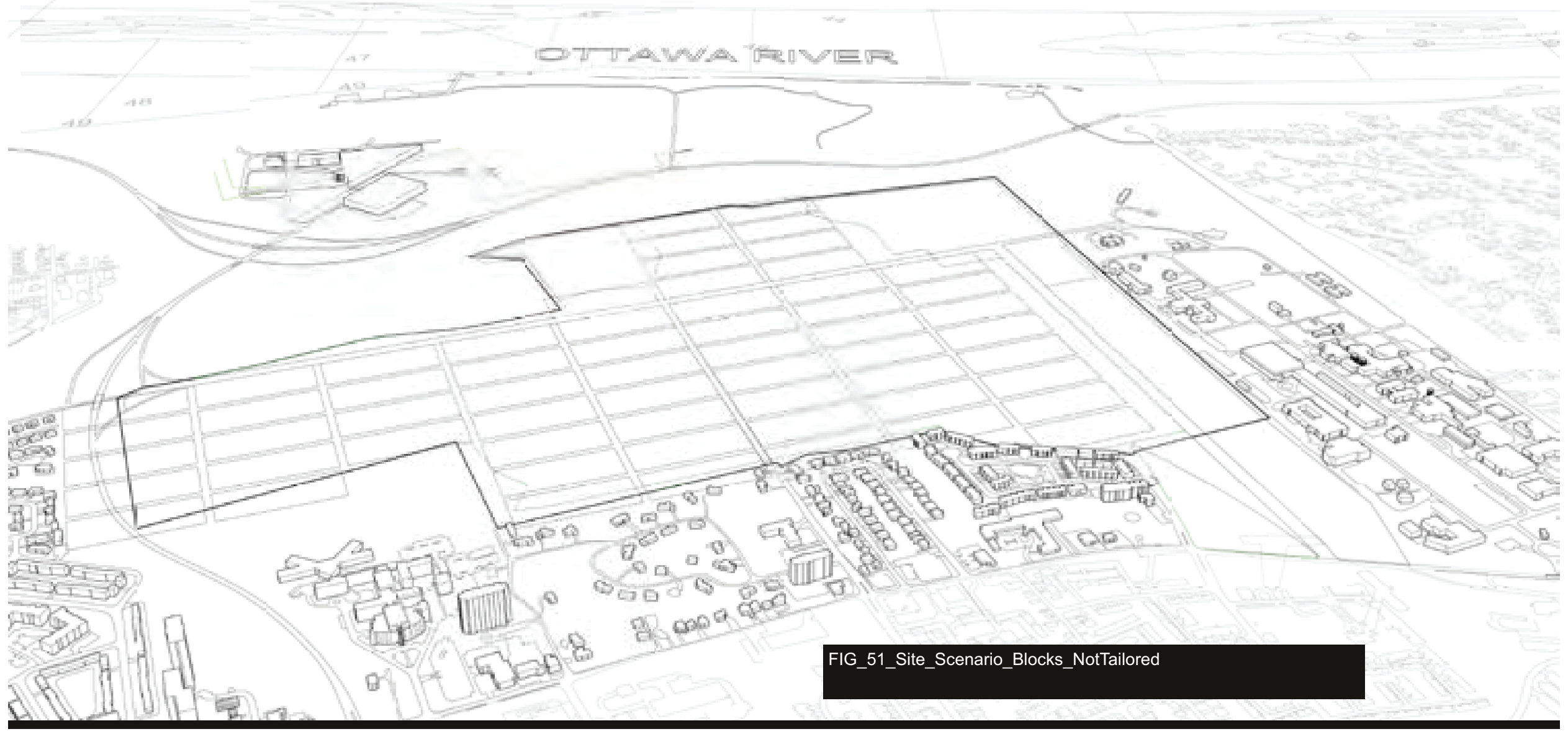




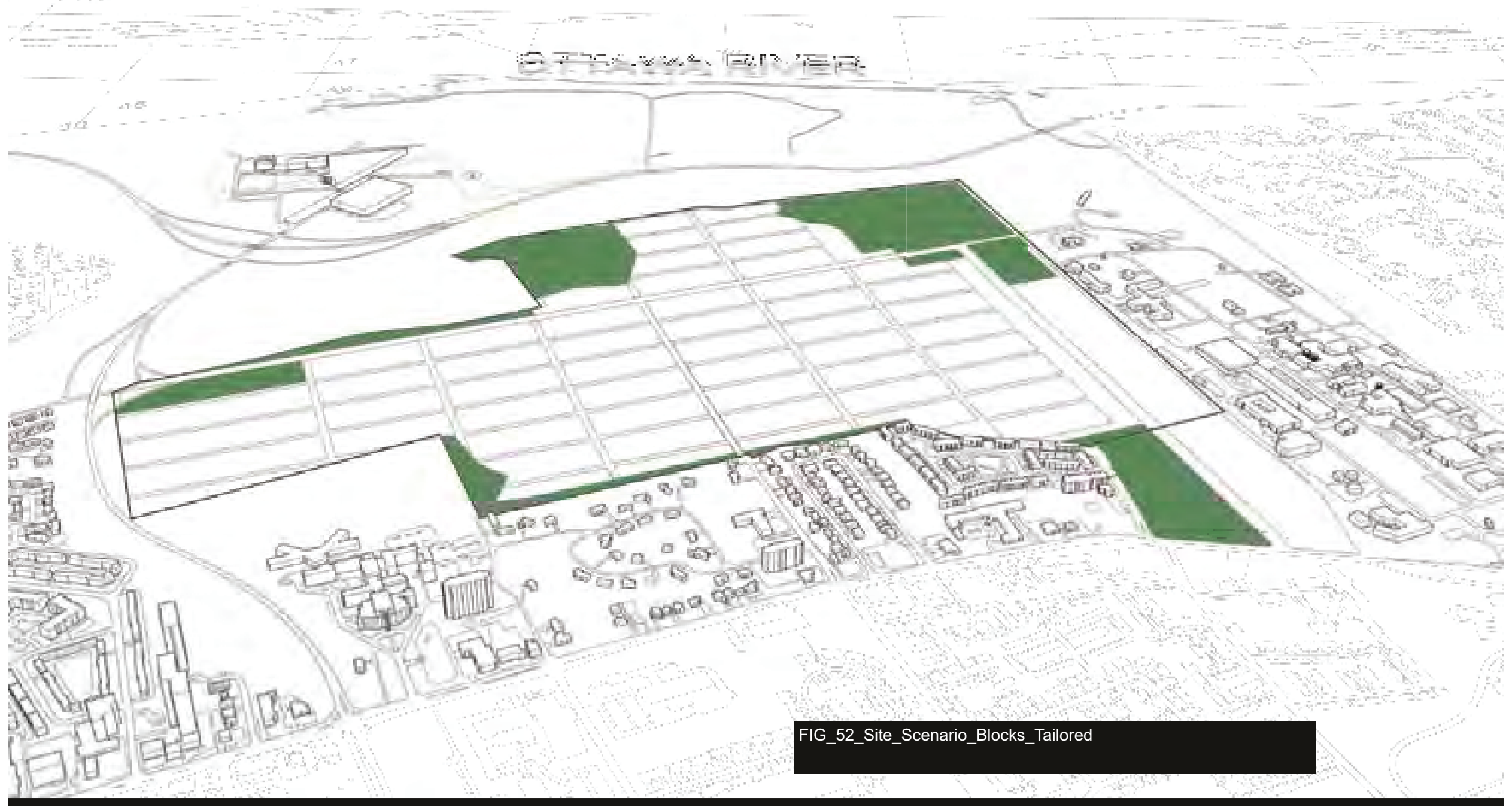




\section{5) Typology Placement/Arrangement}

Once the grid is placed, this gives the ability to start arraying the varying typologies across the blocks. In one scenario, the highest typology types can be placed along the arterial streets such as in the previous non-site specific scenarios. From those streets, the density can therefore start to decrease towards the peripheral edges of the site.

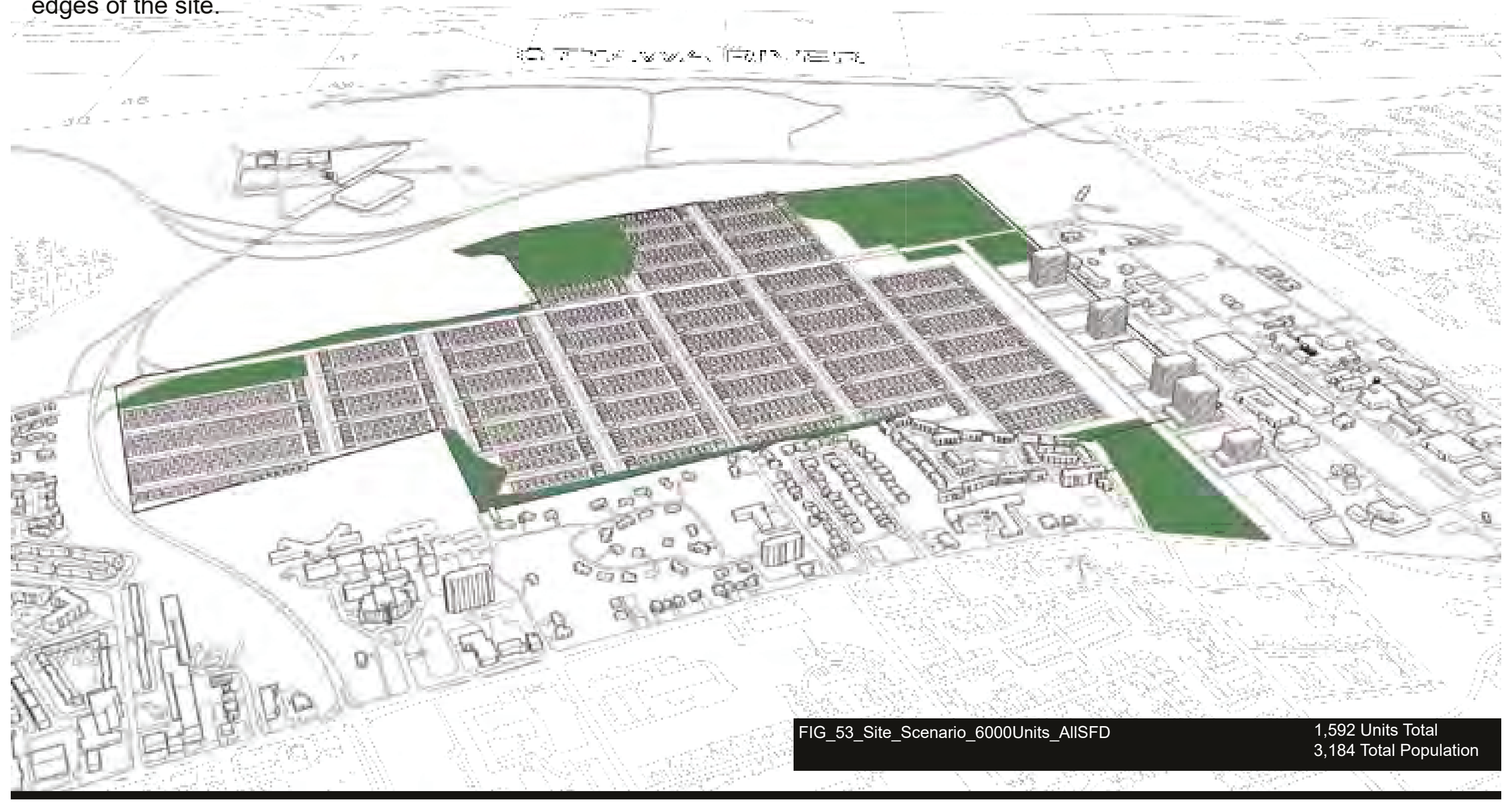




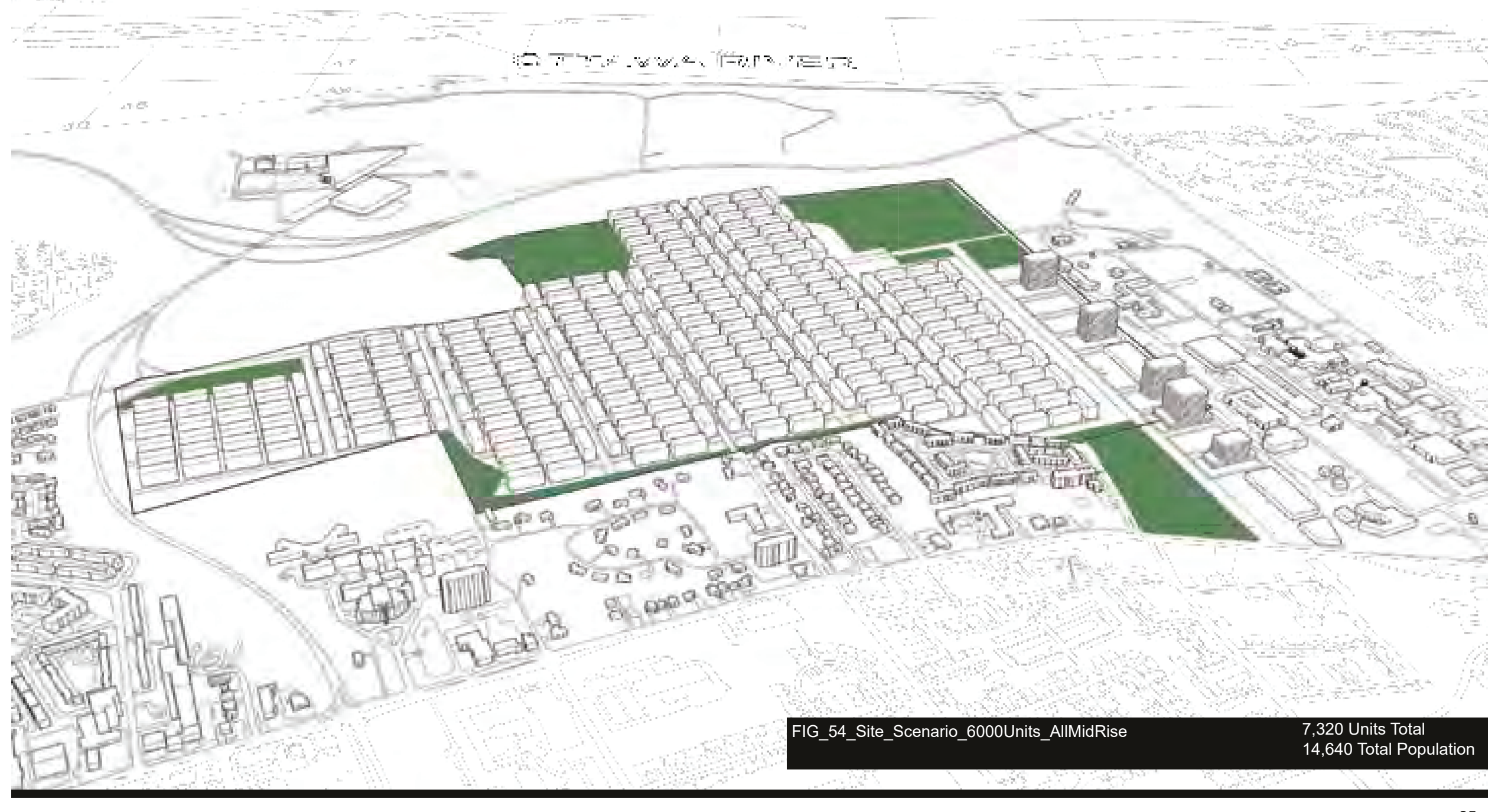




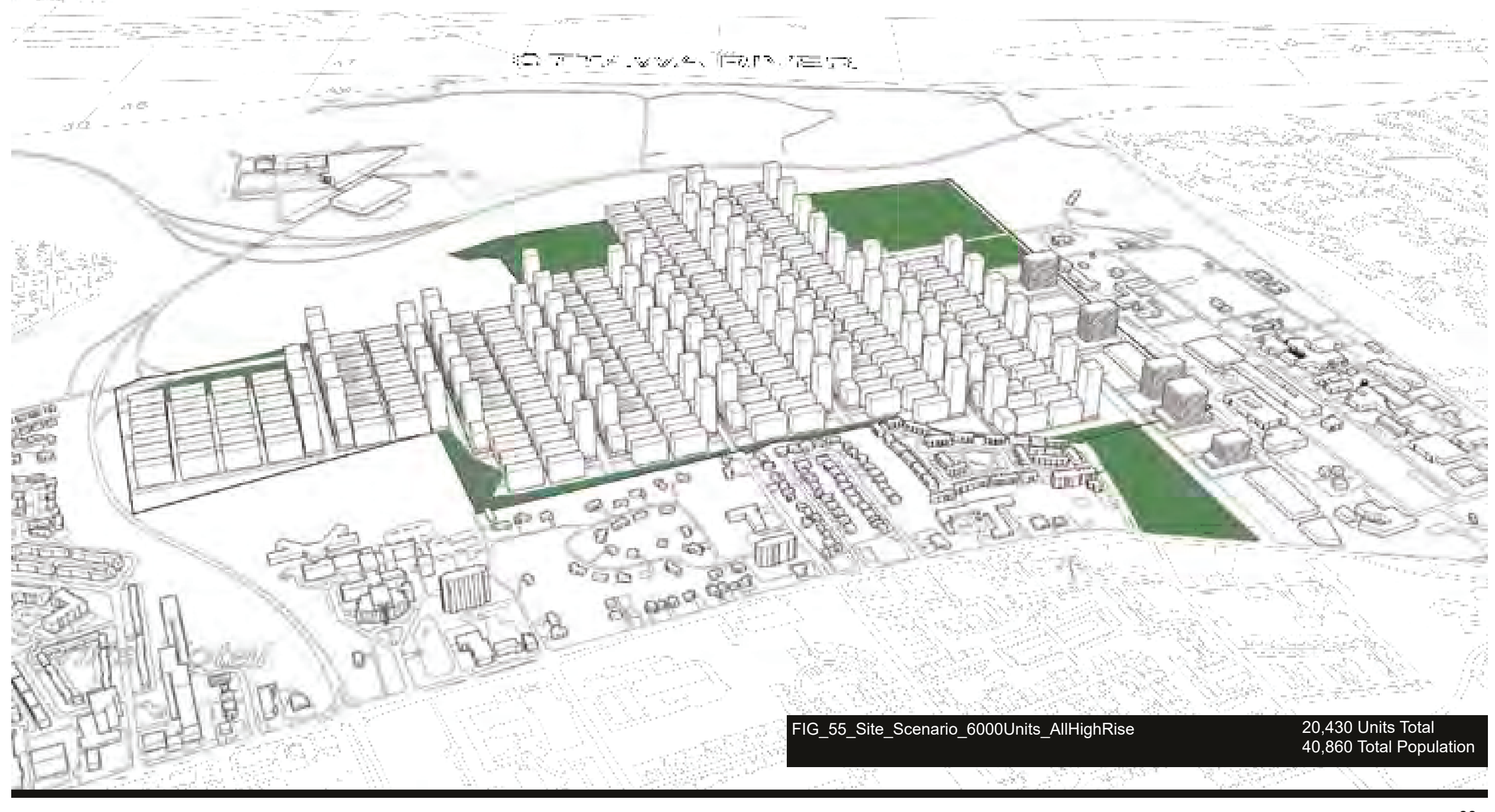




\section{6) Open space/ Green Space placement - finding the}

\section{existing hydraulic marsh}

The site dictates the open/green space conditions (again, not a site or landscape design proposal). This could be done in more than a variety of ways, however for the purpose of these scenarios' the open space is created by analyzing the sites topography, and through that finding the hydraulic marsh which gives a starting basis for where the open space should go.

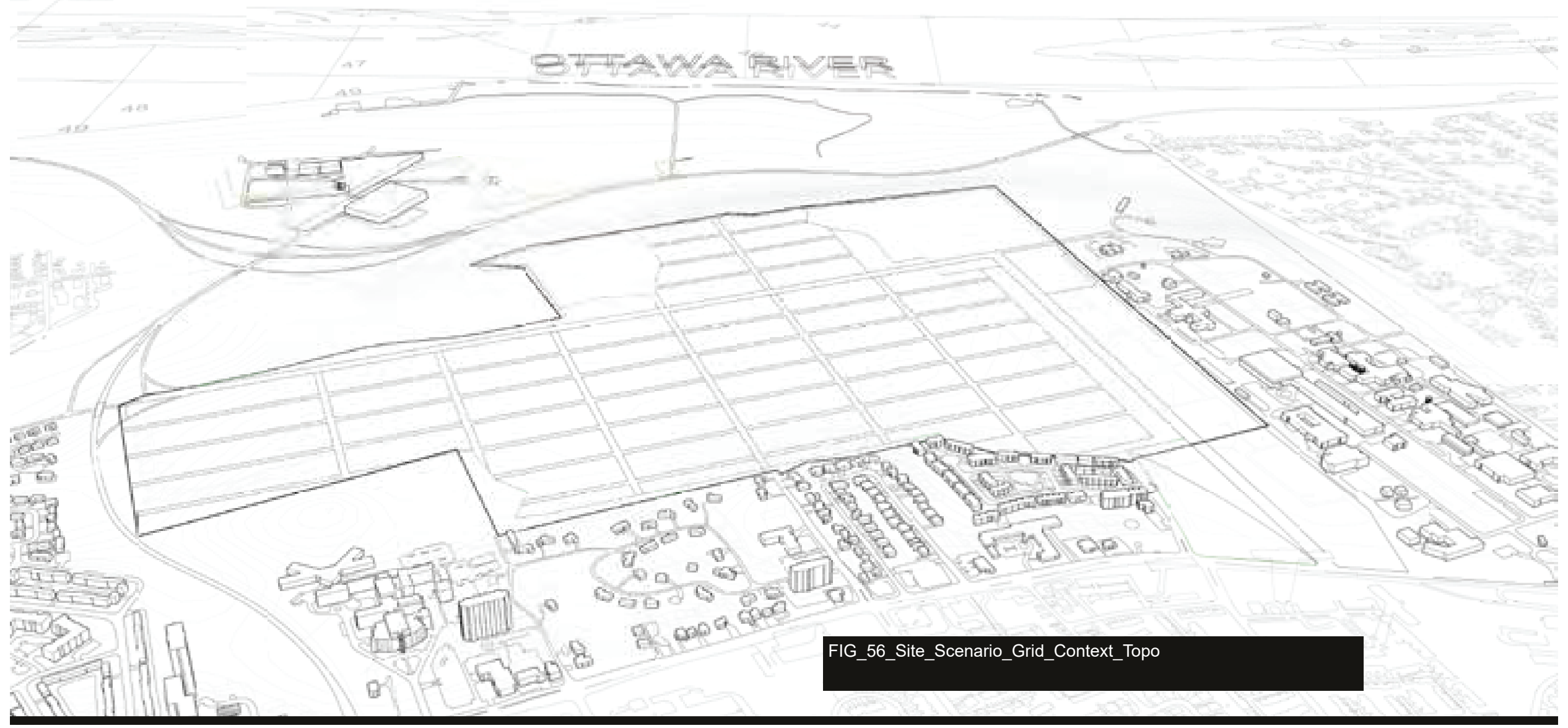




\section{Open space/ Green Space placement - finding the}

\section{existing hydraulic marsh}

Based upon the void that the open space creates, the higher density typology is arrayed around the borders of the open space.

In a secondary scenario, the the typology arrangement could be reversed, where a lower typology could be placed closer to the open space boundaries. However, the assessment must be made if this still meets the required density. Once the open/ green space r. is established, institutions such as schools, police stations, etc.

can begin to appropriate. Once the fabric becomes discontinuous, anomalies can happen. In this case, the designers' sensibility comes in, and appropriates the correct formulation to what should

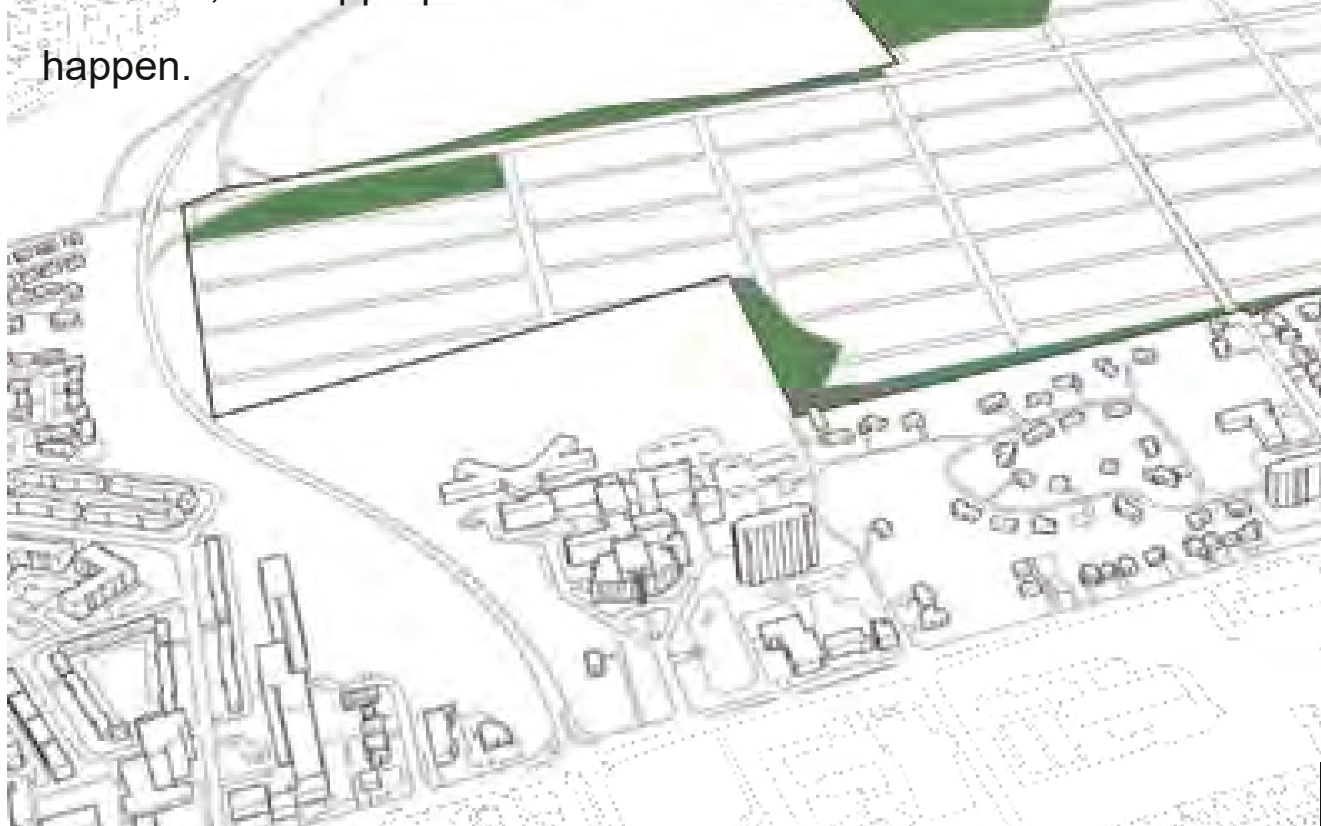




\section{7) Typology Arrangement - Reiterated}

From the previous result, there are variations of the typology arrangement based on the desired typology and the aim to densify to 6,000 units, the replaced density is placed back into the site through denser typologies on the established blocks that have been set to be developed. Moving forward, all that is left is to parametrically dictate the typological arrangement based on the desired overall density of the specific area.

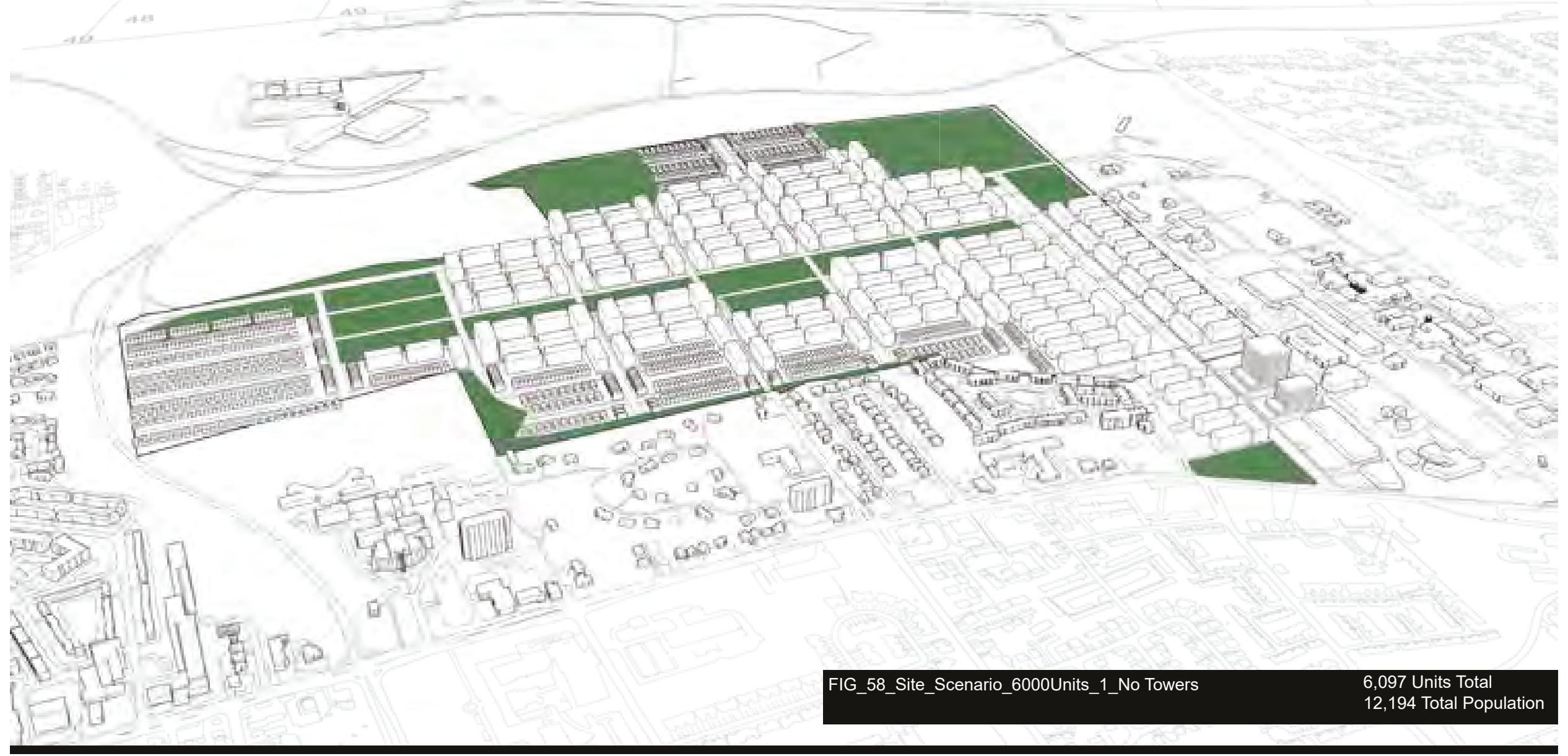


The current Rockcliffe community design plan proposes a site with no high-rise typologies. This scenario images a study where towers are present in the scheme, located on the north arterial street. The remainder of the types don't change, however the density is increased by 1,482 units/2,964 people.

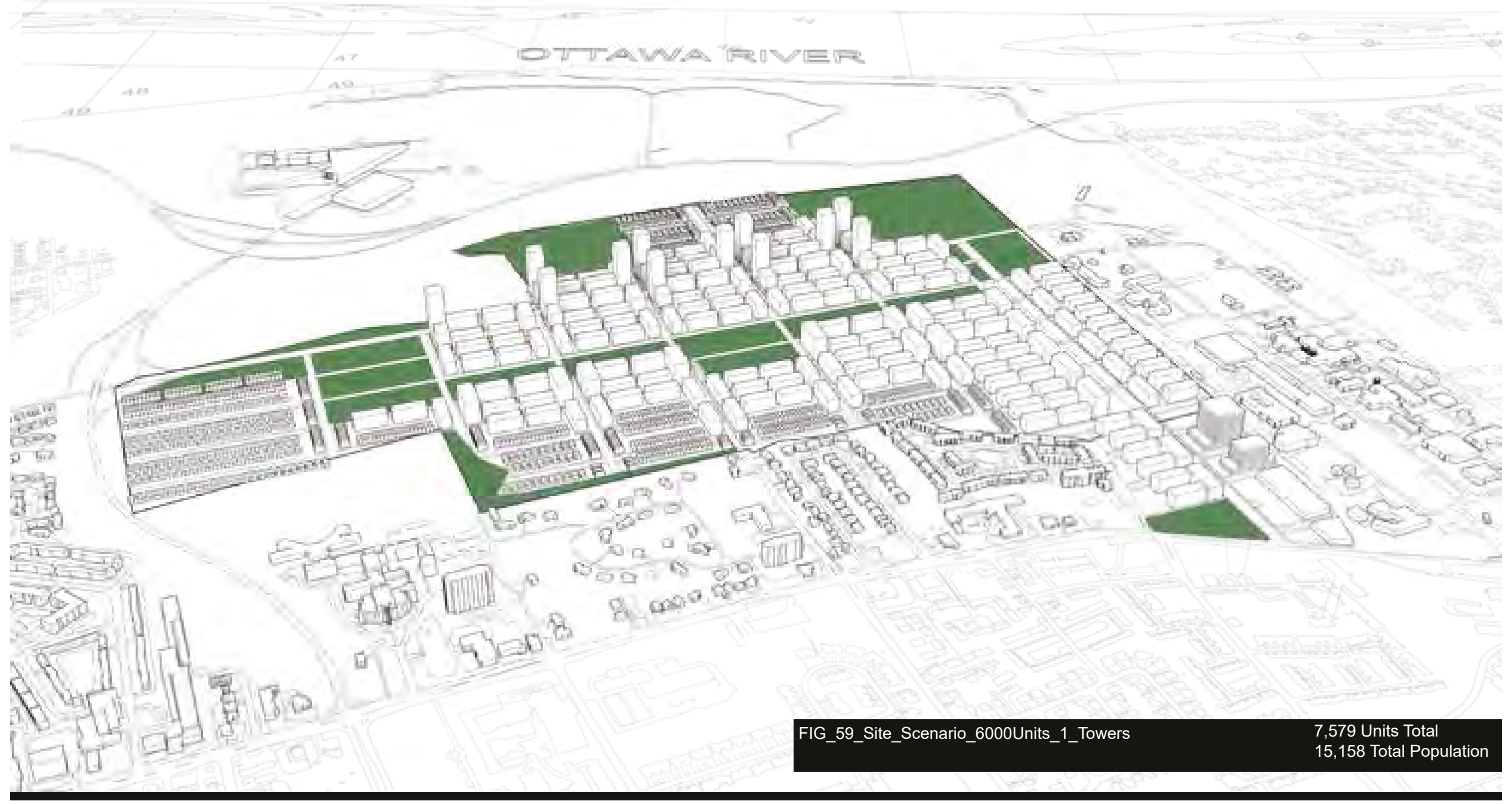


In order to keep the density close to 6,000 Units, and keeping

the previously established towers, the algorithm then allows for a significant increase in lower residential typologies such as single family homes and row houses.

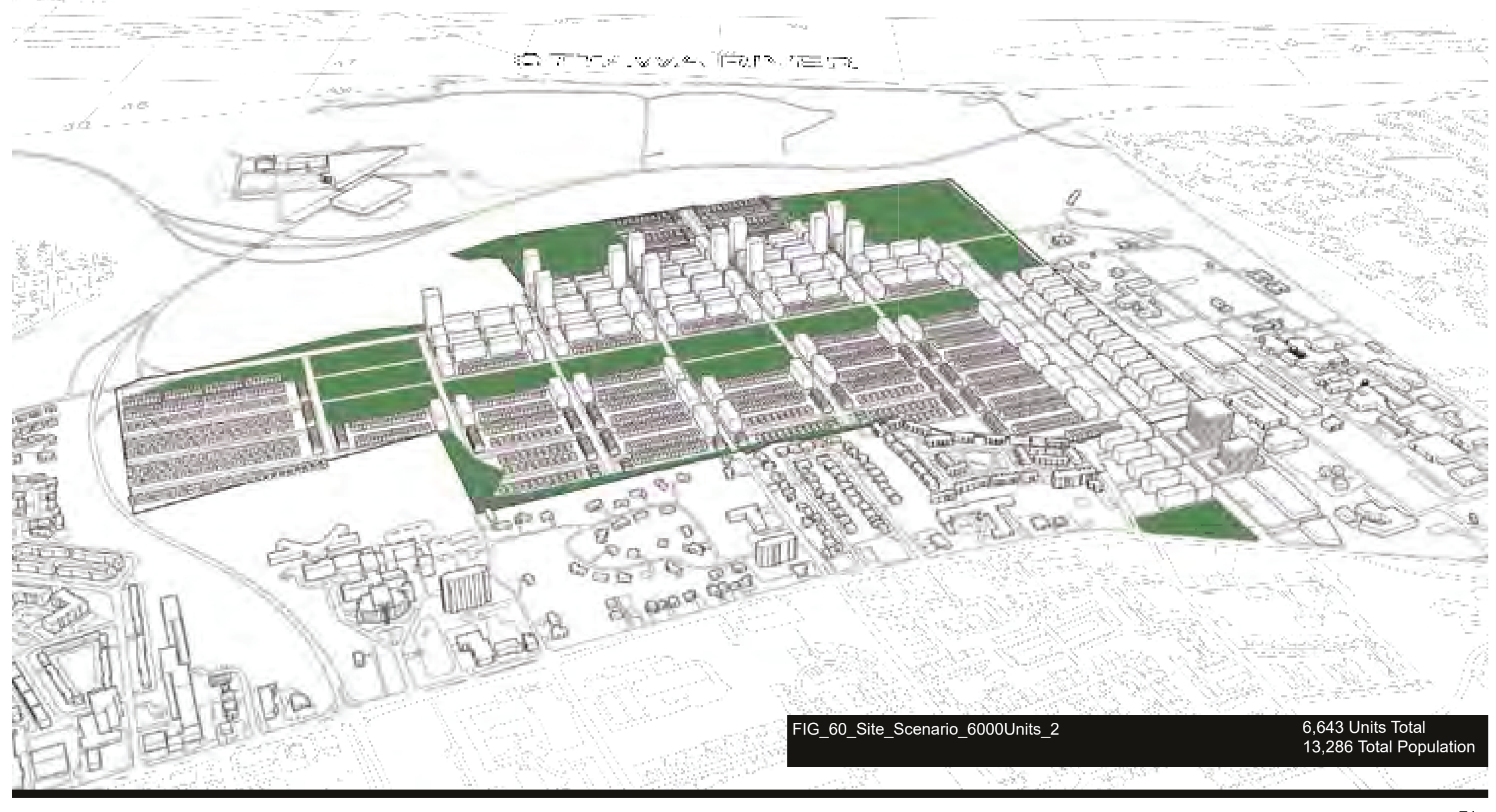


If the desire is to have more single family houses, then the algorithm responds accordingly, however this significantly falls short of the desired density target.....

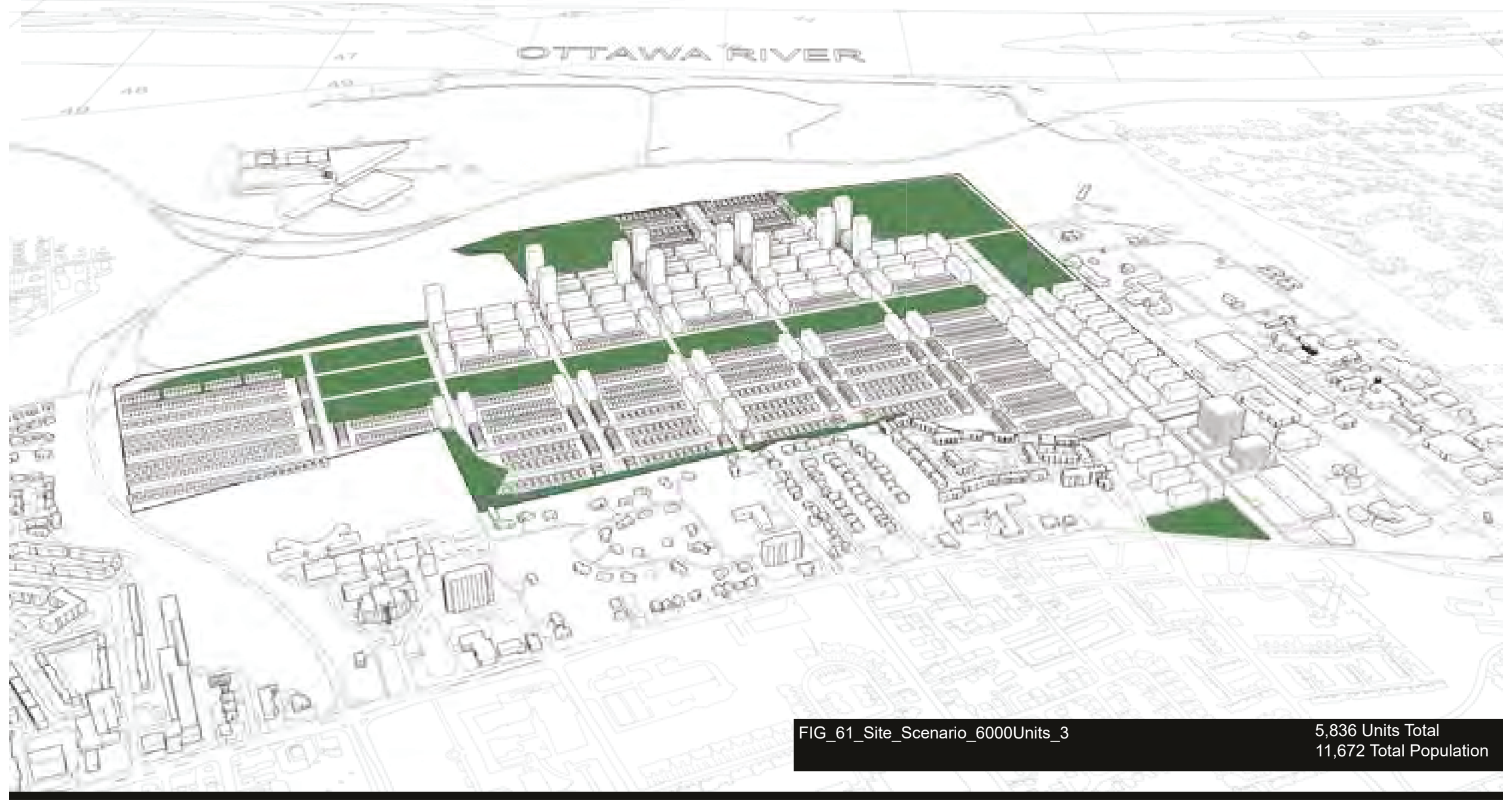


.....therefore in the next strategy the assumption is to leave the houses the way they are planned, but the eastern portion of the development allows for the placement of 5 high-rise types which brings back the density to the desired target.

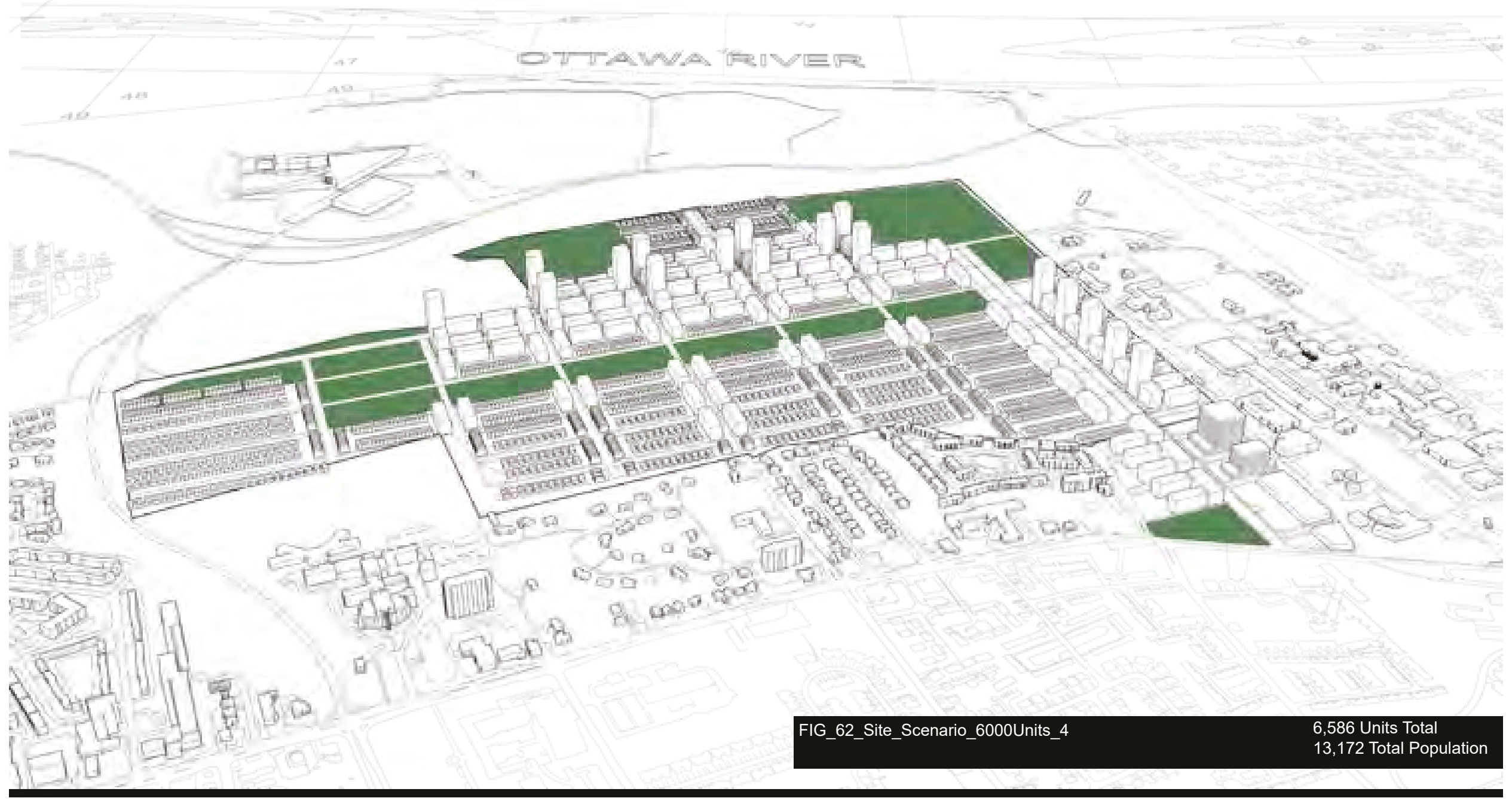




\section{8) Typology Arrangement - Reiterated/Increase Density}

In the eventuality that the development needs to increase the density

to 11,000 units, the algorithm is prepared to respond accordingly.

However, this may present an issue to a potential community due

to the amount of high rise typologies.

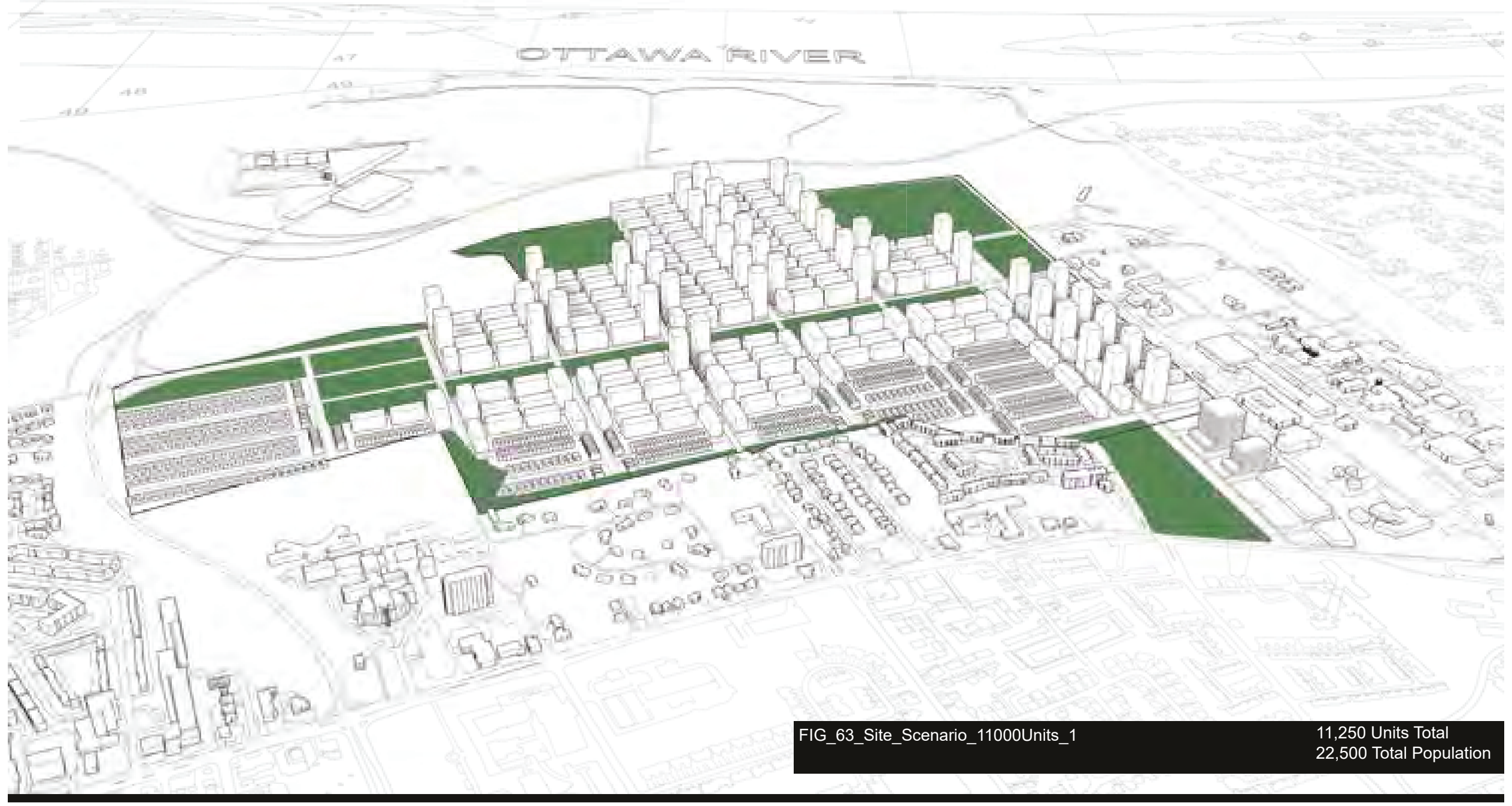


If the desire is to eliminate some tower typologies, then the algorithm responds. In this case, the elimination of a few towers can increase the desired amount in the lower residential types while still meeting the desired density target.

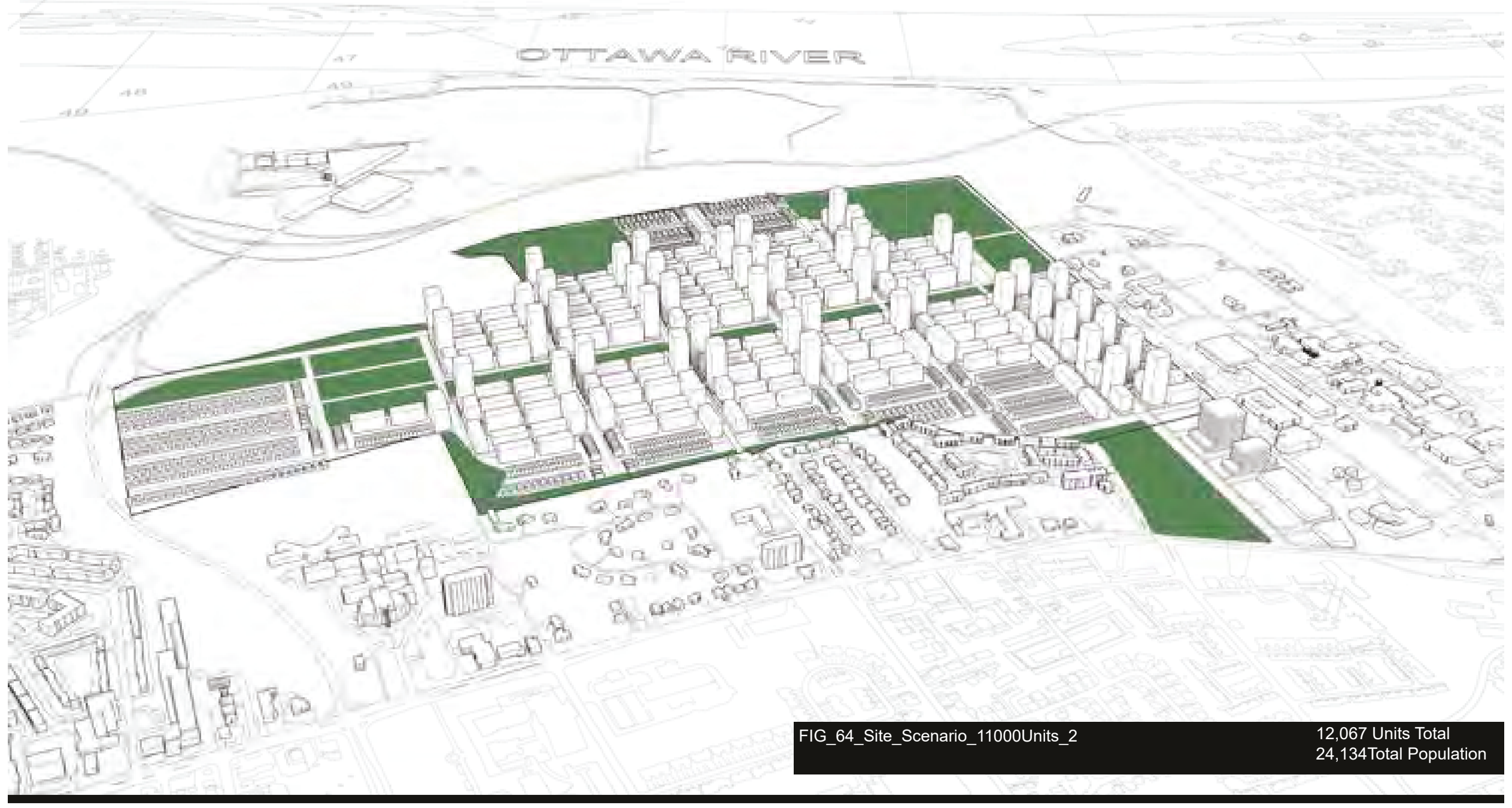


If the tower typologies continue to be removed, there are not enough lots to accommodate lower residential typologies to meet the targeted density. Therefore, the compromise is to develop more mid-rise typologies.

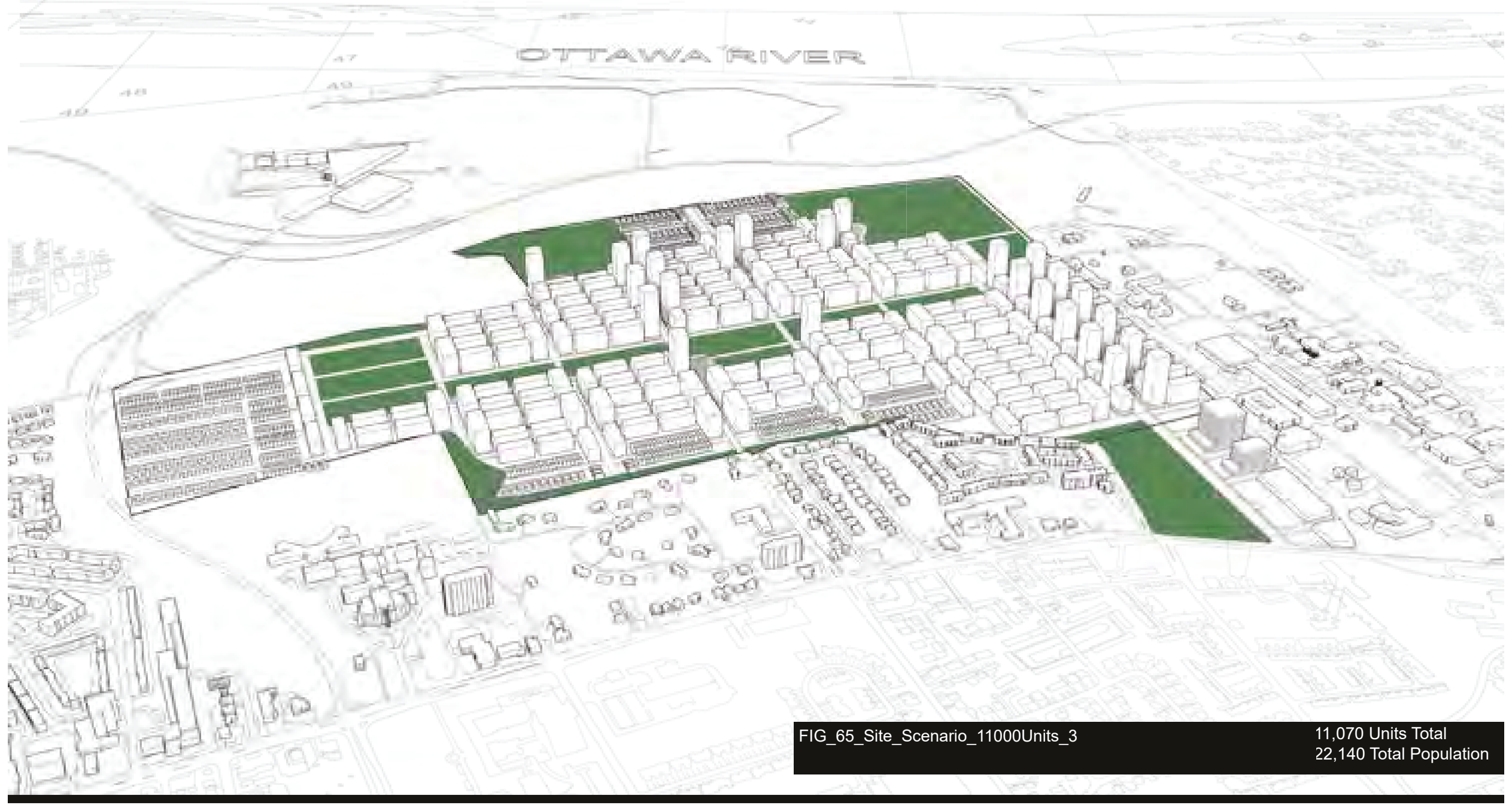


By taking the same process further, adding more mid-rises as a substitution for the high rises delineates from achieving the desired density.

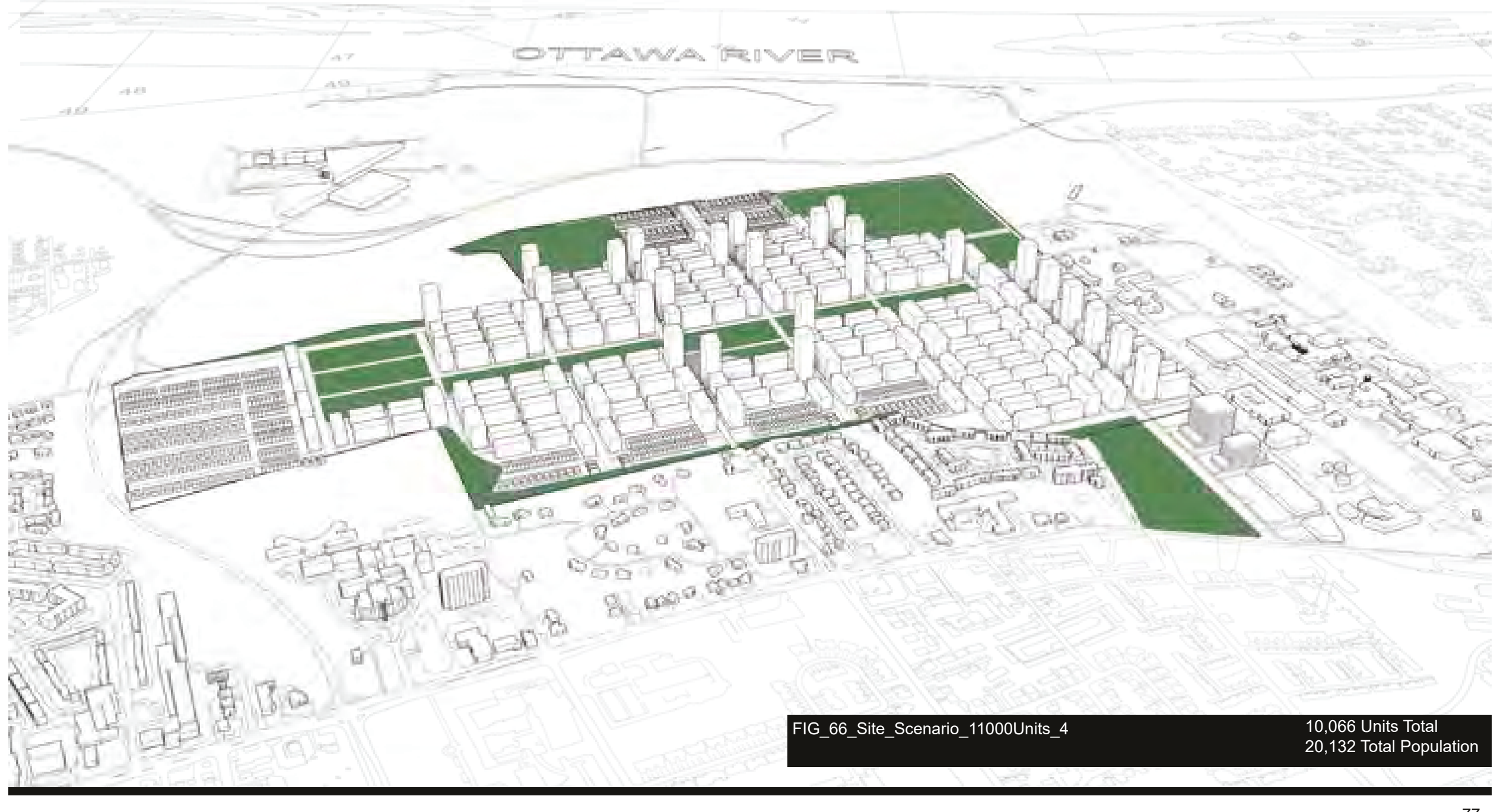




\section{9) Typology Arrangement - New Road placement}

Due to the nature of landscape design possibilities, the need may arise to change certain site elements such as roads. In the next scenario iterations, the images depict scenarios where the main artilery road has been changed, therefore cutting certain blocks and rearranging the typologies orientation. In some instances the algorithm is set to eliminate certain masses from the new road line,

however, to keep the same density, the types are reappropriated tor

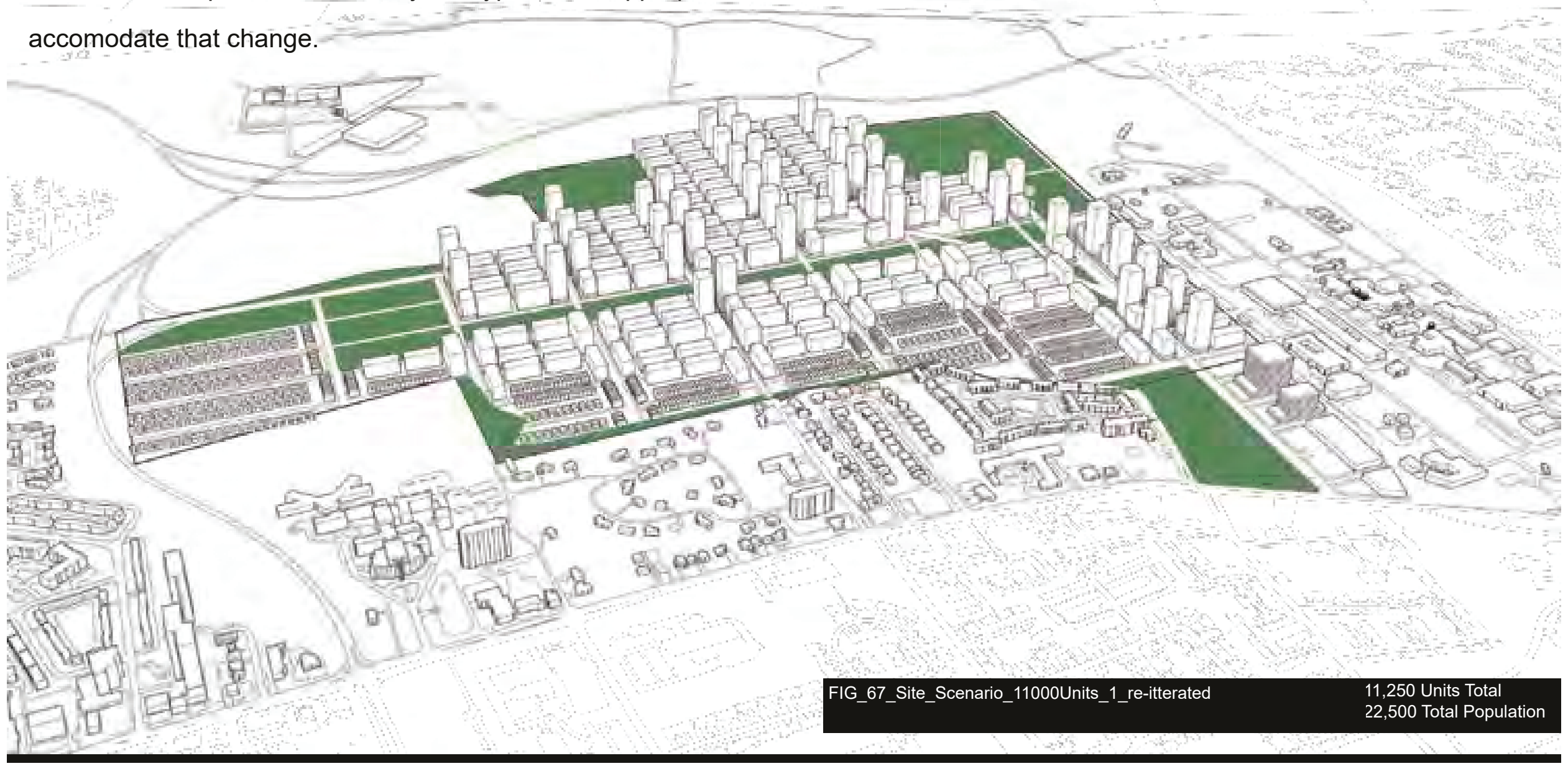



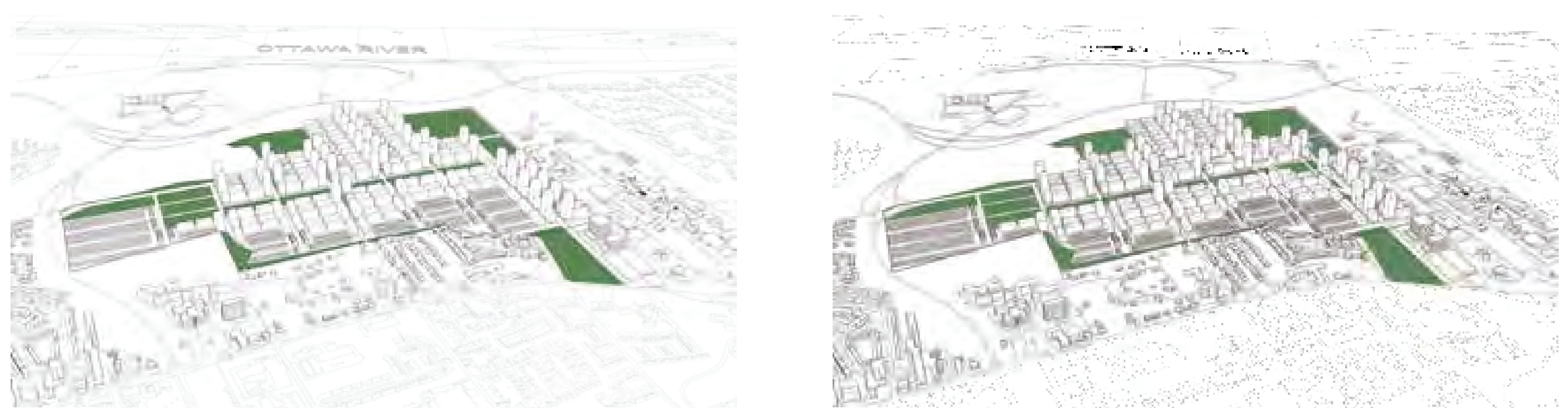


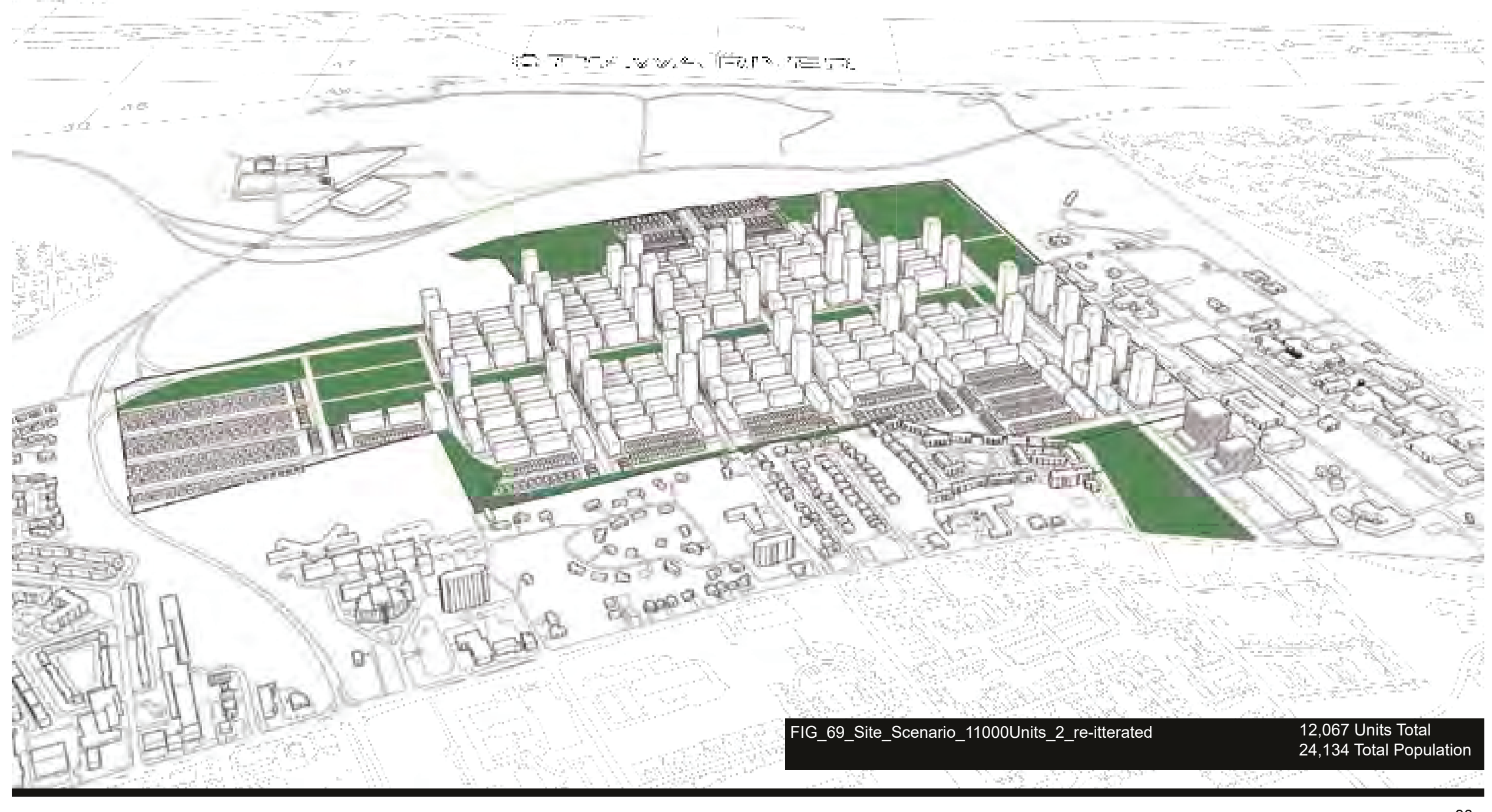



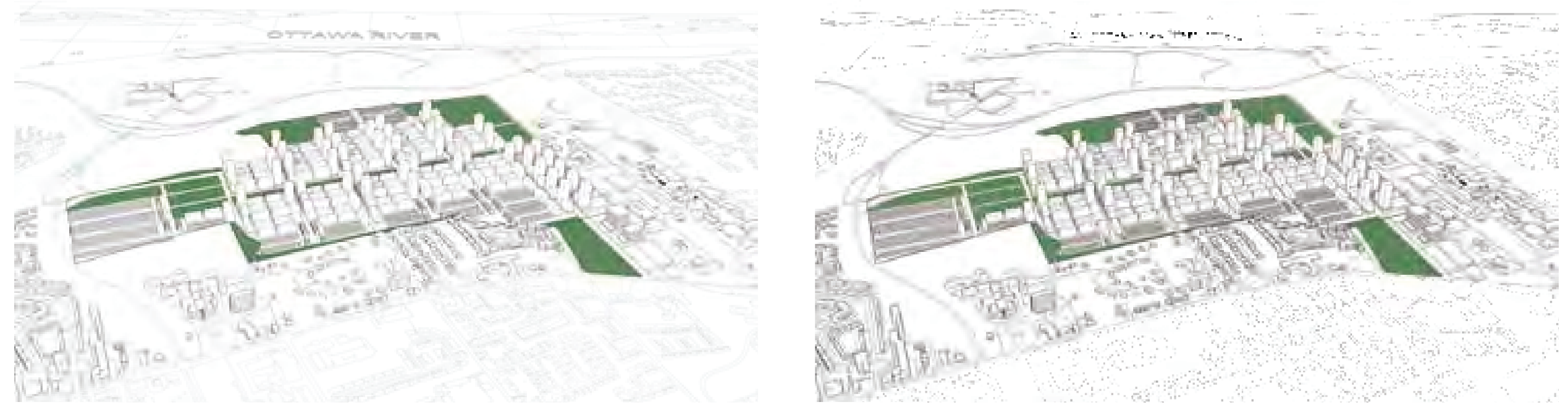


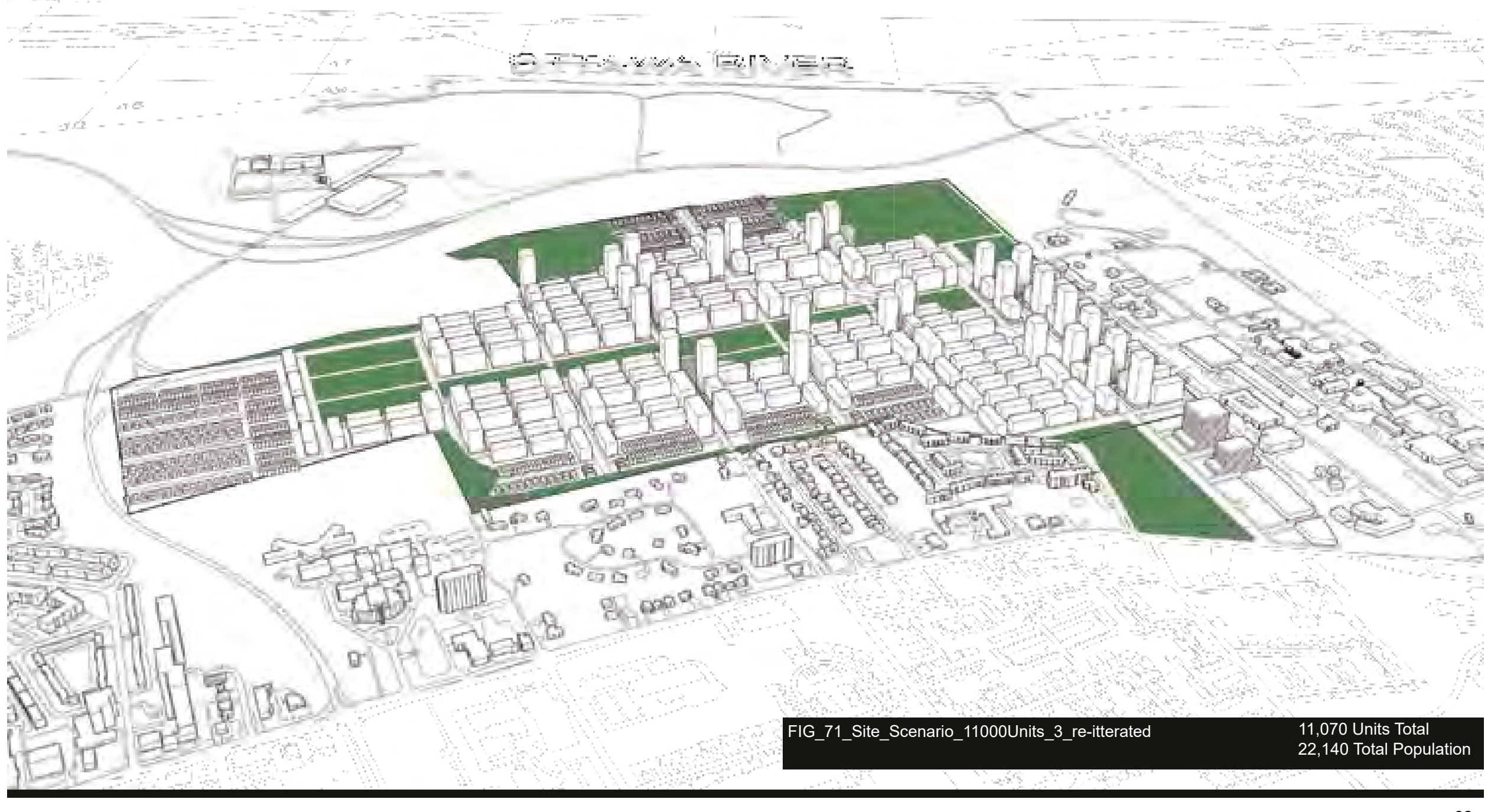



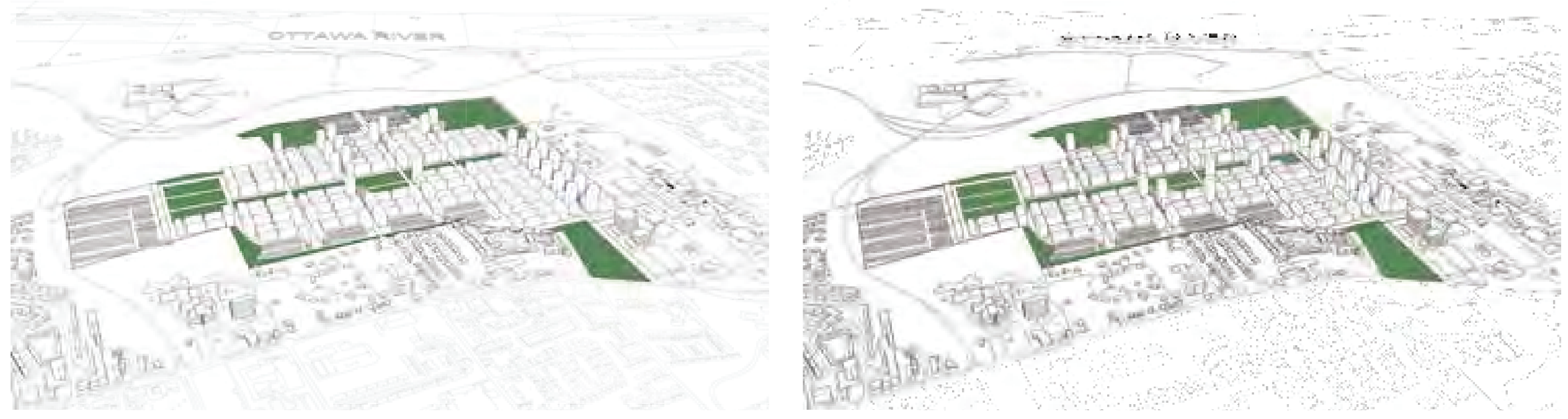


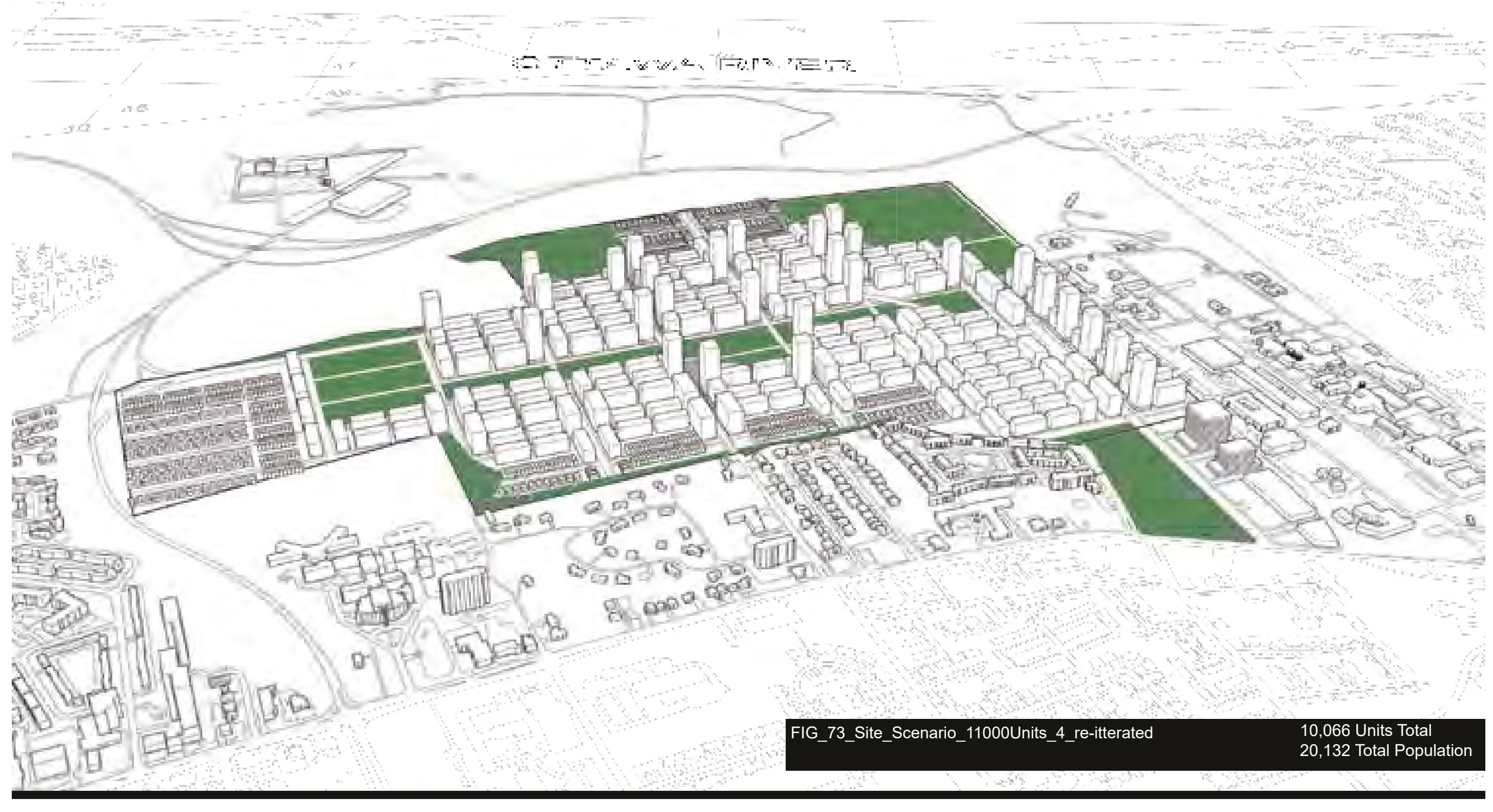



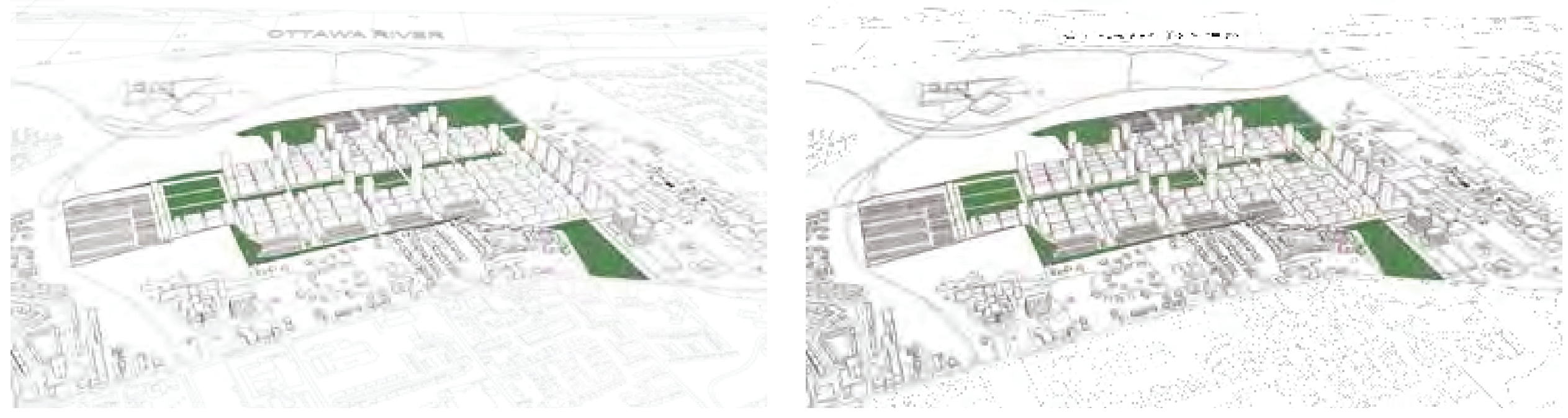
At the end of this process, the next step would be to bring in the design aspect of the ratio. With the terms of reference already established, the designer could then re-imagine the iterations proposed by taking advantage of not only what the algorithm and design tools have to offer, but simultaneously add his/her own values which could then be re-added into the algorithm as additional parameters. The designer has the ability then to not accept fully what the process has generated, but instead appropriate a different design strategy while working within the framework given to him/ her. 
Once all the factors have been determined, elements of design creativity can be added to the algorithm. The next series of iterations represent scenario's where design constraints have been applied.

Such constraints could potentially be such:

- Bending geometry for better orientation

- Placement of nodes which inform pathways.

- Central Nodes where the designer can nowbe assessing where most likely there would be a dense amount of traffic.

(NOTE: These can appear in any order)

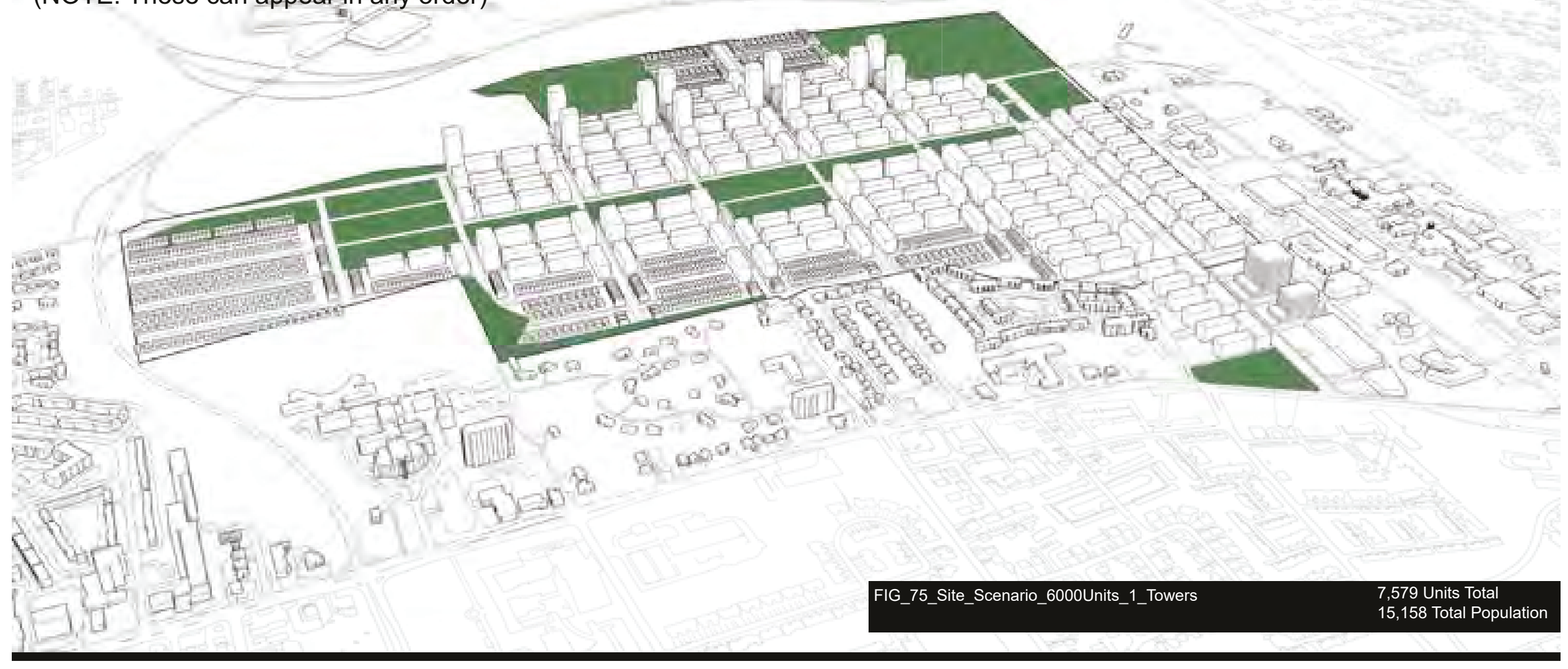


It is important to remember that as the design parameters are applied, anomalies will most likely occur where parts of the masses may be cut or deleted, therefore removing density. Because the desire still remains to uphold the density, the algorithm responsd intuitively by replacing that which has been removed.

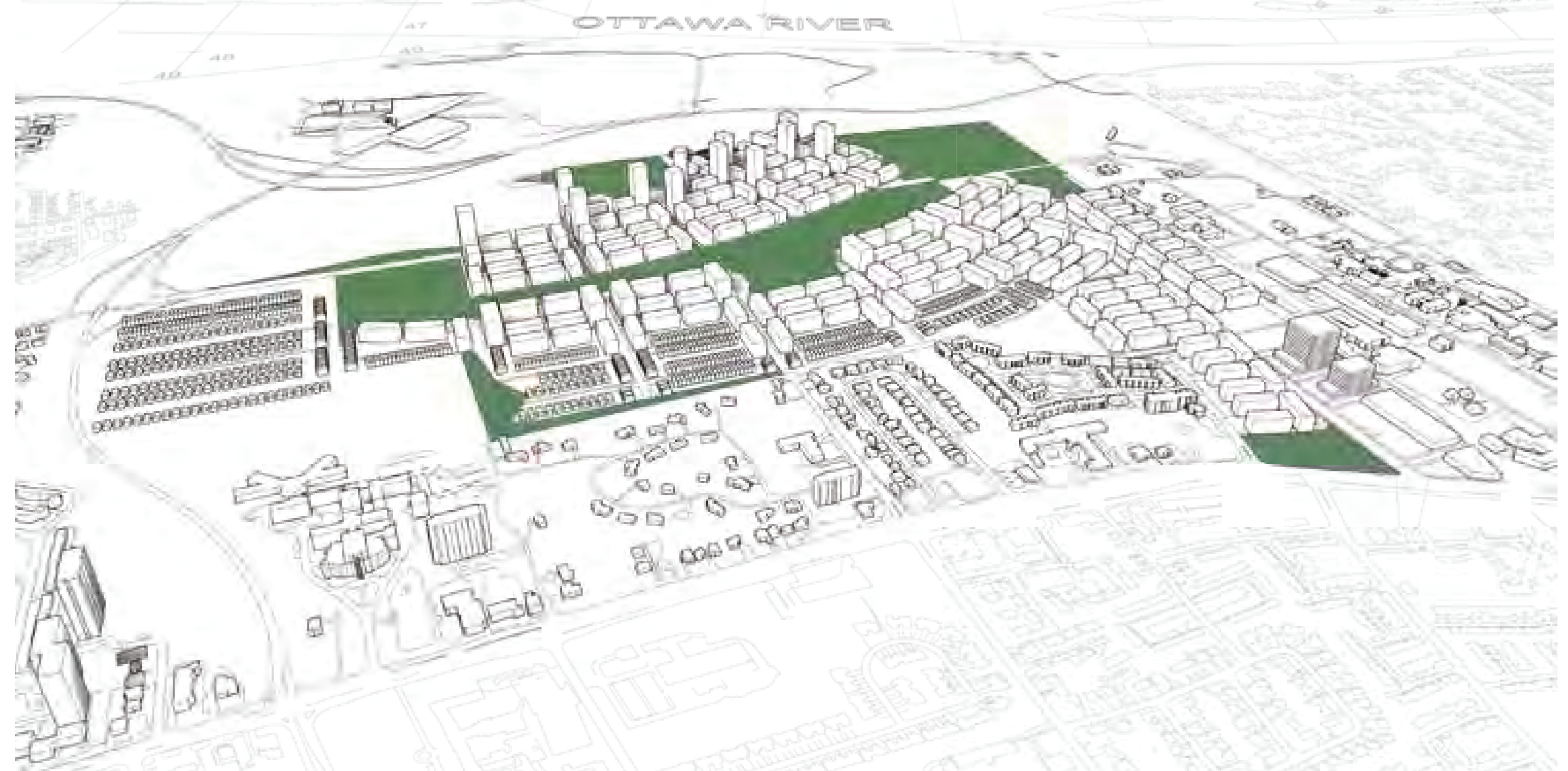




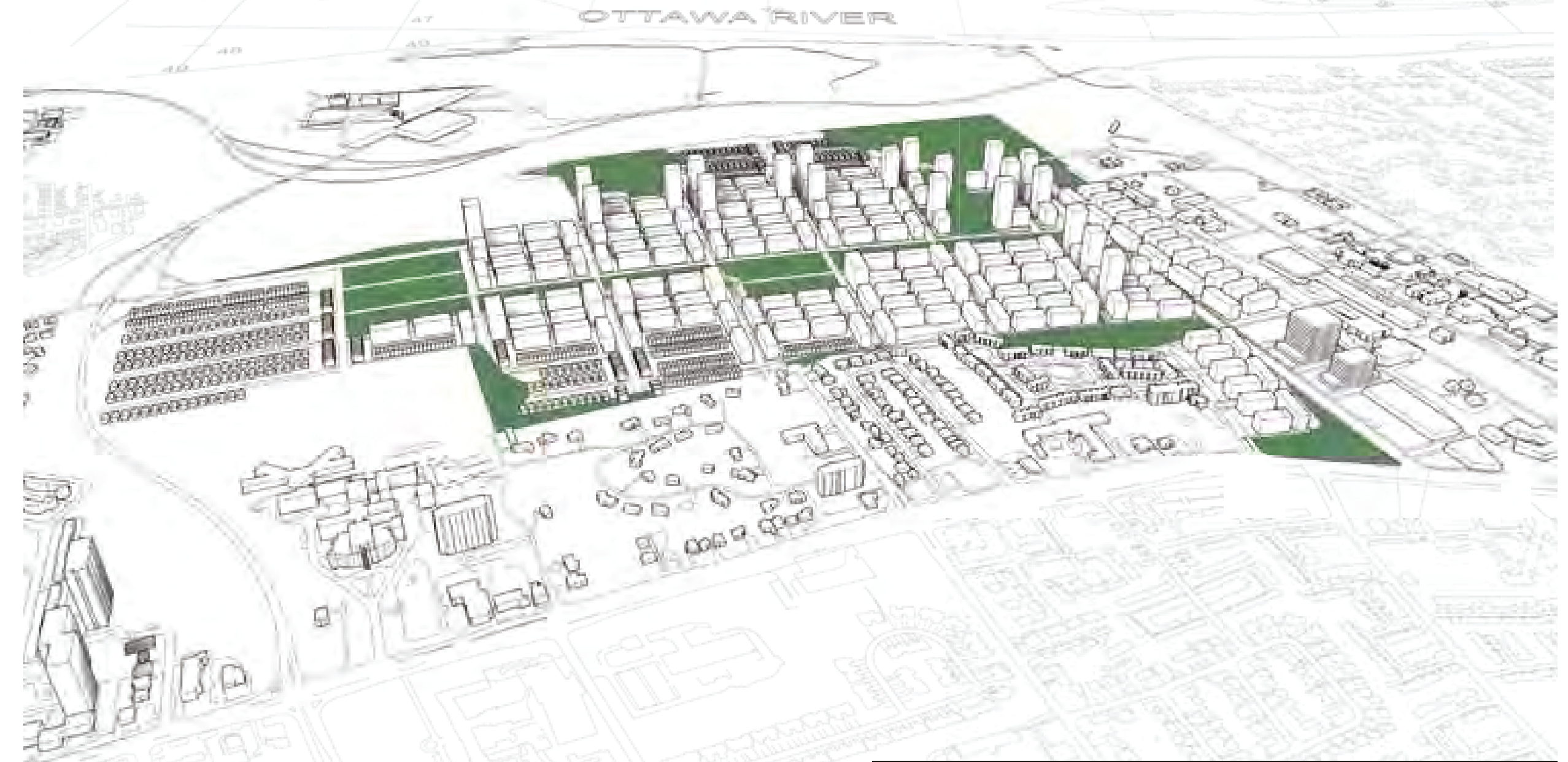


In some instances, the designer may want to change the typology, therefore this Figure represents a scenario where the density is still kept, yet the northern portion of the site has transformed into high residential only for the purpose of maximizing open space, but keeping to the variety of typologies available.

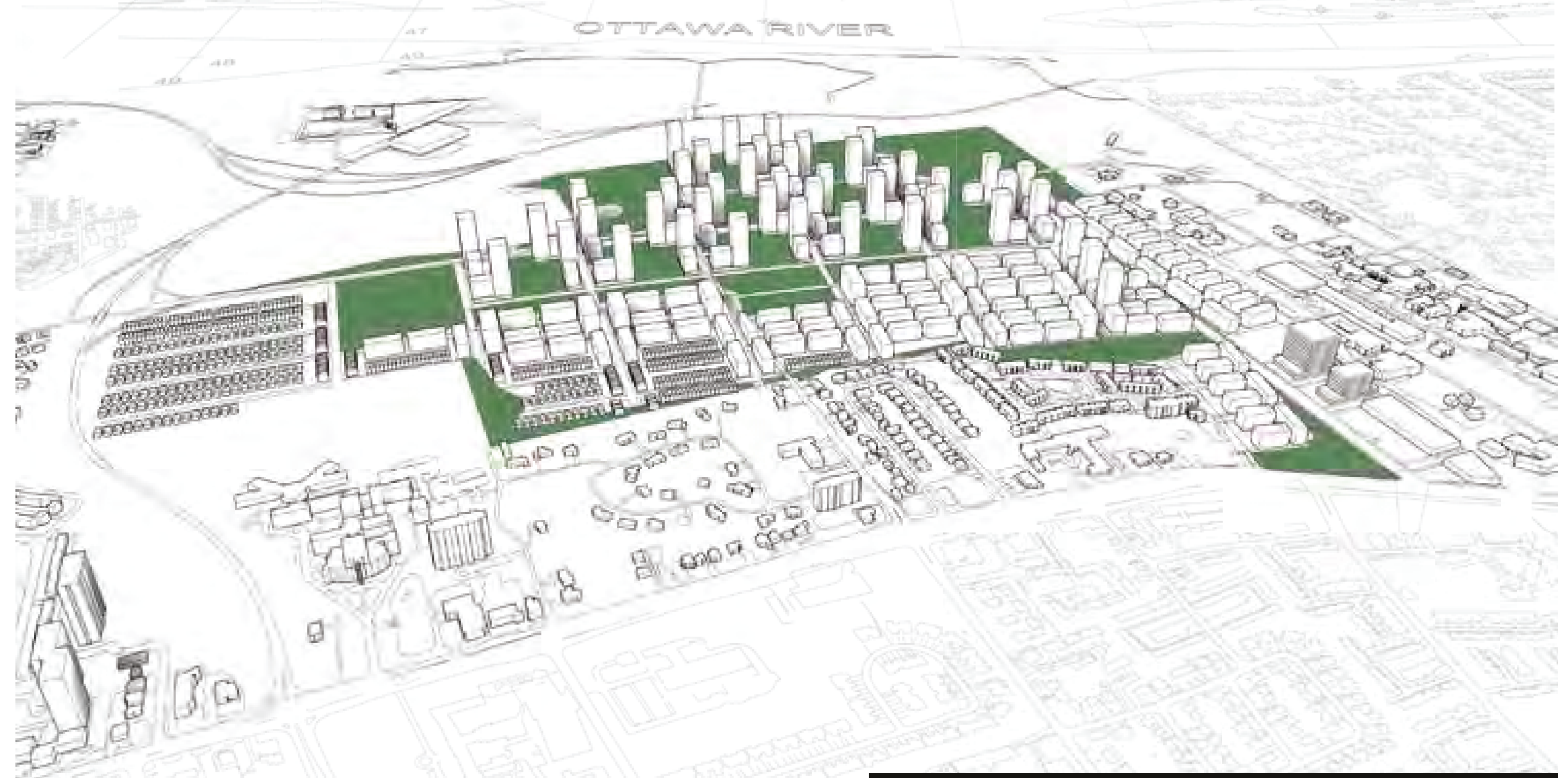


Following, the last itteration could show more design parameters such as innitiating a "Zaha-esque" style of gradient to the masterplan

- where the heights of the buildings are now varied, but the density is still kept.

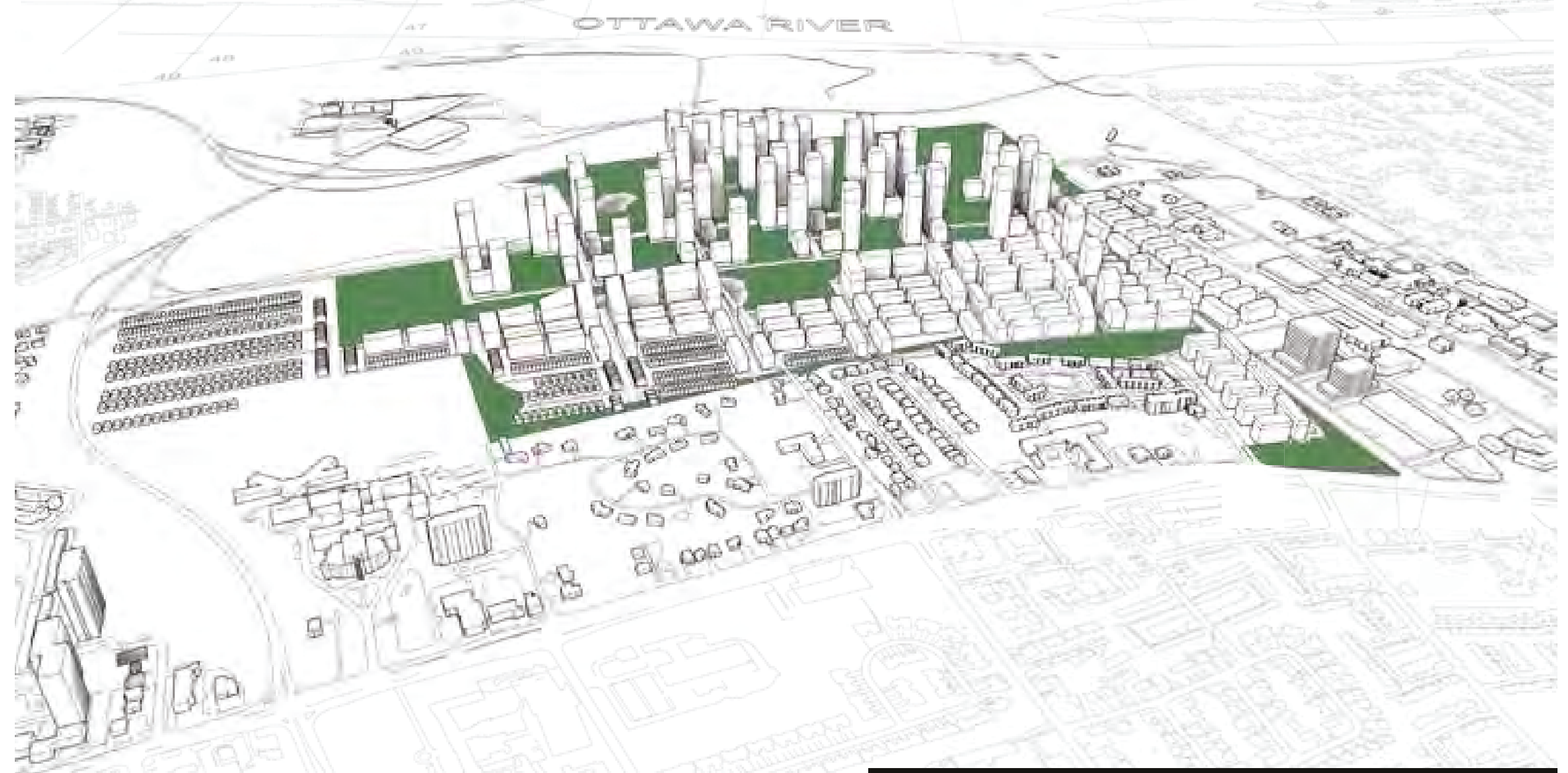




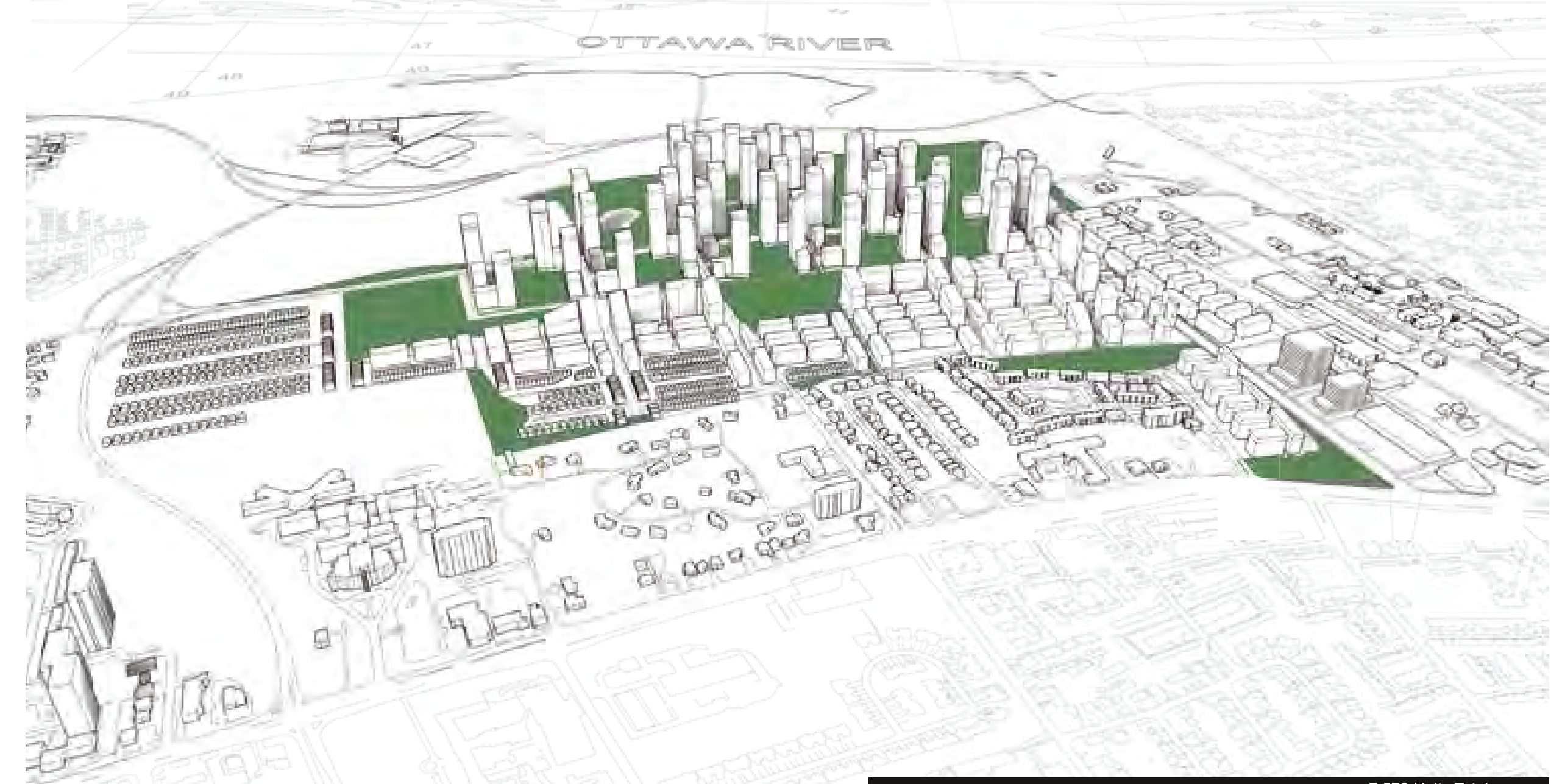




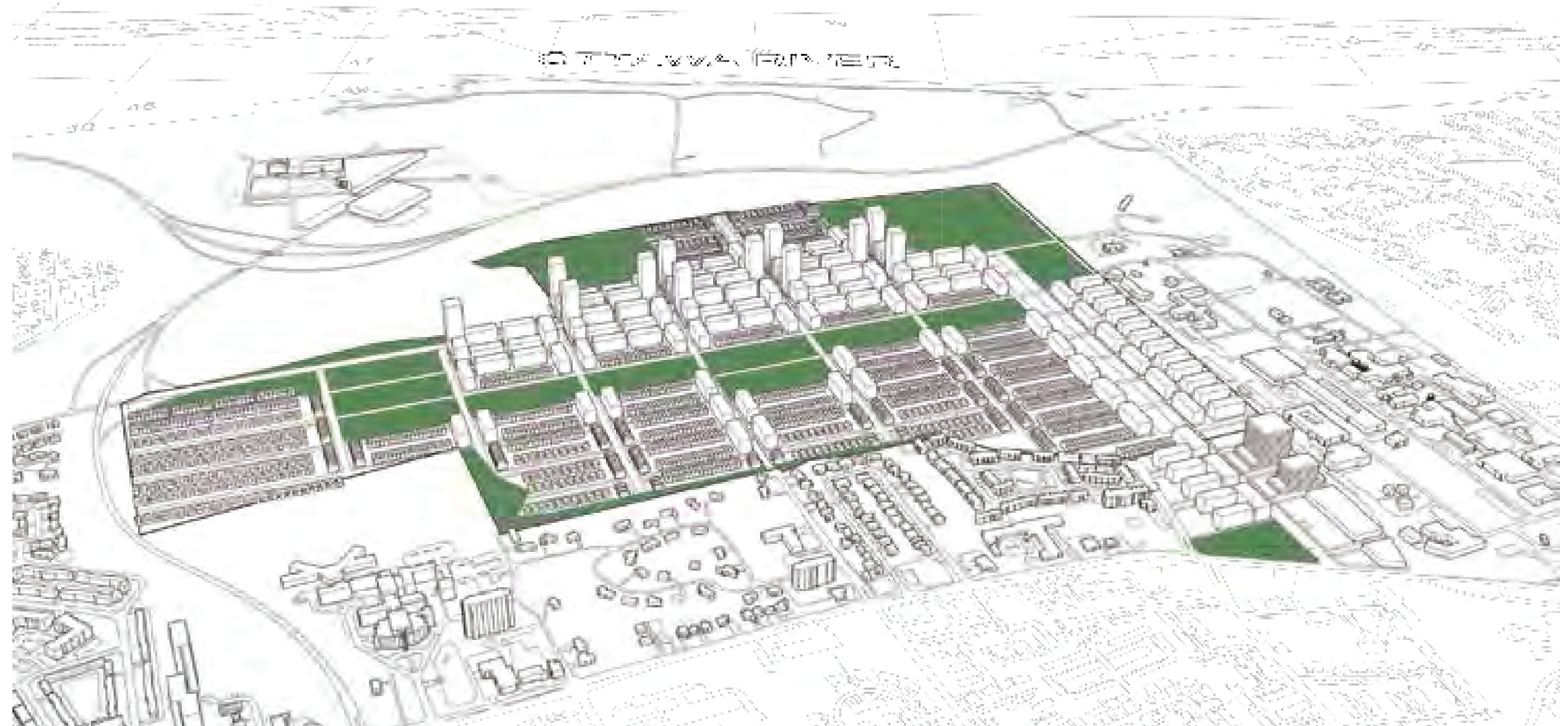

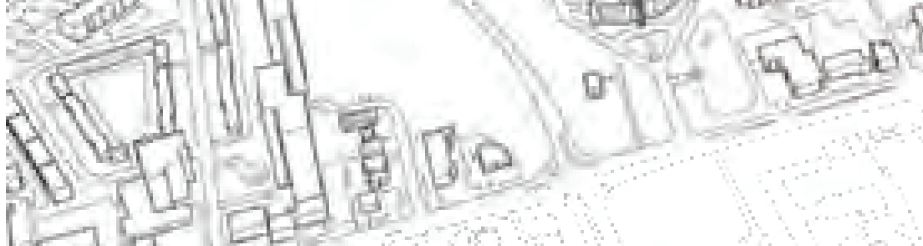




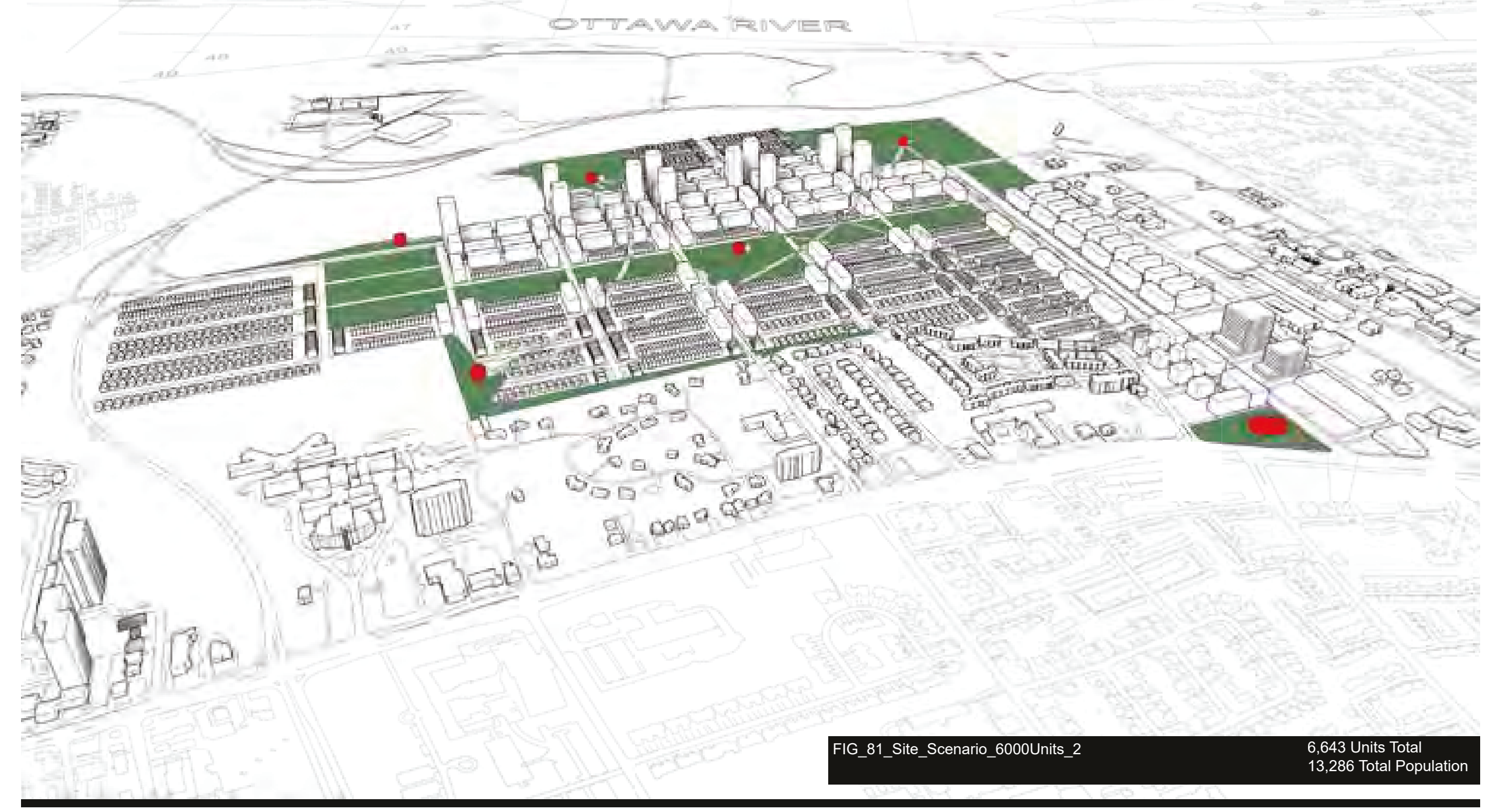




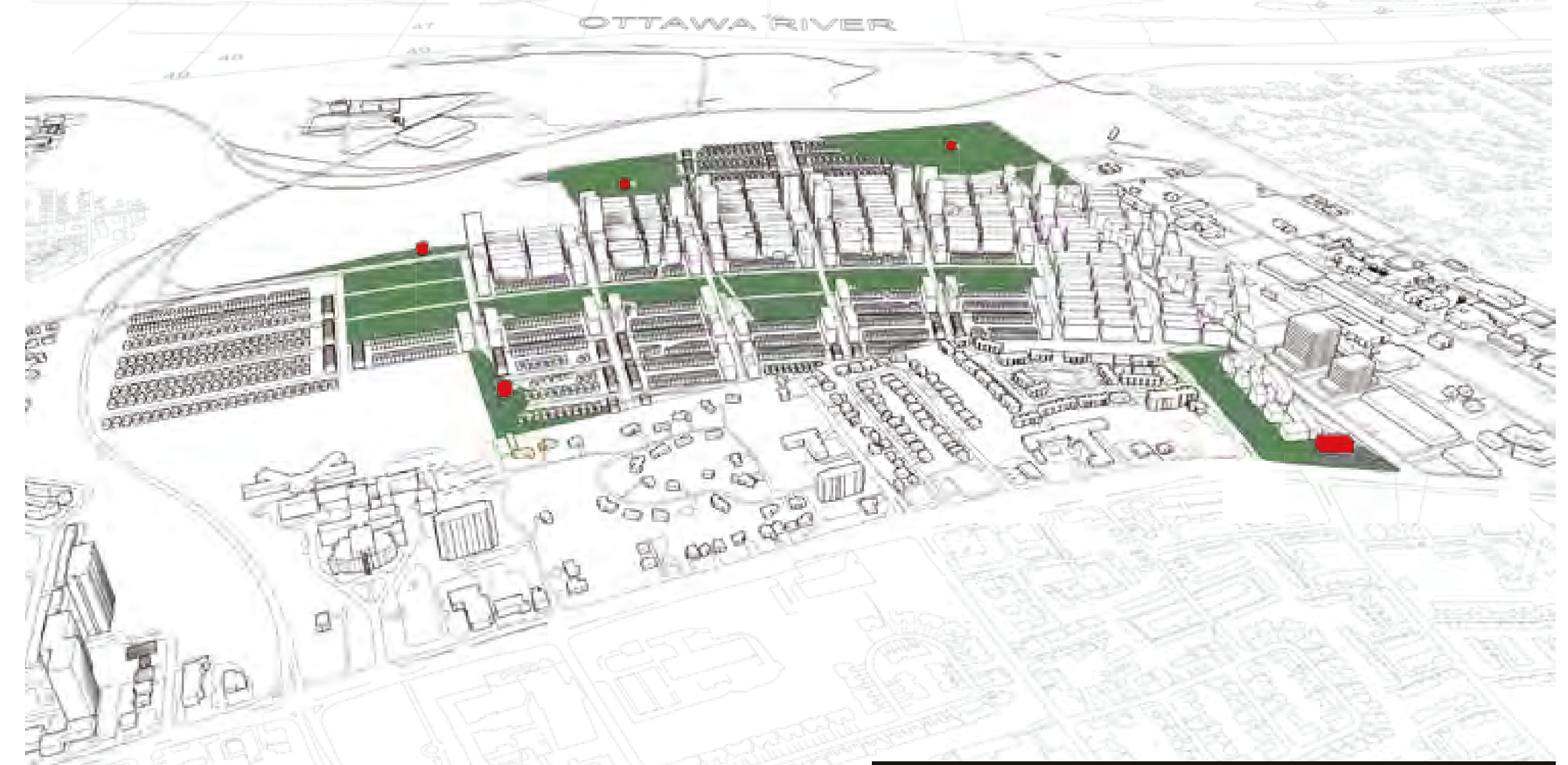




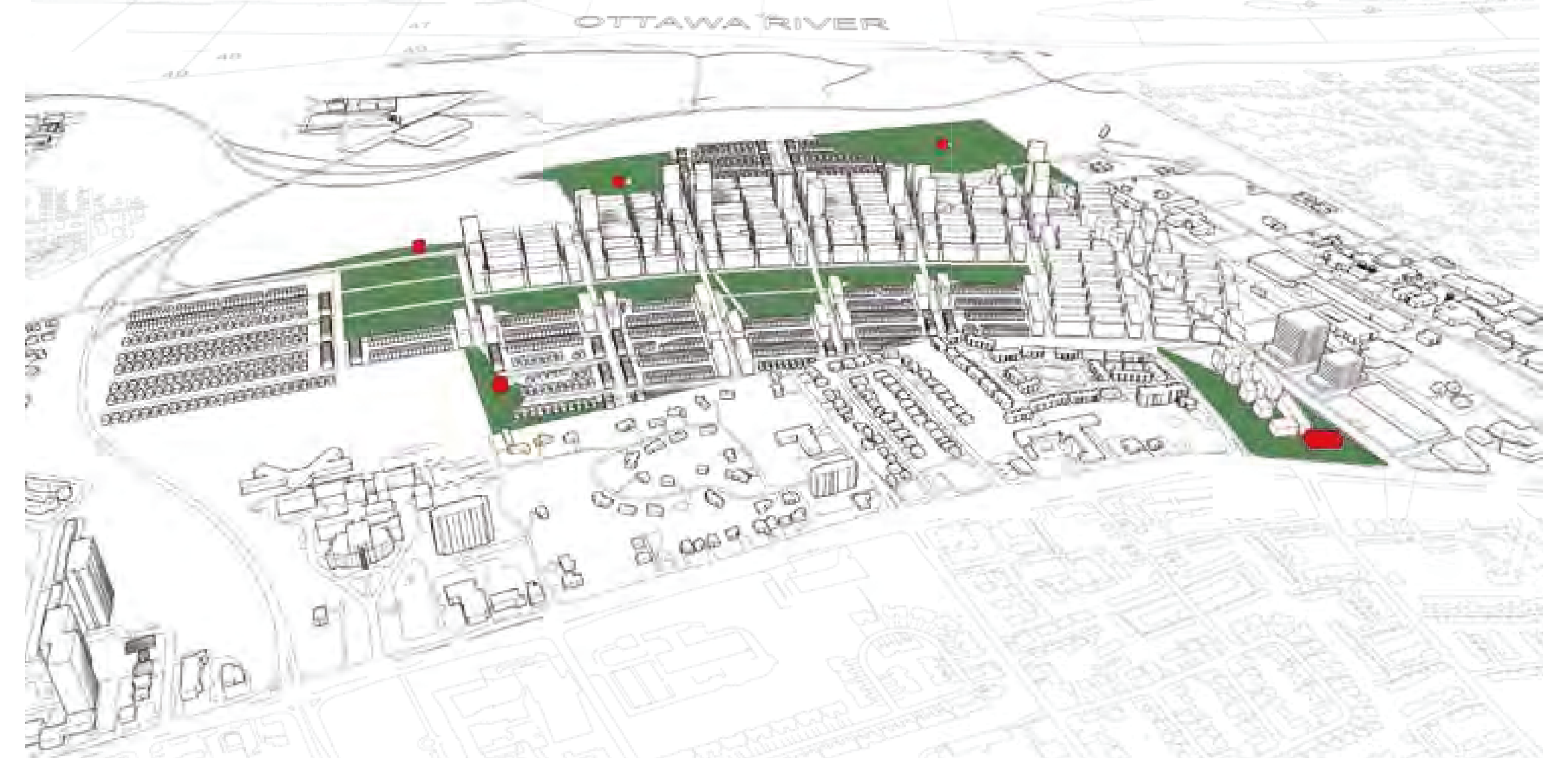




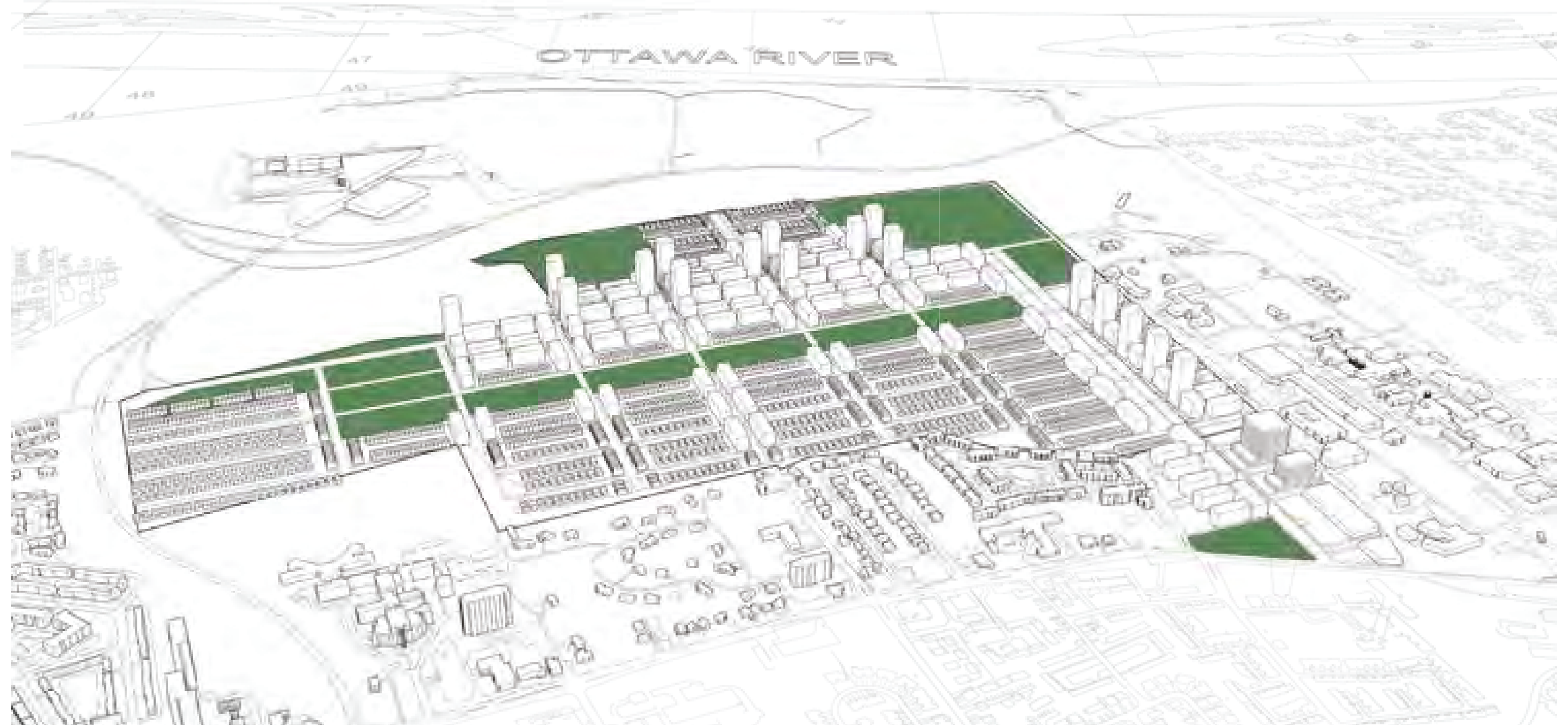

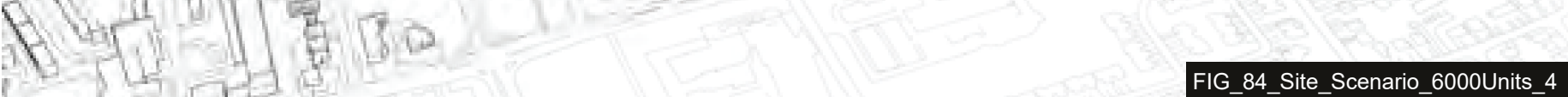




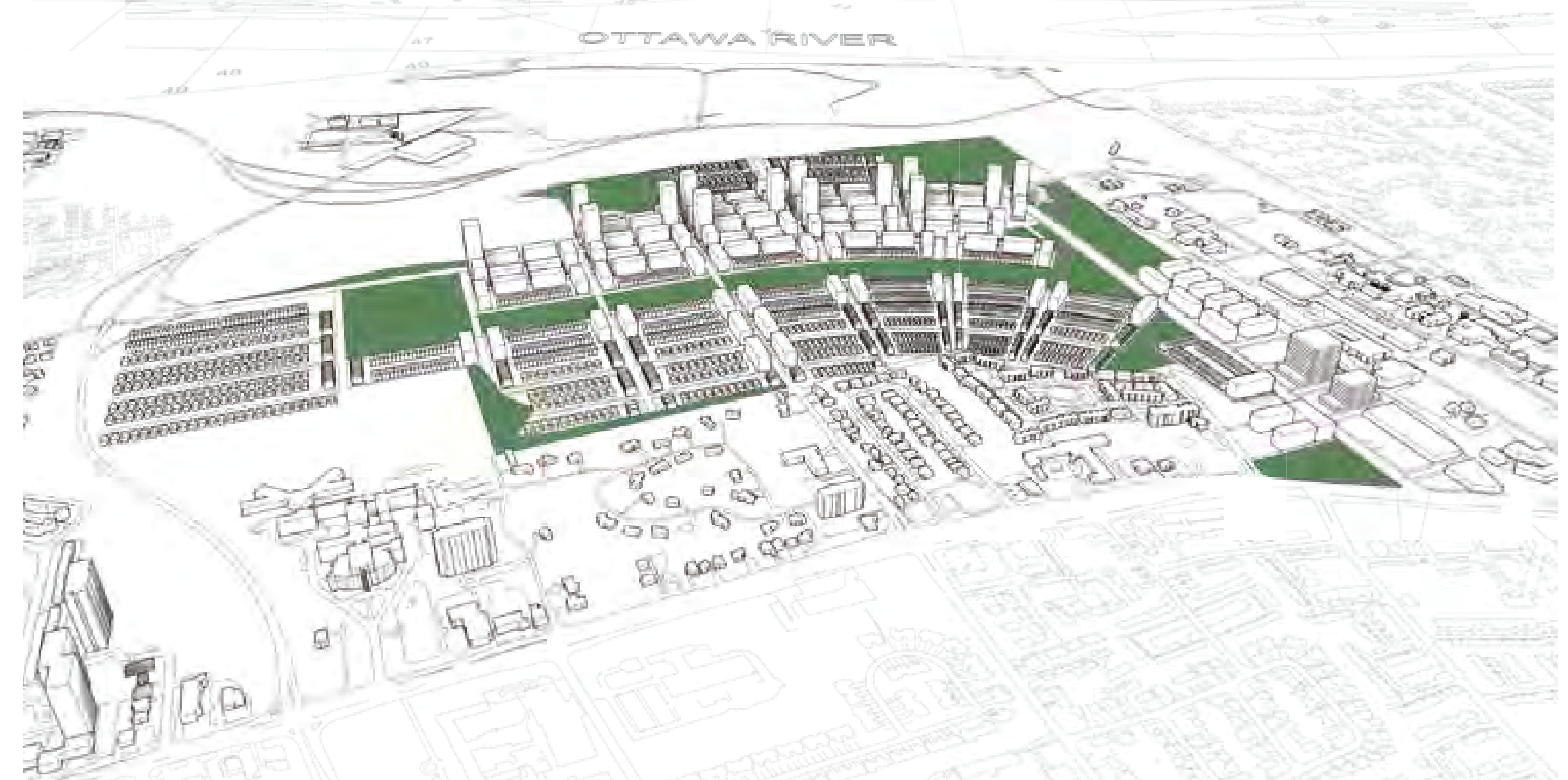




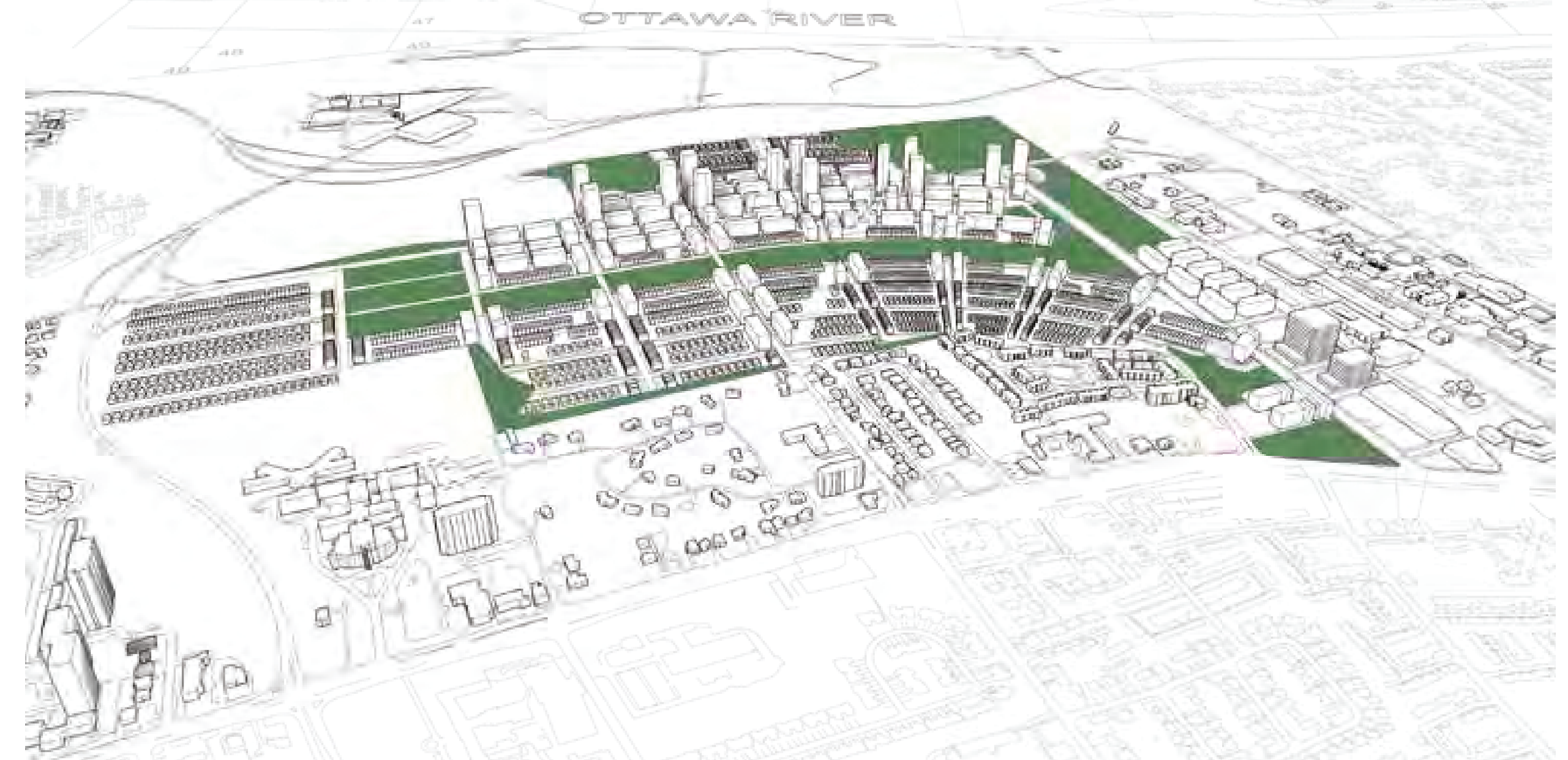




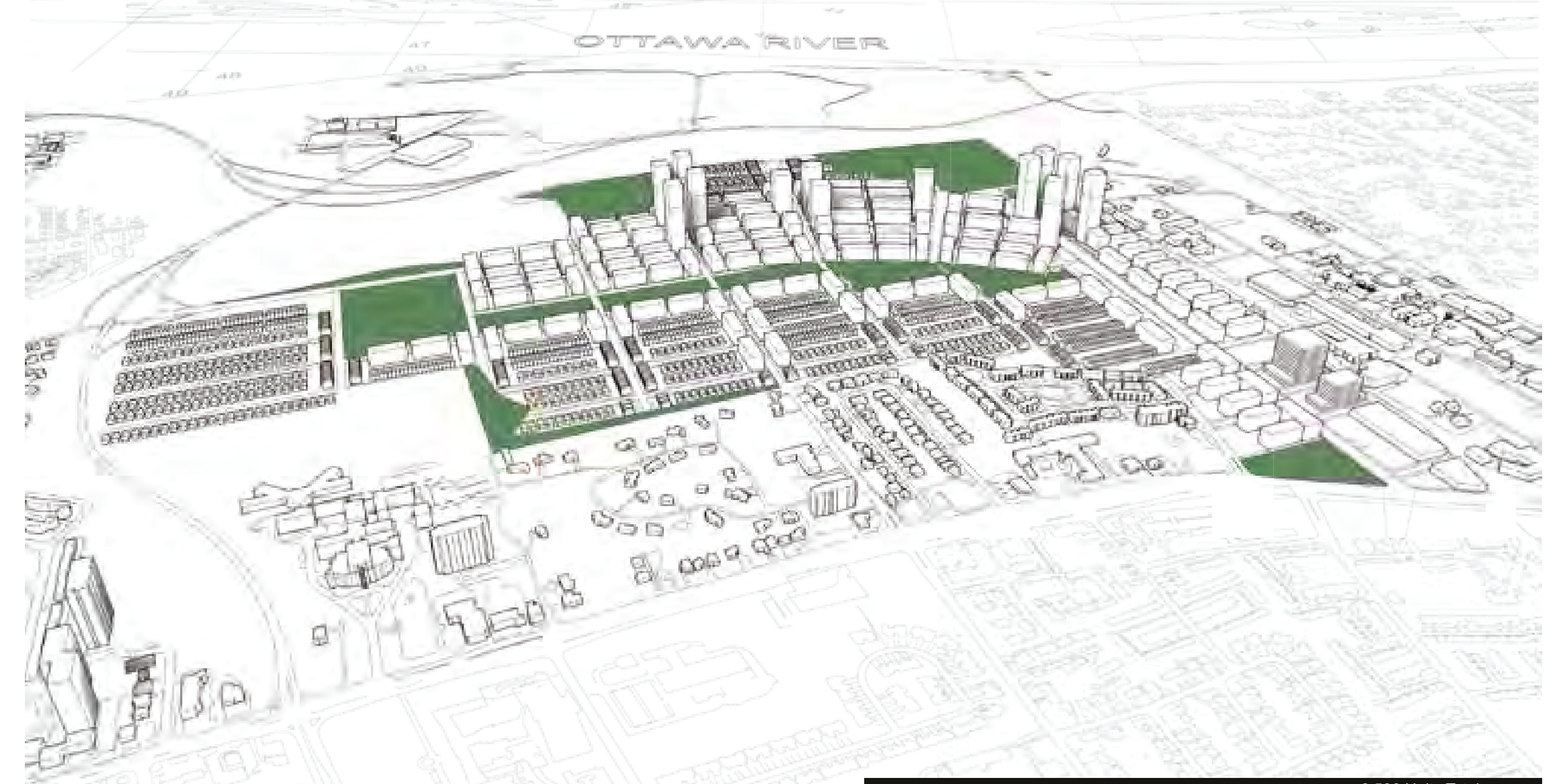




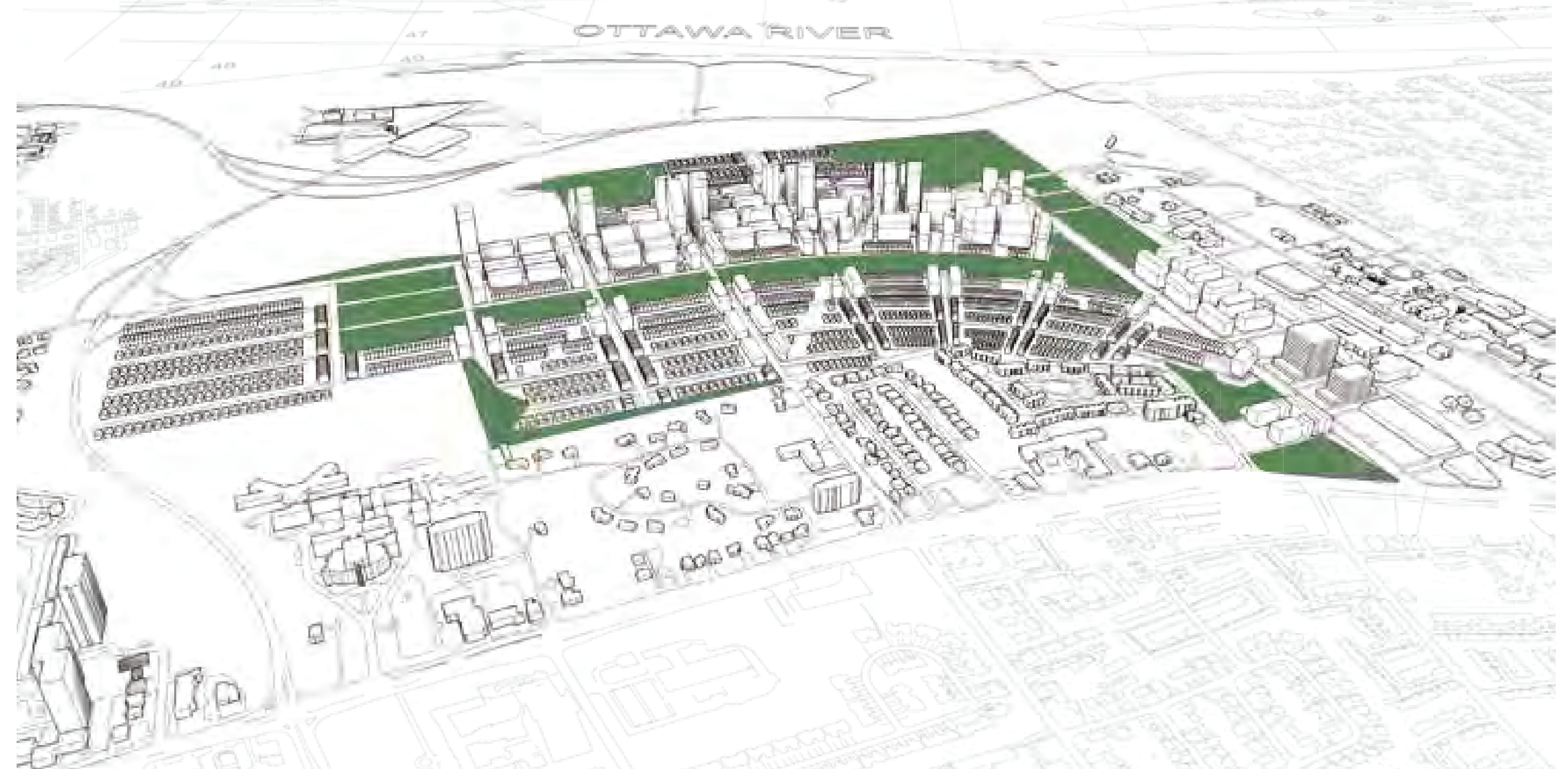




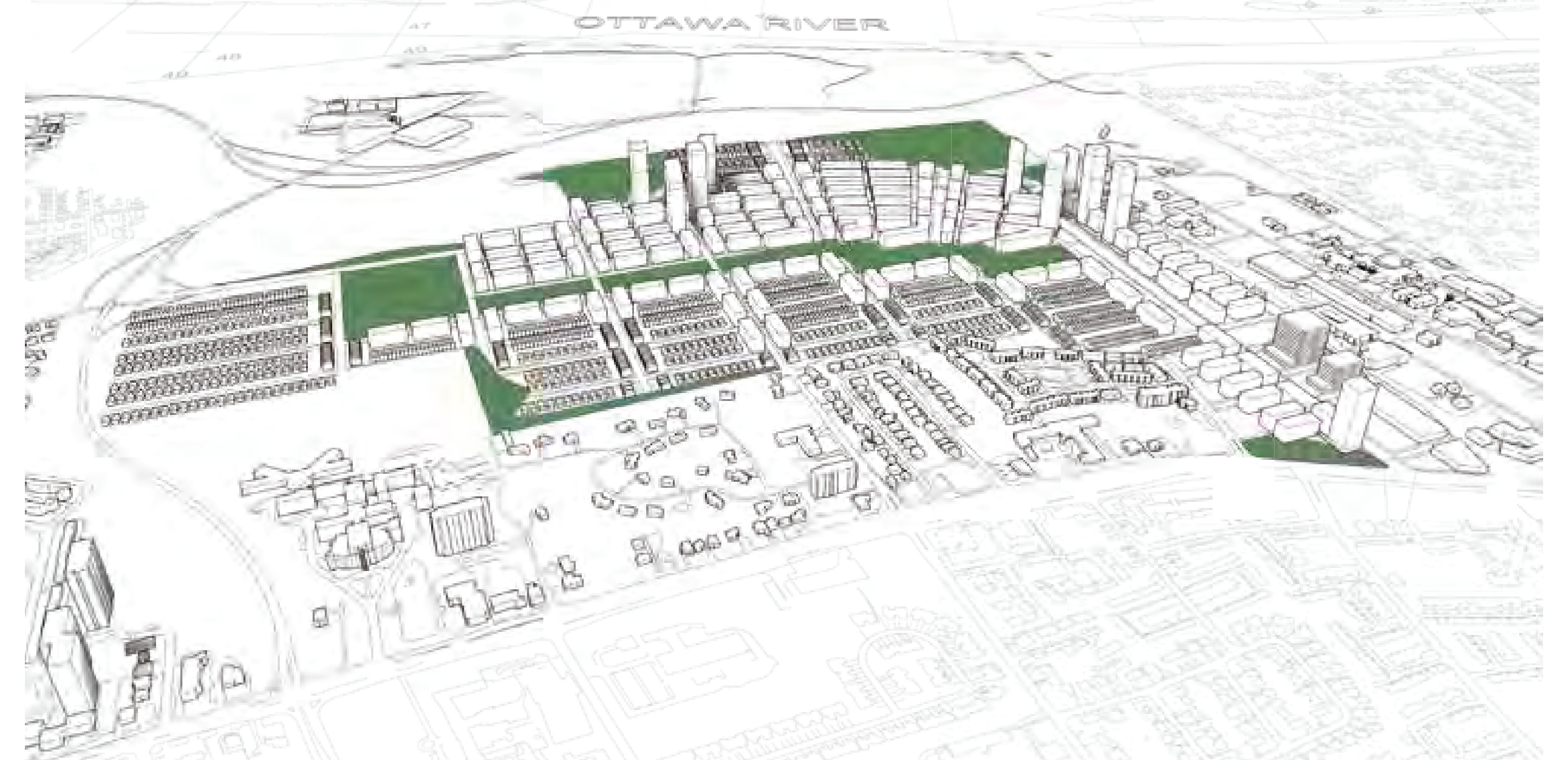




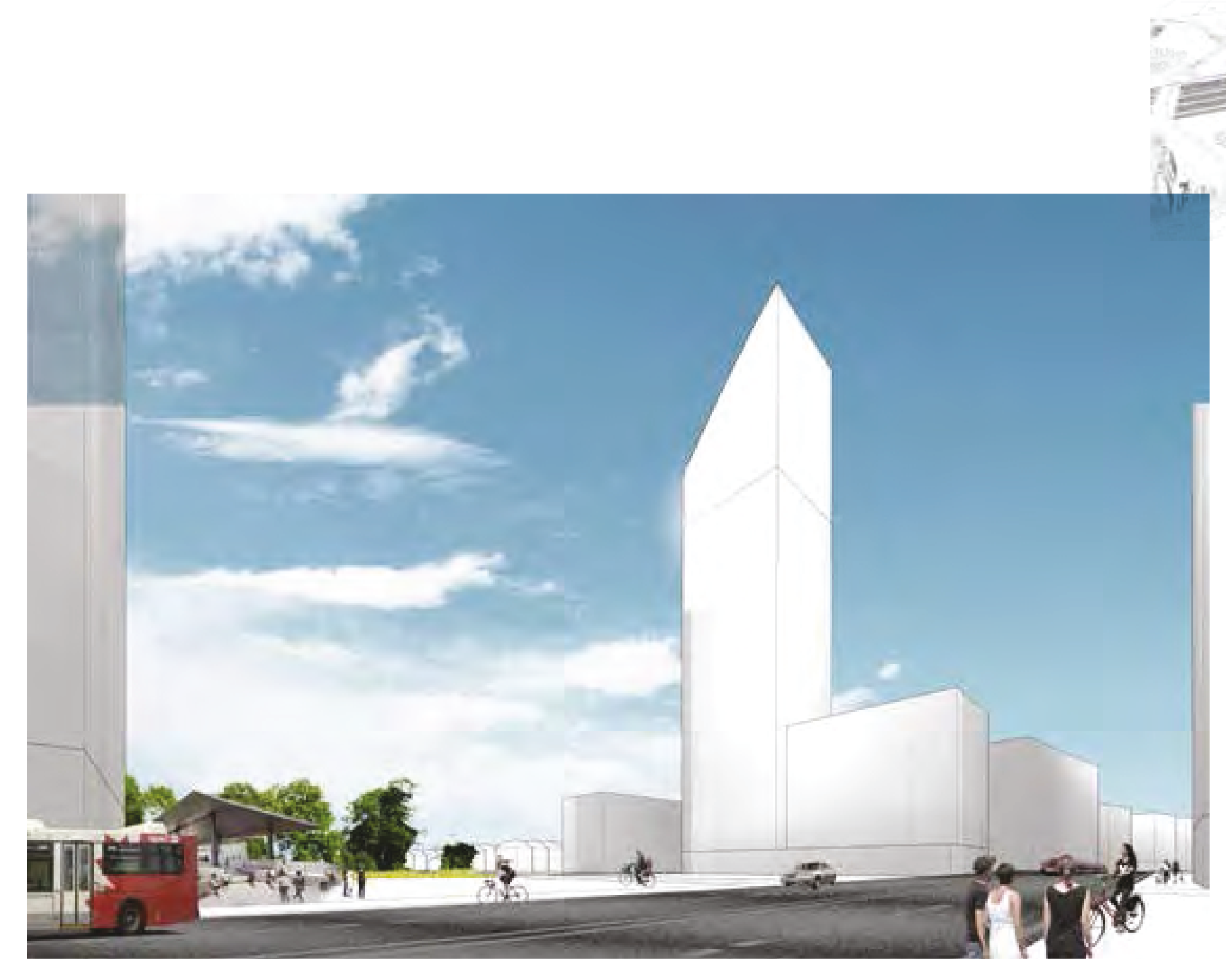




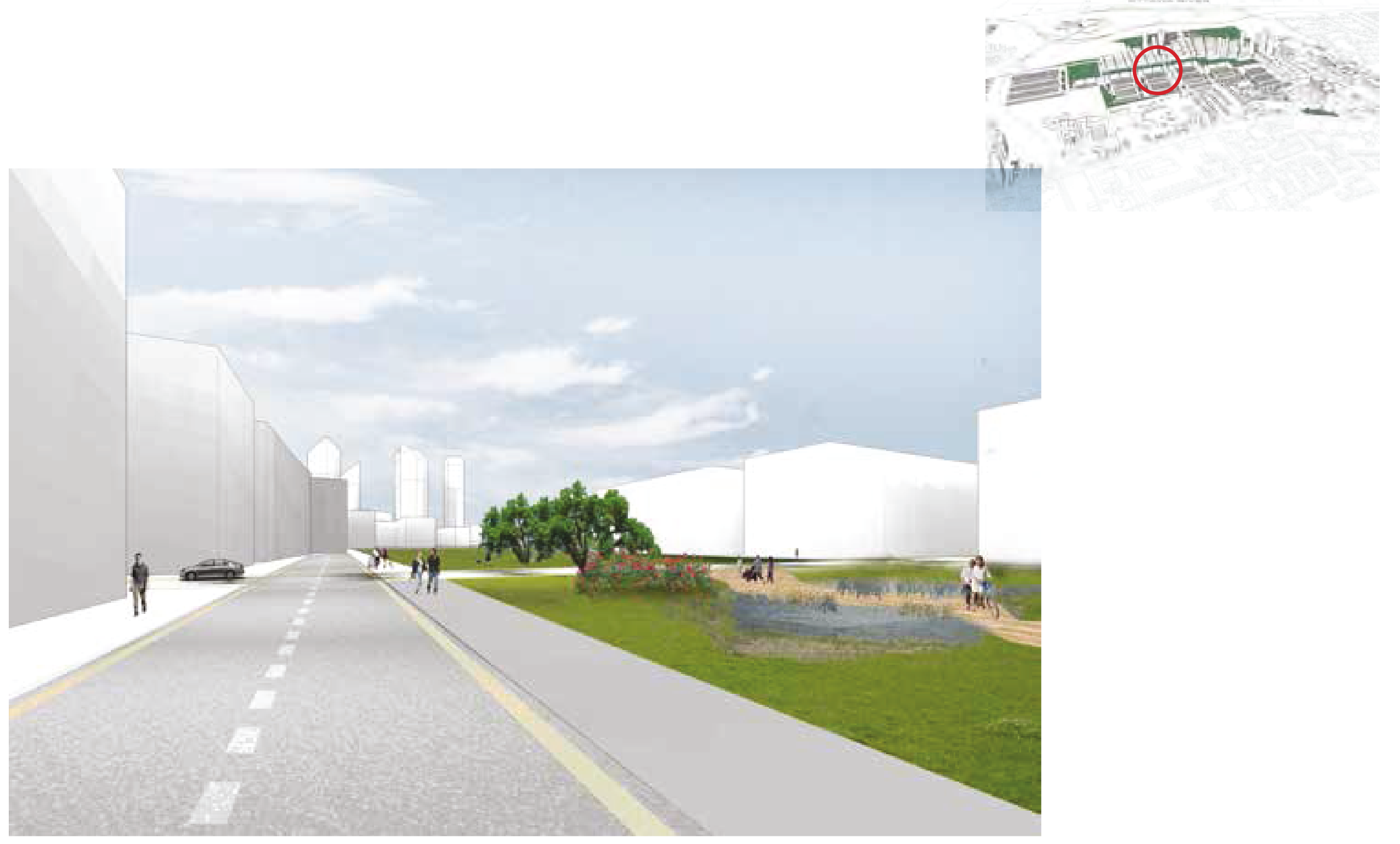




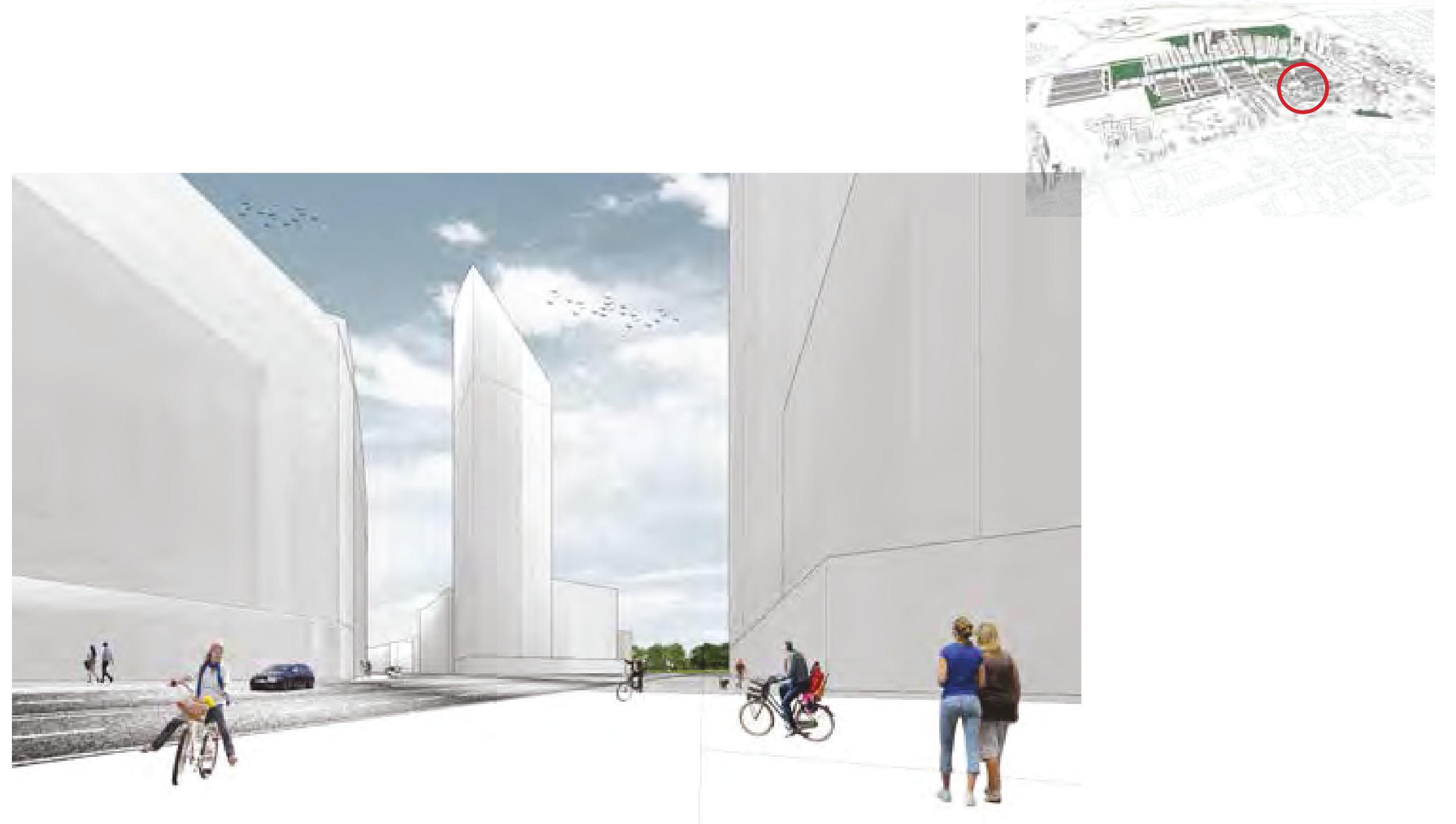




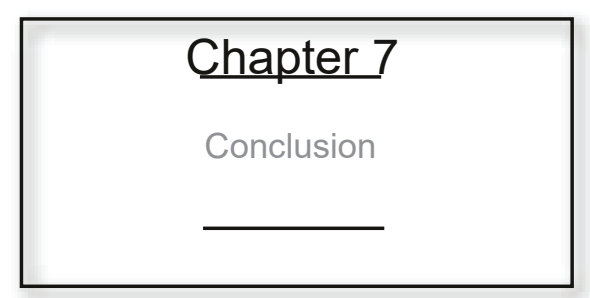

With digital tools, it seems that architects and designers become obsessed with the built form, and although this thesis is not a criticism on form making, the same strategies for form making are misplaced when applied to the search of new methods of urbanism. The form of urbanism must be distributed by a particular logic, followed by the aesthetic design. Cities are after all, complex systems of regulations, and the same rules that apply to architecture cannot necessarily apply to urbanism because they can not be adapted appropriately due to the difference in scale.

This thesis divorced itself from the realm of aesthetics early on in the process. It established a framework with a set of logics that generated understandable urban forms that related to quantified 
appropriations of density, i.e certain building types represented different types of density. Following this, a series of logics were established to optimize for building orientation such as limiting the placement of point towers on the end of blocks and changing building morphology across the block, rather than across the street.

Through this methodology, this thesis looks at the "scaling up" of parametric design - both critically (with respect to what ZHA is championing) and practically. It questions what's involved with the shift from applying parametric design at the scale of the building to the scale of the block, neighborhood - and ultimately to the city. It explores the potential of using parametric tools to help make transitions between different types and densities of urban fabric.

The final scenario's presented are not meant to be static and permanent solutions, rather a set of scenarios that can be studied, detailed and consulted in every stage as the masterplan develops. Although this can become a complex process, the benefit of having this system developed in the digital mainframe is such that it can produce and calculate a multitude of scenarios much faster and more efficiently than a group of planners. But what has to be established are working terms of reference which will inform the 
system.

Such rigorous processes can open up the discussion to what kind of city a community desires. The aim for this is to assess the right relation of typology to density, while simultaneously sparking a rigorous conversation about how architects, urban planners or members of a community want to develop density. Additionally, the scenario must meet the needs of a community, while fulfilling the challenge of the current urbanization issues such as densifying areas of the existing city.

The actual usage of parametric tools is seen by the masses as an ostensible methodology and aesthetically inadequate, since urban planning is not merely dependent on the shape of what is proposed but of urban and social factors (Beirao \& Duarte, 2005, p. 493). By solely giving importance to formal and aesthetic aspects of the creation of complex geometries, possible through parametrization, there is a lack of relevance beyond most important urban concepts such as the social, political, and as proven in this thesis, the typological aspects of urbanization.

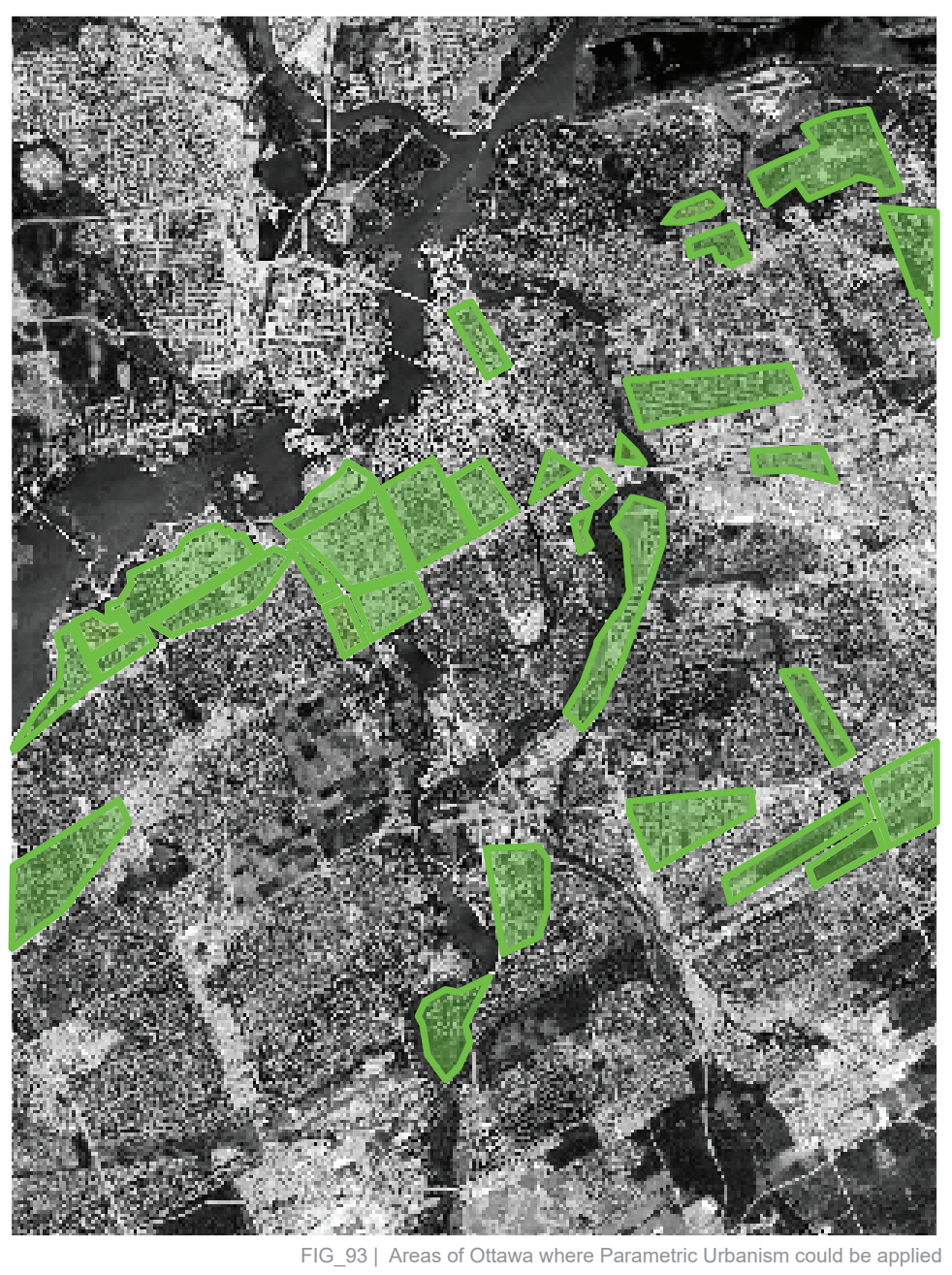

The academic example of developing a masterplan for the 
Rockcliffe site in Ottawa revealed a methodology that offers greater ability to quickly and efficiently adapt to changes in the urban system in terms of the typology. The methodology allows a variety of possible solutions generated in a simple way which can be easily adjusted and modified, making the process much more dynamic and sensitive to a multitude of factors.developed in this thesis where to be applied to adequately plan scenarios in the existing context of Ottawa, a city could viably assess the solutions and strategies it would prefer, specifically to the types of densities and relations to open and public spaces. As cities continue to grow in population, there are existing city areas that could be developed to accommodate for growth. With Ottawa being surrounded by the greenbelt, it is critical to assess growth strategies within the existing city, eliminating as much urban sprawl as possible.

Cities in North America could already be appropriating methods of densification, whether in the downtown core or in its immediate context. In the context of Ottawa, there are many areas of the city where densification could happen. The Lebreton Flats and existing Rockcliffe community design plans are a few examples of how a city, planners and architects are strategizing to tackle the issues of densification, creating communities with high-rise and mid-rise 
developments. The targeted density for the Lebreton flats is 7,000 people, existing within a mixed-use community.

It is crucial to plan cities well. If this method of Parametric Urbanism developed in this thesis where to be applied to adequately plan scenarios in the existing context of Ottawa, a city could viably assess the solutions and strategies it would prefer, specifically to the types of densities and relations to open and public spaces. As cities continue to grow in population, there are existing city areas that could be developed to accommodate for growth. With Ottawa being surrounded by the greenbelt, it is critical to assess growth strategies within the existing city, eliminating as much urban sprawl as possible.

If Parametric Urbanism is to be a vital method appropriated for urban planning, then it can only act within a system of logics, because otherwise city planning and the resulting built environment would degrade into chaos. The method allows a variety of possible solutions generated in a simple way and where those can be solutions generated in a simple way and where those can be easily adjusted and modified, making the process much more dynamic and sensitive to several factors. This ability to adequately 
propose multiple solutions to urban problems may be the biggest advantages of Parametric Urbanism. 


\section{Bibliography}

\section{Parametricism}

Amiroll, Haviz. "Generative Algorithms as Design Tool in the Transformative Urbanism of Bandung." Scribd. 2010. Web. 7 Oct. 2015. <http://www.scribd. com/doc/40012685/Generative-Algorithms-as-Design-Tool-in-the-Transformative-Urbanism-of-Bandung\#scribd>.

“Forward." Parametric Architecture with Grasshopper 1.1 (2010): 7-9. Print.

Verebes, Tom. Masterplanning the Adaptive City: Computational Urbanism in the Twenty-first Century. Print.

"Parametric Urbanism Shanghai Expo 2010 craft id Overview." Parametric Urbanism Shanghai Expo 2010_craft_id Overview. 2010. Web. 7 Oct. 2015.

Saleh, M. "Using the Tools of Parametric Urbanism: Toward a More Responsive Environmental Urban Morphology." Using the Tools of Parametric Urbanism: Toward a More Responsive Environmental Urban Morphology. Web. 7 Oct. 2015.

"Is 'Parametricism' the Sustainable Style of the Future?" Planetizen: The Urban Planning, Design, and Development Network. 7 May 2010. Web. 7 Oct. 2015. <http://www.planetizen.com/node/44107>.

Schumacher, Patrik. "Digital Cities." Architecture Design Magazine. 1 Aug. 2009. Web. 7 Oct. 2015. <http://profs.info.uaic.ro/ avitcu/2013-2014/MINCU 2013-2014/Urbanism \& Peisagistica/AD1.pdf>.

Schumacher, Patrik. "Parametricism as Style - Parametricist Manifesto." Parametricism as Style - Parametricist Manifesto. 2008. Web. 7 Oct. 2015. <http:// www.patrikschumacher.com/Texts/Parametricism as Style.htm>.

"3lements - an Urban Strategy - Lab-eds." 3lements - an Urban Strategy - Labeds. Web. 7 Oct. 2015.

\section{Urbanization}

"Community Architect: The Digital City: Dream or Horror?" Community Architect: The Digital City: Dream or Horror? 14 May 2014. Web. 7 Oct. 2015.

Buchanan, Peter. "The Big Rethink Part 11: Urban Design." The Big Rethink Part 11: Urban Design. Web. 7 Oct. 2015. <http://www.architectural-review. com/essays/the-big-rethink-part-11-urban-design/8643367.article>

Flint, Anthony. "The Potential Perils of Rapid-Fire Urbanization." City Lab. Web. 7 Oct. 2015. <http://www.citylab.com/politics/2013/05/potential-perils-rapid-fire-urbanization/5491/>.

Leinberger, Christopher B. "Foot Traffic Ahead - Ranking Walkable Urbanism in America's Largest Metros." Smart Growth America. The George Washington University School of Business, 2014. Web. 8 Dec. 2016. <http://www. smartgrowthamerica.org/documents/foot-traffic-ahead.pdf>

"Monitoring Urbanization in the 21st Century." Earthzine. 21 Jan. 2013. Web. 7 Oct. 2015.

U. N. Department of Economic \& Social Affairs Population Division, "World urbanization prospects: the 2011 revision," April 2012. [Online]. Available: http:// esa.un.org/unpd/wup/pdf/WUP2011_Highlights.pdf

"Global Trends of Urbanization." MORPHOCODE. Web. 7 Oct. 2015. <http:// morphocode.com/global-trends-urbanisation/>.

Jacobs, Jane. The Death and Life of Great American Cities. Print.

"Monitoring Urbanization in the 21st Century." Earthzine. Oceanic Engineering Society, 21 Jan. 2013. Web. 12 Oct. 2015. <http://earthzine. org/2013/01/21/monitoring-urbanization-in-the-21st-century/>.

Vaz, Eric. "Predicting Urban Growth of the Greater Toronto Area - Coupling a Markov Cellular Automata with Document Meta-Analysis." 29 Mar. 2015. Web. 7 Oct. 2015. <http://www.geog.uni-heidelberg.de/md/chemgeo/geog/ gis/markov_cellular.pdf $>$. 


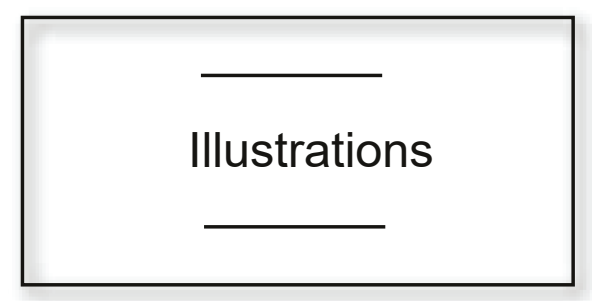

\section{Images}

Fig. 1 | Abu Dhabi performing arts centre | Zaha Hadid Architects Zaha Hadid Architects. Abu Dhabi Performing Arts Centre. Digital image. Www. ies/>.

Fig. 2 | King Abdullah Petroleum Studies and Research centre | Zaha Hadid Architects

aha Hadid Architects. King Abdullah Petroleum Studies and Research Centre. Digital image. Www.zaha-hadid.com. N.p., n.d. Web. <http://wwwzaha-hadid. esign/global-cities/>

Fig. 3 | Cairo, Egypt's Urbanization

Sith, David A. Affordable Housing in Egypt. Digital image. Affordable Housing Institute. Affordable Housing Institute, 15 June 2012. Web ing-in-egypt.html>.

Fig. 4 | Hong Kong

Tan, Albert. Hong Kong. Digital image. Ask.com. N.p., 01 July 2014 Web. <http://www.ask.com/history/did-hong-kong-become-independent-9250a85d033af4ae>

Fig. 9 | Kawloon

Hong Kong. Digital image. Abdil's World. N.p., 05 July 2013. Web. <http:/

dilsud. blogspot.ca/2013 $05 \quad 01$ archive. htmls.

Fig. 10 | CODE | Zaha Hadid Architects

Zaha Hadid Architects. code. Digital image. Www.zaha-hadid.com. N.p., n.d. Web. <http://www.zaha-hadid.com/design/global-cities/>.

Fig. 11 | CODE | Zaha Hadid Architects

Zaha Hadid Architects. code. Digital image. Www.zaha-hadid.com N p nd

Web. <http://www.zaha-hadid.com/design/global-cities/>.

Fig. 12 | Kartal Pendik Masterplan | Zaha Hadid Architects

Zaha Hadid Architects. Kartal Pendik Masterplan. Digital image. Www zaha-hadid.com.
global-cities/>.

Fig. 13 | Deep Ground Longang Centre | Ground Lab

Verebes, Tom. DRL Sahra Team Digital imauge Lab

June 2010. Web < <ttp./1www uzemneplany.sk/forum/5/369/41/2dp=2>

Fig 19: DRL Sahra team (Tutor: Tom Verebes.) 2007-2009

our different scenarios of urban growth and development of Ras A-

Khaimah in UAE.
FIG_1_Abu Dhabi performing arts centre | Zaha Hadid Architects

FIG_2_King Abdullah Petroleum Studies and Research centre | Zaha Hadid Architects

FIG_3_Cairo, Egypt's Urbanization

\section{FIG_4_Hong Kong}

FIG 5 Infographic illustrating the density of cities in terms of population

FIG_6_Infographic illustrating the increase in cities with specific dense populations

FIG_7_Infographic illustrating the predicted increase of people living in cities

FIG_8_Infographic illustrating the variety of urban form with different programmatic building typologies across the globe.

FIG_9_Kawloon Wall, Hong Kong/ Lueng Chopan

FIG_10_CODE Zaha Hadid Architects

FIG_11_CODE Zaha Hadid Architects

FIG_12_Kartal Pendik Masterplan Zaha Hadid Architects

FIG_13_Deep Gound Longang Centre, Ground Lab

Fig 14 Form Array Graphic 1.

Fig_15_Form Array Graphic 2

FIG_16_Form Array Graphic 3

FIG_17_ Graphic illustration of single form being scaled incrementally.

FIG_18_Graphic Illustration of morphological phase shit.

FIG_19_DRL Sahra team (Tutor: Tom Verebes.) 2007-2009. Four different scenarios of urban growth and development of Ras Al-Khaimah in UAE. 
FIG_20_Graphic Representation of proposed process for parametric urbanism.

FIG_21_Grasshopper Algorithm/Scripts

FIG_22_Density Typologies

FIG_23_Density Typologies-combinations on block

FIG_24_Block_Array_Density

FIG_25_Block_Array_Density_1

FIG_26_Block_Array_Density_2

FIG_27_Block_Array_Density_3

FIG_28_Diagram_Type_All

FIG_29_Diagram_Type_1

FIG_30_Diagram_Type_2

FIG_31_Diagram_Type_3

FIG_32_Diagram_Type_4

FIG_33_Diagram_Type_5

FIG_34_Diagram_Type_6

FIG_35_Diagram_Type_7

FIG_36_Diagram_Type_8

FIG_37_Diagram_Type_9

FIG_38_Diagram_Type_10

FIG_39_Diagram_Type_11
FIG_40_Diagram_Type_12

FIG_41_Diagram_Type_13

FIG_43_Diagram_Type_15

FIG_44_Diagram_Type_16

FIG_45_Diagram_Type_17

FIG_46_Site_Map and Aerial Diagram

FIG_47_Site_Scenario_Context

FIG_48_Site_Scenario_Roads

FIG_49_Site_Scenario_CommercialArea

FIG_50_Site_Scenario_Protected Area

FIG_51_Site_Scenario_Blocks_NotTailored

FIG_52_Site_Scenario_Blocks_Tailored

FIG_53_Site_Scenario_6000Units_AllSFD

FIG_54_Site_Scenario_6000Units_AllMidRise

FIG_55_Site_Scenario_6000Units_AllHighRise

FIG_56_Site_Scenario_Grid_Context_Topo

FIG_57_Site_Scenario_HydraulicMarsh

FIG_58_Site_Scenario_6000Units_1_NoTowers

FIG_59_Site_Scenario_6000Units_1_Towers

FIG_60_Site_Scenario_6000Units_2

FIG_61_Site_Scenario_6000Units_3 
FIG_62_Site_Scenario_6000Units_4

FIG_63_Site_Scenario_11000Units_1

FIG_64_Site_Scenario_11000Units_2

FIG_65_Site_Scenario_11000Units_3

FIG_66_Site_Scenario_11000Units_4

FIG_67_Site_Scenario_11000Units_1_re-itterated

FIG_68_Site_Scenario_11000Units_1_comparison

FIG_69_Site_Scenario_11000Units_2_re-itterated

FIG_70_Site_Scenario_11000Units_2_comparison

FIG_71_Site_Scenario_11000Units_3_re-itterated

FIG_72_Site_Scenario_11000Units_3_comparison

FIG_73_Site_Scenario_11000Units_4_re-itterated

FIG_74_Site_Scenario_11000Units_4_comparison

FIG_75_Site_Scenario_6000Units_1_Towers

FIG_76_Site_Scenario_6000Units_1_Towers

FIG_77_Site_Scenario_6000Units_1_Towers

FIG_78_Site_Scenario_6000Units_1_Towers

FIG_79_Site_Scenario_6000Units_1_Towers

FIG_80_Site_Scenario_6000Units_1_Towers

FIG_81_Site_Scenario_6000Units_2

FIG_82_Site_Scenario_6000Units_2
FIG_83_Site_Scenario_6000Units_2

FIG_84_Site_Scenario_6000Units_4

FIG_85_Site_Scenario_6000Units_4

FIG_86_Site_Scenario_6000Units_4

FIG_87_Site_Scenario_6000Units_4

FIG_88_Site_Scenario_6000Units_4

FIG_89_Site_Scenario_6000Units_4

FIG_90_Site_Scenario_6000Units_4_View_1

FIG_91_Site_Scenario_6000Units_4_View_2

FIG_92_Site_Scenario_6000Units_4_View_3

FIG_93_Areas of Ottawa where Parametric Urbanism could be applied 
